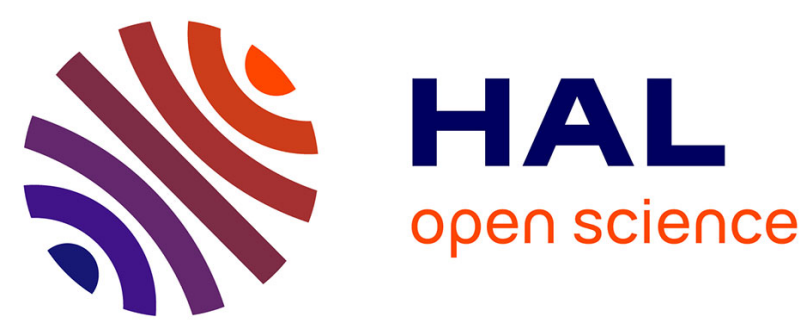

\title{
Polymer-based materials for achieving high energy density film capacitors
}

Benhui Fan, Delong He, Mingyu Zhou, Chong Zhang, Jinbo Bai

\section{To cite this version:}

Benhui Fan, Delong He, Mingyu Zhou, Chong Zhang, Jinbo Bai. Polymer-based materials for achieving high energy density film capacitors. Progress in Polymer Science, 2019, 97, pp.101143. 10.1016/j.progpolymsci.2019.06.003 . hal-02546469

\section{HAL Id: hal-02546469 \\ https://hal.science/hal-02546469}

Submitted on 3 Dec 2020

HAL is a multi-disciplinary open access archive for the deposit and dissemination of scientific research documents, whether they are published or not. The documents may come from teaching and research institutions in France or abroad, or from public or private research centers.
L'archive ouverte pluridisciplinaire HAL, est destinée au dépôt et à la diffusion de documents scientifiques de niveau recherche, publiés ou non, émanant des établissements d'enseignement et de recherche français ou étrangers, des laboratoires publics ou privés. 


\begin{tabular}{|c|c|}
\hline *Title: & $\begin{array}{l}\text { Polymer-based Materials for Achieving High Energy Density } \\
\text { Film Capacitors }\end{array}$ \\
\hline *Authors: & $\begin{array}{l}\text { Benhui FAN }{ }^{1} \text {, Delong } \mathrm{HE}^{1} \text {, Mingyu } \mathrm{ZHOU}^{2} \text {, Chong } \mathrm{ZHANG}^{3} \text { and Jinbo } \\
\text { BAI }^{1 *}\end{array}$ \\
\hline *Affiliations: & $\begin{array}{l}{ }^{1} \text { Laboratoire Mécanique des Sols, Structures et Matériaux (MSSMat), CNRS } \\
\text { UMR 8579, CentraleSupélec, Université Paris Saclay, 8-10 Rue, Joliot-Curie, } \\
\text { 91190, Gif-sur-Yvette, France } \\
{ }^{2} \text { Global Energy Interconnection Research Institute Europe GmbH, Kantstr.162, } \\
\text { 10623, Berlin, Germany } \\
{ }^{3} \text { State Key Laboratory of Advanced Transmission Technology, Global Energy } \\
\text { Interconnection Research Institute, Beijing 102211, People's Republic of China }\end{array}$ \\
\hline $\begin{array}{l}\text { *Contact } \\
\text { email: }\end{array}$ & Jinbo Bai: Jinbo.bai@ecp.fr \\
\hline *Co-authors: & $\begin{array}{l}\text { Benhui Fan: } \underline{\text { benhui.fan@ecp.fr }} \\
\text { Delong He }: \underline{\text { delong.he@ecp.fr }} \\
\text { Mingyu Zhou: zhoumingyu_geirieu@163.com } \\
\text { Chong Zhang: chongzhang@ustb.edu.cn }\end{array}$ \\
\hline *CATEGORY: & $\begin{array}{l}\text { Polymers and Plastics } \\
\text { Surfaces, Coatings and Films }\end{array}$ \\
\hline
\end{tabular}




\title{
Polymer-based Materials for Achieving High Energy Density Film Capacitors
}

\author{
Benhui FAN ${ }^{1}$, Delong $\mathrm{HE}^{1}$, Mingyu $\mathrm{ZHOU}^{2}$, Chong $\mathrm{ZHANG}^{3}$ and Jinbo BAI ${ }^{1}$ * \\ ${ }^{1}$ Laboratoire Mécanique des Sols, Structures et Matériaux (MSSMat), CNRS UMR 8579, \\ CentraleSupélec, Université Paris Saclay, 8-10 Rue, Joliot-Curie, 91190, Gif-sur-Yvette, France \\ ${ }^{2}$ Global Energy Interconnection Research Institute Europe GmbH, Kantstr.162, 10623, Berlin, \\ Germany \\ ${ }^{3}$ State Key Laboratory of Advanced Transmission Technology, Global Energy Interconnection \\ Research Institute, Beijing 102211, People's Republic of China \\ Corresponding authors: Jinbo BAI, jinbo.bai@centralesupelec.fr
}

\begin{abstract}
Film capacitors with high energy storage are becoming particularly important with the development of advanced electronic and electrical power systems. Polymer-based materials have stood out from other materials and have become the main dielectrics in film capacitors because of their flexibility, cost-effectiveness, and tailorable functional properties. A core issue for achieving films with high performance is to process a material with high dielectric permittivity and breakdown strength but low dielectric loss. Nanocomposites and all-polymer dielectrics are two promising avenues to address this issue. Thus, in this work, the advances of the past decade are highlighted to reflect the latest developments in polymer-based film dielectrics. The key factors of dielectric properties, including polarization mechanisms, dielectric breakdown strength, filler-matrix interface, and hierarchical structures are discussed in detail. A comprehensive understanding of the fabrication of polymer-based materials with special constituents, molecular segments, and microstructures will provide guidance to engineers on the fabrication of polymer-based materials with high performance.
\end{abstract}




\section{Introduction}

Capacitors are important energy storage devices, having been developed originally over 250 years ago from a simple form to the complex devices of today. ${ }^{1}$ Fixed capacitors used in electronic equipment can be generally divided into two types: non-polarized and polarized. Film capacitors belong to the non-polarized type with a capacitance range from $\mathrm{nF}$ to $\mathrm{mF}$. They have a variety of applications such as electronic circuits, analog filter networks, resonant circuits, and high-voltage power transmission systems. ${ }^{2,3}$ As important passive components, capacitors generally occupy a large volume (up to $70 \%$ in some cases) or weight in electronic systems. The miniaturization of these systems, the scaling-down of integrated circuits, and the development of new technologies (such as hybrid vehicles and implantable heart defibrillators) require capacitors with high energy density to improve efficiency.

A film capacitor is typically composed of two electrically conductive plates filled with a dielectric layer. ${ }^{4}$ Under an external voltage, electric polarization occurs in the dielectric along the direction of the electric field and results in accumulated charges on the conductive plate surfaces, which is known as the charging process. When an electric field $(E)$ is applied to a dielectric, it induces an electric displacement $(D)$ and the energy of charge $(U)$ is ${ }^{5,6}$

$$
\mathrm{U}=\frac{\mathrm{W}}{\mathrm{Ad}}=\frac{\int_{0}^{\mathrm{Q} \max } \mathrm{vdq}}{\mathrm{Ad}}=\int_{0}^{\mathrm{D}_{\max }} \mathrm{EdD}
$$

where $D$ is related to the polarization $(P)$ and dielectric permittivity $\left(\varepsilon_{r}\right)$ of a dielectric as presented in Equation (2), where $\varepsilon_{0}$ is the vacuum dielectric constant $\left(8.85 \times 10^{-12} \mathrm{~F} / \mathrm{m}\right)$.

$$
\mathrm{D}=\mathrm{P}+\varepsilon_{\mathrm{r}} \mathrm{E}
$$

The energy density of a dielectric can be calculated by integrating the effective area between the polarization axis and the discharging curve of an electric displacement-electric $(D-E)$ field loop or 
polarization-electric $(P-E)$ field loop as shown in Figure $1 .^{2}$ For non-linear polymers such as poly(vinylidene fluoride) (PVDF) and its copolymers, the energy density is illustrated by the green area in the D-E loops. For linear dielectric polymers, such as polyethylene (PE) and polypropylene (PP), the electric displacement varies with little remnant polarizations, and the energy density can be simplified as Equation (3) and is illustrated by the sum of the blue and green areas.

$$
\mathrm{U}_{\mathrm{e}}=\frac{1}{2} \varepsilon_{0} \varepsilon_{\mathrm{r}} \mathrm{E}^{2}
$$

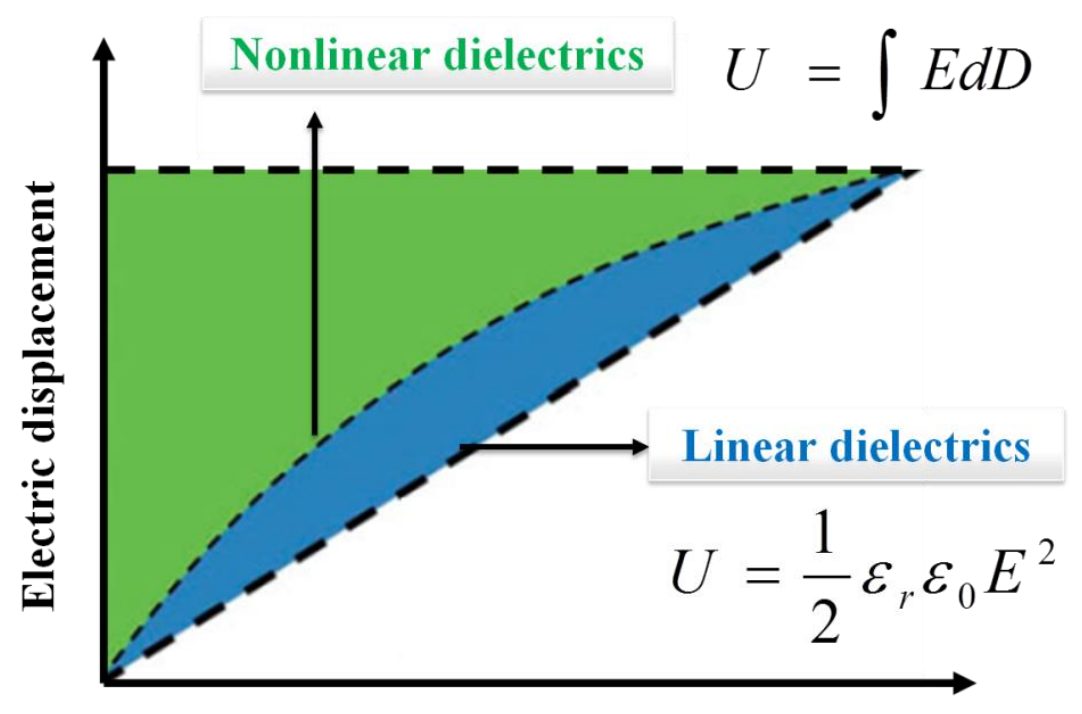

\section{Electric field}

Figure $\mathbf{1}^{2}$ Graphical representation of D-E loops used for the calculation of energy density: For nonlinear dielectrics, the discharge energy density is determined from the area in green, whereas for linear dielectrics, the discharge energy density is determined from the triangular area (blue + green). Copyright (C) COPYRIGHT: (C) Materials Research Society 2015

Given that energy density is largely determined by the dielectric properties involving dielectric permittivity and breakdown strength, the selection of appropriate materials and processing technologies is crucial for the enhancement of dielectric properties. ${ }^{3,7}$ Conventional dielectric materials are ceramics 
with high dielectric permittivity and thermal stability, but their applications are largely impeded because of their poor flexibility. ${ }^{5}$ Polymer-based materials can provide a greater possibility of being molded into various configurations and thus have considerable potential in modern electronic and electrical systems. ${ }^{\mathbf{8} 9}$

Commonly used polymers include PE, polystyrene, polyethylene terephthalate (PET), polycarbonate (PC), polyphenylene sulfide, and PVDF. Table 1 lists some of the main features including the dielectric and rheological properties of these dielectric polymer films. ${ }^{4,8}$ Current state-of-the-art technology uses metallized biaxially oriented polypropylene (BOPP) film because of its high breakdown strength (> $700 \mathrm{~V} / \mathrm{m}$ ), ultralow dielectric loss ( $\tan \delta$ of $\sim 0.2 \%$ ), and "graceful failure" at breakdown (e.g., an open circuit is formed). ${ }^{3}$ However, as shown in Table 1, the major drawback of polymer dielectrics is relatively low dielectric permittivity values (except PVDF, others usually $<3$ ), which consequently results in low energy densities $\left(<2 \mathrm{~J} / \mathrm{cm}^{3}\right)$ in practical devices.

Table 1 Properties of commonly used polymers for film capacitors including glass transition temperature $\left(\mathrm{T}_{\mathrm{g}}\right)$, melting temperature of the polymer crystals $\left(\mathrm{T}_{\mathrm{m}}\right)$, fraction of crystallites in the morphology $(\chi)$, relative dielectric permittivity $\left(\varepsilon_{\mathrm{r}}\right) /$ dielectric loss $(\tan \delta)$ at room temperature at 1000 $\mathrm{Hz}$, dielectric breakdown field $\left(\mathrm{E}_{\mathrm{b}}\right)$ and energy density $\left(\mathrm{U}_{\mathrm{e}}\right)$.

\begin{tabular}{cccccccc}
\hline Polymer & $\mathbf{T}_{\mathbf{g}}\left({ }^{\circ} \mathbf{C}\right)$ & $\mathbf{T}_{\mathbf{m}}\left({ }^{\circ} \mathbf{C}\right)$ & $\chi$ & $\boldsymbol{\varepsilon}_{\mathbf{r}}$ & $\tan \boldsymbol{\delta} \%$ & $\mathbf{E}_{\mathbf{b}}(\mathbf{M V} / \mathbf{m})$ & $\mathbf{U}_{\mathbf{e}}\left(\mathbf{J} / \mathbf{c m}^{3}\right)$ \\
\hline PP & $<25$ & 160 & $>60 \%$ & 2.2 & $<0.2$ & 640 & $1-1.2$ \\
PET & $75-80$ & 225 & $\approx 50 \%$ & 3.3 & $<0.5$ & 570 & $1-1.5$ \\
PC & $145-150$ & $215-230$ & $<30 \%$ & 2.8 & $<0.15$ & 528 & $0.5-1$ \\
PPS & 120 & 285 & $\approx 40 \%$ & 3.1 & $<0.3$ & 550 & $1-1.5$ \\
\hline
\end{tabular}




\begin{tabular}{|c|c|c|c|c|c|c|c|}
\hline PVDF & $\approx-40$ & 170 & $\approx 50 \%$ & 12 & $<1.8$ & 590 & 2.4 \\
\hline
\end{tabular}

Enormous research has shown that by simply using one kind of polymer, it is difficult to further improve the energy density, while developing polymer-based multiphase materials represents the most promising avenue. In the past decade, specific advances including theoretical and experimental results have been reported and some polymer-based materials have achieved energy densities as high as 20-31 $\mathrm{J} / \mathrm{cm}^{3}$. In the simulation, the rational design based on band gaps and molecular structures has been applied for the synthesis of repeat units with high polarization in macromolecular chains. The concept of dielectric anisotropy has been introduced for the investigation of dielectric strength based on various morphologies and spatial alignments of nanofillers. In the experimental works, polymer-based materials with improved energy densities have been achieved by various strategies which can be summarized as two domains: nanocomposites and all-polymer dielectrics. However, it should be pointed out that the reported results have varied significantly. Taking PVDF or its copolymer-based materials as examples: as listed in Table 2, the values of energy density varied from $4-31 \mathrm{~J} / \mathrm{cm}^{3}$. Even using the same fillers, the obtained dielectric properties still exhibited a large disparity. Hence, to clarify the concepts and relationships, the key factors including polarization mechanism, dielectric breakdown strength, and the interfaces of filler-matrix and hierarchical structures are discussed by combining the successful examples reported in current scientific studies. A review on the recent processes for achieving polymer-based materials with high performance will hopefully lead to a comprehensive understanding of the fabrication of polymer-based materials with special constituents, molecular segments, and microstructures. 
Table 2 Dielectric properties of PVDF and its copolymers based composites

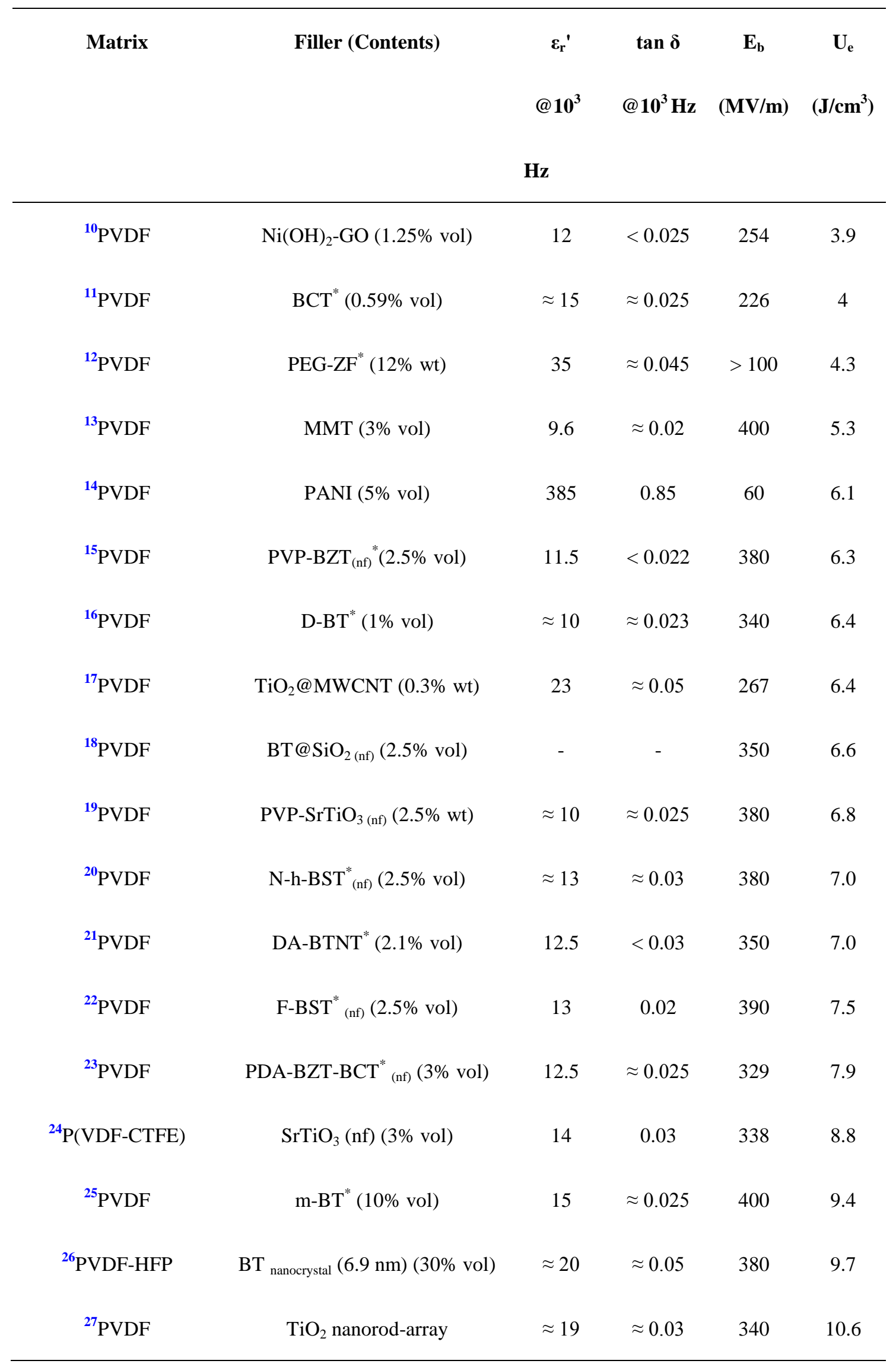




\begin{tabular}{|c|c|c|c|c|c|}
\hline${ }^{28} \mathrm{PVDF}$ & $\mathrm{BiVO}_{4}(8 \% \mathrm{wt})$ & 44 & 0.02 & 400 & 11 \\
\hline${ }^{29} \mathrm{P}(\mathrm{VDF}-\mathrm{HFP})$ & h-DOPA ${ }^{*}-\mathrm{TiO}_{2 \text { (nf) }}(2.5 \%$ vol $)$ & $\approx 11.5$ & $\approx 0.06$ & 520 & 11.1 \\
\hline${ }^{30} \mathrm{P}(\mathrm{VDF}-\mathrm{CTFE})$ & $\mathrm{ZrO}_{2}(9.1 \%$ wt $)$ & $\approx 10$ & $\approx 0.07$ & 270 & 11.2 \\
\hline${ }^{31} \mathrm{PVDF}$ & $\mathrm{BT} @ \mathrm{Al}_{2} \mathrm{O}_{3(\mathrm{nf})}(4 \%$ vol $)$ & $\approx 12.5$ & $<0.025$ & 450 & 12.4 \\
\hline${ }^{32} \mathrm{P}(\mathrm{VDF}-\mathrm{TrFE}-\mathrm{CTFE})$ & PTFMPCS*-BT (5\% vol) & 57 & 0.05 & 514 & 16.2 \\
\hline${ }^{33} \mathrm{PVDF}$ & $\mathrm{GR}-\mathrm{OH}^{*}(0.2 \% \mathrm{wt})$ & 98.91 & 0.5 & 199 & 17.3 \\
\hline${ }^{34} \mathrm{P}(\mathrm{VDF}-\mathrm{HFP})$ & Kaolinite (5\% wt) & 12 & $\approx 0.025$ & 780 & 19 \\
\hline${ }^{35}$ PVDF-HFP & $\mathrm{BT}(37 \% \mathrm{vol})+\mathrm{CNT}(3 \% \mathrm{vol})$ & 71.6 & 0.04 & 251 & 19.8 \\
\hline${ }^{36} \mathrm{PVDF}$ & $\mathrm{BT} @ \mathrm{TiO}_{2(\mathrm{nf})}(3 \% \mathrm{vol})$ & 17 & $\approx 0.025$ & 646 & 20 \\
\hline${ }^{37} \mathrm{P}(\mathrm{VDF}-\mathrm{TrFE}-\mathrm{CFE})$ & $\mathrm{BNNS}^{*}(12 \% \mathrm{wt})$ & - & $\approx 0.027$ & 610 & 20.3 \\
\hline${ }^{38} \mathrm{P}(\mathrm{VDF}-\mathrm{CTFE})$ & BNNS $(12 \% w t)+$ BT $(15 \% w t)$ & 12 & - & 550 & 21.2 \\
\hline${ }^{39} \mathrm{PVDF}$ & $\operatorname{APTMS}-B T-H N S^{*}(16 \% \mathrm{wt})$ & 109 & $\approx 0.0002$ & 381 & 21.7 \\
\hline${ }^{40} \mathrm{P}(\mathrm{VDF}-\mathrm{HFP})$ & $\mathrm{BT} @ \mathrm{TiO}_{2(\mathrm{nf})}(3 \% \mathrm{vol})$ & $\approx 18$ & $\approx 0.05$ & 797 & 31.2 \\
\hline
\end{tabular}

*BCT: $\mathrm{Ba}(\mathrm{Sn}, \mathrm{Ti}) \mathrm{O}_{3}-(\mathrm{Ba}, \mathrm{Ca}) \mathrm{TiO}_{3}$

ZF-PEG: polyethylene glycol (PEG-6000) functionalized zinc ferrites

PVP-BZT: polyvinylpyrrolidone modified $\mathrm{Ba}\left(\mathrm{Zr}_{0.3} \mathrm{Ti}_{0.7}\right) \mathrm{O}_{3}$

D-BT: dopamine hydrochloride modified BT nanofillers

N-h-BST: isopropyl dioleic(dioctyl- phosphate) titanate (NDZ 101)-functionalized $\mathrm{Ba}_{0.6} \mathrm{Sr}_{0.4} \mathrm{TiO}_{3}$ nanofiber

DA-BTNT: dopamine modified BT nanotubes

F-BST: surface-fluorinated $\mathrm{Ba}_{0.6} \mathrm{Sr}_{0.4} \mathrm{TiO}_{3}$

PDA-BZT-BCT: polydopamine coated $0.5 \mathrm{Ba}\left(\mathrm{Zr}_{0.2} \mathrm{Ti}_{0.8}\right) \mathrm{O}_{3}-0.5\left(\mathrm{Ba}_{0.7} \mathrm{Ca}_{0.3}\right) \mathrm{TiO}_{3}$ 
m-BT: 2,3,4,5-tetrafluorobenzoic acid modified BT nanofillers

h-DOPA: brush-like chain tailed dopamine derivative

PTFMPCS: Rigid-fluoropolymer

GR-OH: hydroxylated graphene

APTMS-BT-HNS: (3-aminopropyl)trimethoxysilane modified BT hollow nanospheres (20 nm)

BNNS: ultra-thin boron nitride nano-sheet

\section{Polarization and dielectric properties}

A complex dielectric permittivity is calculated by impedance measurements where a sample with electrodes on double faces is viewed as a plane capacitor equivalent to a parallel resistor-capacitor (RC) circuit. It consists of real and imaginary permittivities as $\mathbf{4 1 , 4 2}$

$$
\varepsilon_{\mathrm{r}}=\varepsilon_{\mathrm{r}}^{\prime}-\mathrm{i} \cdot \varepsilon_{\mathrm{r}}^{\prime \prime}
$$

where $\varepsilon_{r}$ ' is the real part and $\varepsilon_{r}$ "' is the imaginary part. The real permittivity is related to the capacitance, while the imaginary permittivity represents the polarization which cannot follow the oscillating frequency and consequently results in energy dissipation as heat or other forms of energy loss. Peaks of imaginary permittivity are called relaxation peaks which occur at the frequency when relaxations are at the appropriate rate for maximum power dissipation. The relative magnitude of $\varepsilon_{r}$ " with respect to $\varepsilon_{r}$ ' through a quantity, $\tan \delta$, is defined as the dielectric loss factor as

$$
\tan \delta=\frac{\varepsilon_{\mathrm{r}}^{\prime \prime}}{\varepsilon_{\mathrm{r}}^{\prime}}
$$

Since dielectric loss results from the inability of the polarization process in a molecule which fails to follow an oscillating applied electric field instantaneously, the relaxation time $(\tau)$ is used to describe the time for the dipoles to return to their original random orientation. If the relaxation time is smaller or 
comparable to the rate of the oscillating electric field, then there will be no or minimum loss.

Dielectric properties are associated with polarization mechanisms. Polarization is defined as the total dipole moments in a dielectric per unit volume and is related to dielectric permittivity under the homogeneous applied field described as

$$
\mathrm{P}=\left(\varepsilon_{\mathrm{r}}-1\right) \varepsilon_{0} \mathrm{E}
$$

There are four types of polarization which are divided by resonance and relaxation regimes: electronic, ionic, dipolar (orientational), and interfacial (space charge) polarizations as shown in Figure $2 .^{41}$

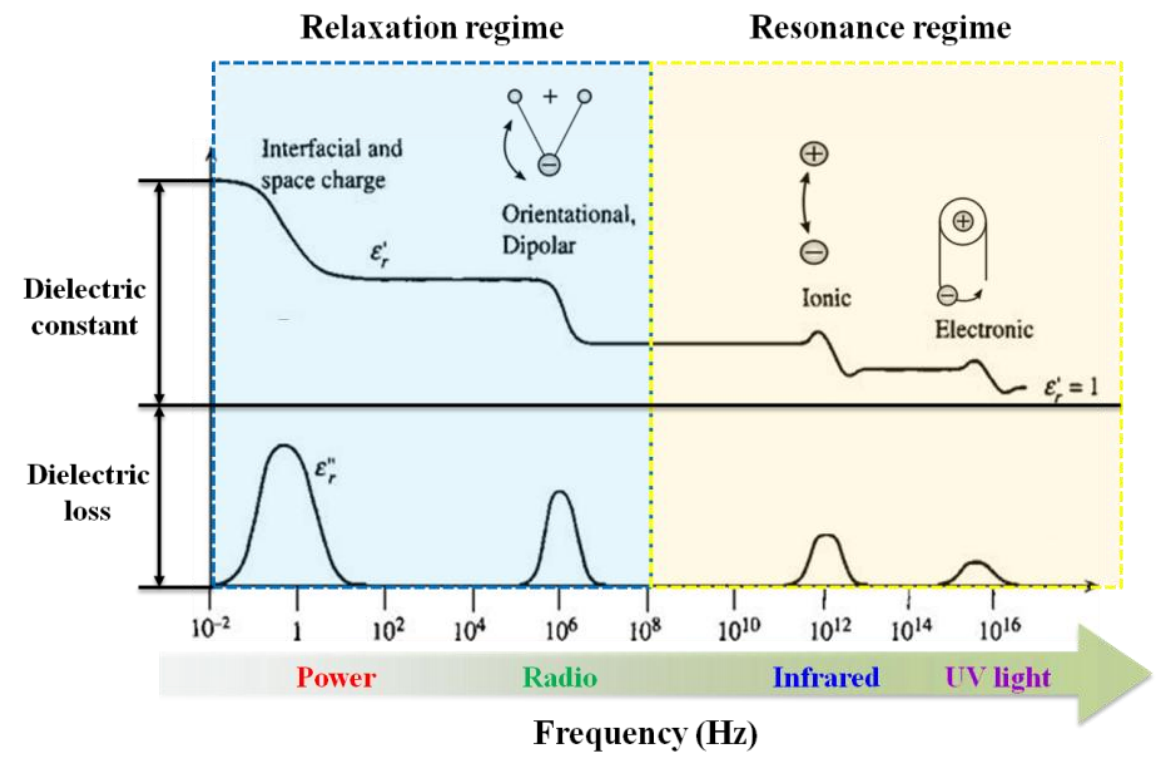

Figure $2^{41,44}$ Four types of polarization and their frequency dependences. Copyright $\odot$ 2016, American Chemical Society

(1) Electronic polarization

Theoretically, the net charge is zero because of the symmetrical structure of a neutral atom. However, a neutral atom is rarely found in practical cases, and atoms usually have a net dipole moment. When an atom is in an external electric field, an induced dipole moment develops. The electrons become easily 
displaced by the field because they are much lighter than the positive nucleus. As shown in Figure $3{ }^{41}$ the separation of the negative charge center from the positive one results in an induced dipole moment termed electric polarization. For a solid with covalent bonds, the electronic polarization from an atom is quite small. The main polarization comes from valence electrons. Valence electrons exist not only in covalent bonds between ionic cores but also in the entire crystal because they may tunnel from bond to bond and exchange places mutually. The wave function of valence electrons is delocalized instead of localized to any particular atom. When an electric field is applied, electrons in covalent bonds are much more flexible than those in individual ionic cores that arouse electronic polarization.

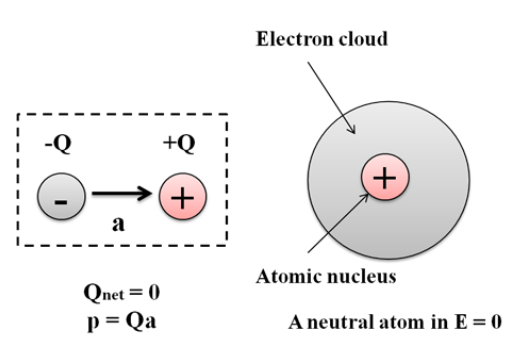

(a)

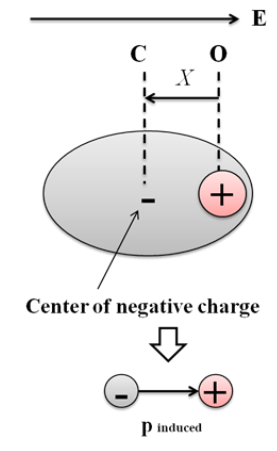

(c)

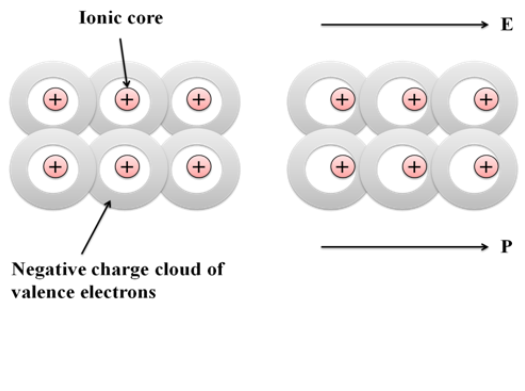

(d)

Figure 3 (a) definition of electric dipole moment, (b) and (c) origin of electronic polarization, and (d) valence electrons in covalent bonds in the absence of an applied field. When an electric field is applied to a covalent solid, valence electrons in covalent bonds shift very easily with respect to positive ionic cores. The whole solid becomes polarized due to the collective shift in the negative charge distribution of valence electrons

(2) Ionic polarization

Ionic polarization occurs in ionic crystals as shown in Figure 4. When an applied field is absent, the 
solid has no net polarization because the moments of dipoles are lined up head-to-head and tail-to-tail.

However, in the presence of an applied electric field $\mathrm{E}$ along the $\mathrm{x}$ direction, negative ions are pushed in the $-x$ direction and positive ions in the $+x$ direction. Consequently, the dipole's moment $\mathrm{p}_{+}$in the $+x$

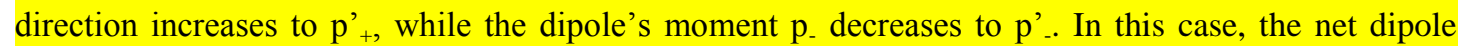
moment (average dipole moment) per ion pair is now p' ${ }_{+}-p^{\prime}$, and the magnitude depends on the electric field. $^{41}$

Electronic polarization and ionic polarization are two kinds of polarization that generally depend on the band gaps of polymers. There is no dielectric loss in either because they occur in the power and radio frequency ranges. ${ }^{43}$ For organic polymers, electrons need to be further delocalized to arouse stronger electronic polarization. Replacing carbon by other elements (such as silicon) may be an effective way to make ions more dynamic and stimulate ionic polarization.

(a)

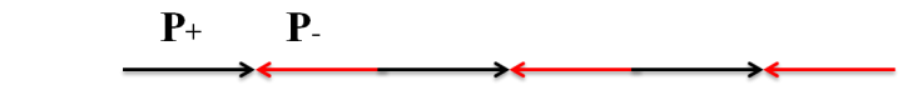

(b)

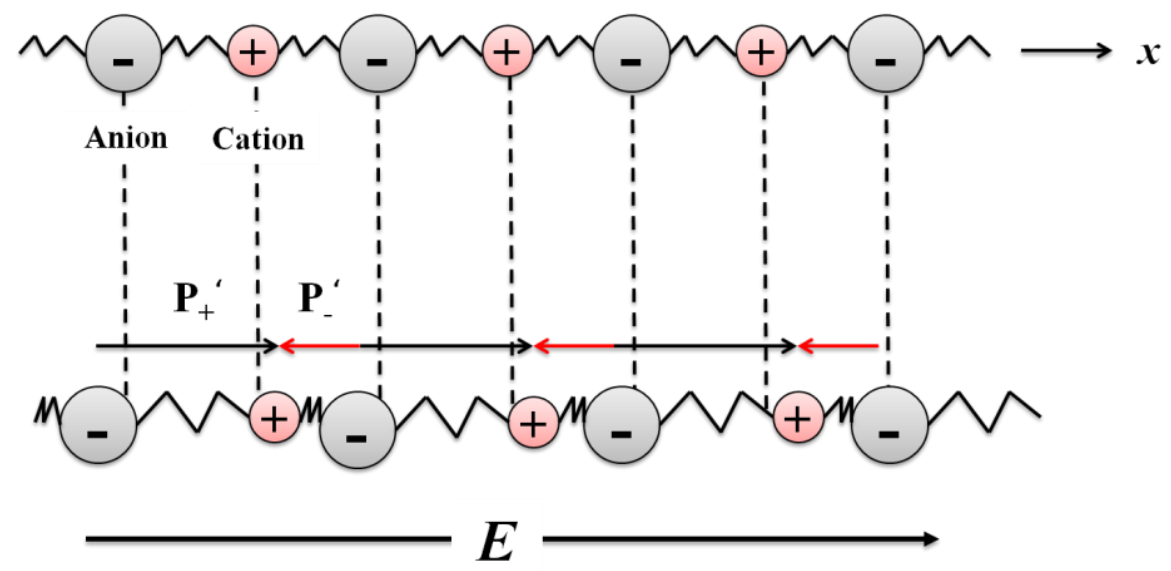

Figure 4 (a) Ion chain in the crystal without an applied field. Average or net dipole moment per ion is zero. (b) In the presence of an applied field, ions become slightly displaced, which leads to a net average dipole moment per ion. 


\section{(3) Dipolar polarization}

Dipolar polarization as shown in Figure 5 is typical for polar gases and polar liquids. ${ }^{41}$ In general, molecules are randomly oriented as a result of thermal agitation when an electric field is absent. Once an electric field is applied, dipoles try to align parallel to the direction of the electric field, and consequently, the material will exhibit net polarization. In the case of polymers, dipolar polarization comes from the polarity of polymers. The polar nature depends on the presence of polar groups and the geometry of the polymer chain. In a non-polar polymer, the dipole moments cancel each other out because of their structural symmetry, and therefore, non-polar polymers usually have low dielectric permittivity. However, a polar polymer has permanent dipole moments because it contains permanent dipoles and therefore exhibits comparatively high dielectric permittivity. Stimulating the mobility of dipoles by adding polar pendant groups in polymer chains or using copolymerization before dipole saturation can be viewed as an effective way to strengthen dipolar polarization.

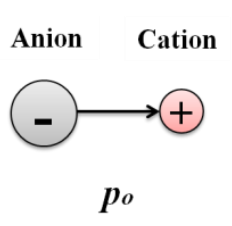

(a)

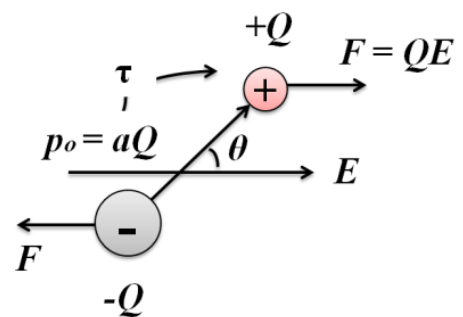

(c)

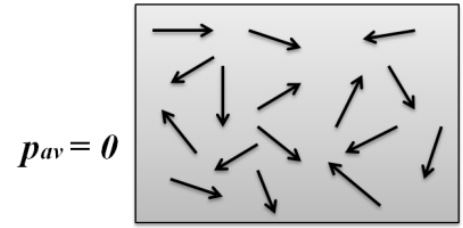

(c)

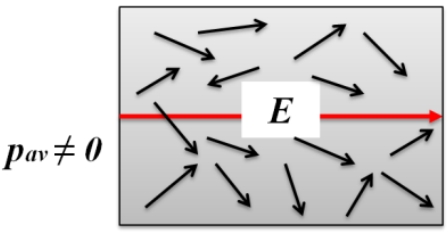

(d)

Figure 5 (a) A polar molecule possesses a permanent dipole moment $p_{0}$. (b) In absence of a field, thermal agitation of molecules results in zero net average dipole moment per molecule. (c) A dipole 
placed in a field experiences a torque that tries a rotate it to align $p_{0}$ with the field $E$. (d) In the presence of an applied field, dipoles try to rotate to align with the field against thermal agitation. There is now a net average dipole moment per molecule along the field.

In the presence of electronic, ionic, and dipolar polarization mechanisms, the average induced dipole moment per molecule is the sum of all contributions in terms of the local field ${ }^{41}$ In addition, interfacial polarization is essential and unavoidable, in particular for composites, but it cannot be simply added into the sum of polarization mechanisms because it occurs at interfaces where the field is not well defined.

(4) Interfacial polarization

Interfacial polarization, also known as Maxwell-Wagner-Sillars polarization, ${ }^{45}$ appears because positive charges accumulate at the interface and the remaining negative charges in the bulk constitute dipole moments that appear in the polarization vector. It occurs whenever there is an accumulation of charge at an interface between two regions, in particular for heterogeneous dielectric materials as shown in Figure 6. In real polymer-based materials, various factors including non-homogeneity, the presence of impurities, crystal-amorphous interfaces, and incomplete contact of film-electrode may lead to interfacial polarization. It usually takes hours to years to discharge and therefore occurs in a low frequency range as presented in Figure 2.

Using fillers with high dielectric permittivity to reinforce a polymer is based on interfacial polarization. Previous investigations concentrated on polymer composites with microfillers. In response to the ever-increasing demands for the miniaturization of devices and enhancement of energy storage, the 
thickness of films has to be reduced as much as possible. ${ }^{\mathbf{4 6}, 47}$ Therefore, it is necessary to replace microfillers with nanofillers in the fabrication of higher-quality dielectric thin films. We next focus on the recent fabrication processes of nanocomposite films with high dielectric performance.

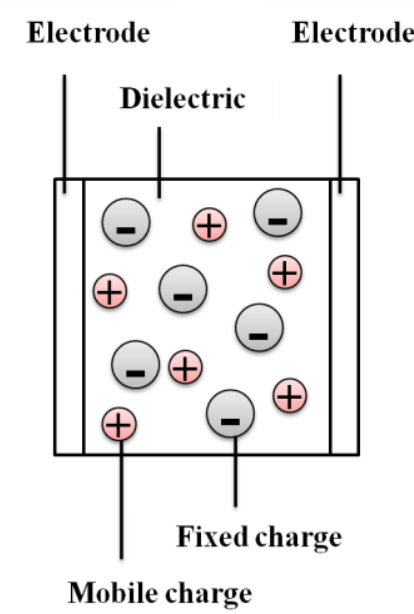

(a)

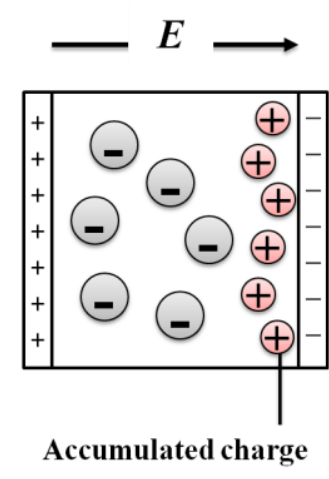

(b)

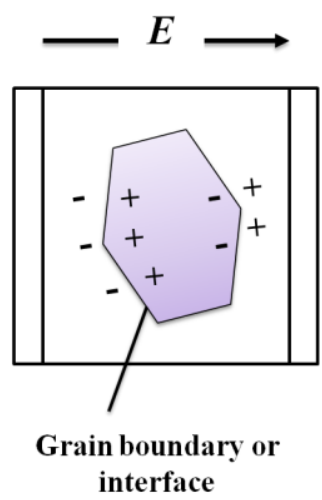

(c)

Figure 6 (a) A crystal with equal number of mobile positive ions and fixed negative ions. In the absence of a field, there is no net separation between all the positive charges and all the negative charges. (b) In the presence of an applied field, the mobile positive ions migrate toward the negative electrode and accumulate there. There is now an overall separation between the negative charges and positive charges in the dielectric. The dielectric therefore exhibits interfacial polarization. (c) Grain boundaries and interfaces between different materials frequently give rise to interfacial polarization.

\section{Nanocomposite films}

\subsection{Theoretical models for dielectric properties of nanocomposites}

The concept of nanodielectrics was first introduced by Lewis in $1994 .^{48}$ By general definition, the diameter range of nanofillers is below the micron dimension $(<0.1 \mu \mathrm{m}) .{ }^{49}$ A more stringent definition 
considers nanofillers with properties that depend on their size because smaller sizes create more interfacial area which favors the promotion of interfacial polarization in the polymer matrix close to the nanofiller. ${ }^{5,45}$ Based on the electrical conductivity of incorporated nanofillers, nanocomposites can be divided into two groups: ${ }^{50}$ dielectric-dielectric nanocomposites incorporating semi-conductive nanofillers with high dielectric permittivity such as $\mathrm{TiO}_{2},{ }^{51} \mathrm{ZrO}_{2},{ }^{52} \mathrm{BaTiO}_{3}(\mathrm{BT}),{ }^{53-55} \mathrm{CaCu}_{3} \mathrm{Ti}_{4} \mathrm{O}_{12},{ }^{56}$ $\mathrm{Pb}(\mathrm{Zr}, \mathrm{Ti}) \mathrm{O}_{3},{ }^{57}$ or $\mathrm{BN}^{58,59}$ and dielectric-conductive nanocomposites incorporating metal conductive nanofillers such as $\mathrm{Ag}^{60}$ or $\mathrm{Cu}^{61}$, conductive polymers such as polyaniline ${ }^{62}$ or polypyrrole, ${ }^{63}$ carbon family materials such as carbon black ${ }^{64,65}$ or carbon nanotube, ${ }^{66,67}$ and graphite nanoplatelets. ${ }^{68,69}$

There are two basic models for calculating the effective dielectric permittivity, $\varepsilon_{e f f}$, of dielectric-dielectric nanocomposites: the parallel and series models as shown in Figure 7 (a) and (b), respectively. The formula is simply written as ${ }^{50}$

$$
\varepsilon_{\mathrm{eff}}^{\mathrm{n}}=(1-\varphi) \varepsilon_{\mathrm{m}}^{\mathrm{n}}+\varphi \varepsilon_{\mathrm{f}}^{\mathrm{n}},
$$

where $\varphi$ is the volume fraction of the filler, $\varepsilon_{m}$ and $\varepsilon_{f}$ are the dielectric permittivities of the matrix and filler, respectively, and $n$ is either " +1 " for the parallel case or "-1" for the series case. Figure 7 (c) illustrates that $\varepsilon_{\text {eff }}$ for the parallel model is always higher than that of the series model, while experimental results are usually between the two. ${ }^{70}$

$$
\left((1-\varphi) \varepsilon_{m}^{-1}+\varphi \varepsilon_{f}^{-1}\right)^{-1} \leq \varepsilon_{e f f} \leq(1-\varphi) \varepsilon_{m}+\varphi \varepsilon_{f}
$$

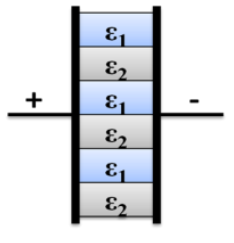

(a)

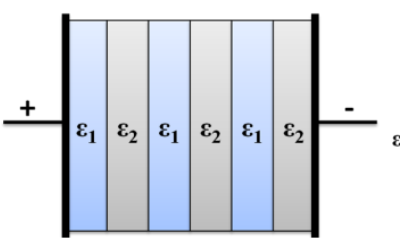

(b)

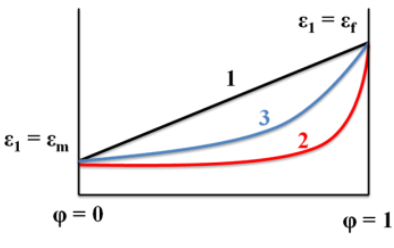

(c)

Figure 7 Schematic of structural patterns for parallel (a) and series (b) models. (c) Schematic of 
effective dielectric permittivity of a composite versus the composition: 1-parallel connection; 2-series connection; 3-real composite (obtained by Lictenecker's logarithmic mixing law)

To modify these basic theoretical models and better fit experimental results, Lichtenecker and Maxwell Garnett mixture laws are two commonly used models for calculating the $\varepsilon_{\text {eff }}$ of a randomly distributed dielectric-dielectric nanocomposite.

(1) Lichtenecker formula

As $n$ approaches 0, Equation (8) can be equivalent to a logarithmic mixture law known as the Lichtenecker formula, ${ }^{41}$

$$
\log \varepsilon_{\mathrm{eff}}=(1-\varphi) \log \varepsilon_{\mathrm{m}}+\varphi \log \varepsilon_{\mathrm{f}}
$$

Despite lacking sufficient scientific evidence, as a compromise between the two extreme limits of the series and parallel mixtures, the Lichtenecker formula shows good applicability to various heterogeneous media.

(2) Maxwell Garnett formula

The Maxwell Garnett (also known as Maxwell-Wagner) mixing rule is applied to calculate the infinite dilution of a dispersed phase (i.e., spherical fillers well separated by distances greater than their characteristic size). Given that the shape of a filler is spherical, the composite can be treated as a dielectric sphere (filler) surrounded by a concentric spherical shell (matrix), and $\varepsilon_{\text {eff }}$ can be calculated $\mathrm{as}^{70}$

$$
\frac{\varepsilon_{\text {eff }}-\varepsilon_{m}}{\varepsilon_{\mathrm{eff}}+2 \varepsilon_{\mathrm{m}}}=\varphi \cdot \frac{\varepsilon_{\mathrm{f}}-\varepsilon_{\mathrm{m}}}{\varepsilon_{\mathrm{f}}+2 \varepsilon_{\mathrm{m}}}
$$


When a filler is not spherical, the general formula needs to be modified by a depolarization factor, $A$. This factor is related to the deviation from sphericity. When $A=1 / 3$, the formula reverts back to fillers with spherical shapes as ${ }^{71}$

$$
\varepsilon_{\text {eff }}=\varepsilon_{\mathrm{m}}\left[1+\frac{\varepsilon_{\mathrm{f}}\left(\varepsilon_{\mathrm{f}}-\varepsilon_{\mathrm{m}}\right)}{\mathrm{A}(1-\varphi)\left(\varepsilon_{\mathrm{f}}-\varepsilon_{\mathrm{m}}\right)+\varepsilon_{\mathrm{m}}}\right] \text { for } \varphi<0.1
$$

For dielectric-conductive nanocomposites, the dielectric properties are based on the percolation model as shown in Figure 8. The percolation transition lies in the fact that the filler particles of the minor phase comes into contact with each other and a continuous cluster extends throughout the system when the volume fraction $(\varphi)$ of the minor phase approaches the critical value $\varphi_{\mathrm{c}}$ (percolation threshold). A dramatic change in the dielectric properties of a composite occurs during the percolation transition. When $\varphi$ is approached from below $\varphi_{\mathrm{c}}, \mathbf{5 , 4 5}$

$$
\varepsilon_{\mathrm{eff}} \propto \varepsilon_{\mathrm{m}}\left|\varphi-\varphi_{\mathrm{c}}\right|^{-\mathrm{q}} \text { for } \varphi<\varphi_{\mathrm{c}}
$$

where $q$ is a critical exponent that controls the variation of physical quantities near $\varphi_{\mathrm{c}}$. It varies from 0.8 to 1 owing to the different interactions between a matrix and fillers.

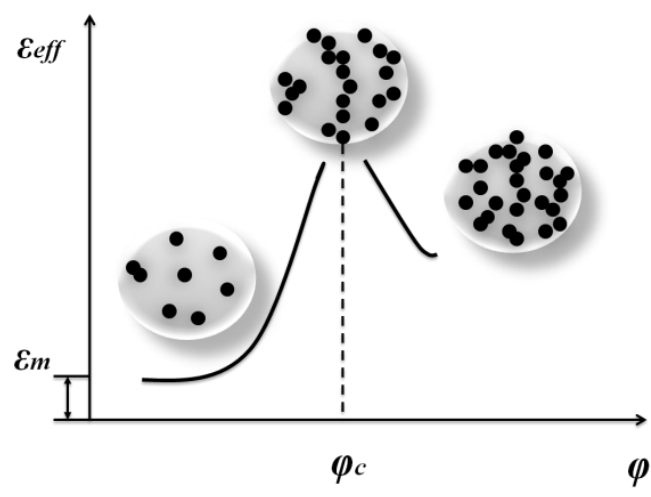

Figure 8 Schematic of the dependence of $\varepsilon_{\text {eff }}$ and filler's volume fractions. The insets show the geometric phase transition of fillers (denoted by dark spots) in the microstructure of a composite near percolation threshold $\varphi_{\mathrm{c}}$. 
The dramatic increase of dielectric permittivity near $\varphi_{\mathrm{c}}$ can be explained by microcapacitor networks. In the composite, each microcapacitor is formed by adjacent conductive fillers with a very thin layer of dielectric in between. With a significant increase in the intensity of the local electric field, each microcapacitor contributes an abnormally large capacitance when the volume fraction of the fillers is close to $\varphi_{\mathrm{c}}$. This process promotes the migration and accumulation of charge carriers at the interfaces between the fillers and the matrix. These charge carriers are generated either by surface plasma resonance or by charge injection from the external electrodes. This accumulation of charges continues with increases of $\varphi$ until the percolation transition where the distances between adjacent conductive fillers are below the electron tunneling range or directly contacting. During the process of accumulation, the charge carriers at interfaces strengthen the interfacial polarization and consequently cause a significant increase in dielectric permittivity at a low frequency.

\subsection{Dielectric strength}

As mentioned above, incorporating semi-conductive or conductive nanofillers can efficiently increase the dielectric permittivity of nanocomposites; however, most investigations have shown that the dielectric permittivity and breakdown strength of a nanocomposite are difficult to enhance simultaneously. Actually, the high dielectric permittivity of a nanofiller is not evidently transferred to its nanocomposite if the inclusion is not high enough to establish mutual connectivity. The effective

medium theory $\mathrm{y}^{70,71}$ shows that $25 \%$ volume fraction (vol) or more inclusion has an appreciable effect on the improvement of dielectric permittivity. However, the breakdown strength of a nanocomposite drops off precipitously even with only $5-10$ vol $\%$ inclusion. ${ }^{72}$ The addition of nanofillers with high 
dielectric permittivity induces an increased inhomogeneous electric field that generates local electrical defect centers (hot spots) and thus reduces the breakdown strength of a material. Since the maximum energy density is determined by the square of the breakdown strength, enhancement of the breakdown strength is extremely important for the final properties.

The breakdown field of a material is hard to predict and depends on surface roughness and the quality of manufacturing. In the engineering domain, the measurement of breakdown is always problematic, and the results generally need to be fitted by Weibull distribution. The Weibull characteristic breakdown field, $\eta_{1}$, varies with area, $A$, as

$$
\eta_{1}=\eta_{0}\left(\frac{A_{0}}{A_{1}}\right)^{\frac{1}{\beta}}
$$

where $\eta_{0}$ is the breakdown field corresponding to the initial area $A_{0}$, and $\eta_{1}$ is the extrapolated breakdown field at area $A_{l}$. The Weibull slope parameter, $\beta$, for the breakdown field of well-manufactured commercial film is in the range of 20 , which indicates a relatively narrow distribution. $^{4,44}$

In dielectric physics, intrinsic breakdown is used to study the breakdown process and is determined by the nature of the dielectric (i.e., the atomic-level structure and bonding). Intrinsic breakdown is assumed to be the result of an electron avalanche at the intrinsic breakdown field and the relevant scattering mechanism of electron-phonon interactions. Generally, electrons gain energy from an external electric field and from collisions with phonons. At low electric fields, the electron energy distribution is in a steady state, and the energy gained from the external electric field is balanced by the loss from collisions with phonons. At a sufficiently high electric field, the electron energy increases indefinitely until reaching a threshold where a high energy electron ionizes the lattice and leads to carrier multiplication. This process is referred as impact ionization, and the avalanche of electrons 
damages the dielectric. The intrinsic breakdown field provides an upper boundary (theoretical limit) to the engineering breakdown.

For a nanocomposite system, the dielectric breakdown strength usually depends on three factors: (1) differences in the properties of nanofillers and the matrix, (2) dielectric anisotropy, and (3) the interface between nanofillers and the matrix.

(1) Difference in properties of nanofillers and matrix

The differences include dielectric behavior, mechanical performance, and surface properties.

Regarding dielectric behavior, the high contrast of dielectric permittivity between nanofillers and a polymer matrix results in a non-uniform distribution of the electric fields expressed as ${ }^{\mathbf{4 4}}$

$$
\begin{gathered}
\mathrm{E}_{\mathrm{m}}=\mathrm{E}_{0}\left[\varphi_{\mathrm{m}}\left(1-\frac{\varepsilon_{\mathrm{m}}}{\varepsilon_{\mathrm{f}}}\right)+\frac{\varepsilon_{\mathrm{m}}}{\varepsilon_{\mathrm{f}}}\right]^{-1}, \\
\mathrm{E}_{\mathrm{f}}=\mathrm{E}_{0}\left[\varphi_{\mathrm{m}}\left(\frac{\varepsilon_{\mathrm{f}}}{\varepsilon_{\mathrm{m}}}-1\right)+1\right]^{-1},
\end{gathered}
$$

where $E_{0}$ is the applied electric field, $E_{m}$ and $E_{f}$ are the electric fields in the polymer matrix and nanofillers, respectively, $\varphi_{m}$ is the volume fraction of the polymer matrix, and $\varepsilon_{m}$ and $\varepsilon_{f}$ are the dielectric permittivity for the polymer matrix and nanofiller, respectively. Based on Equations 14 (a) and (b), it was found that the electric field of a nanofiller is lower than the applied external electric field, while the electric field of a polymer matrix is higher: $E_{m}>E_{0}>E_{f}$. The contrast of dielectric permittivity $\left(\varepsilon_{\mathrm{m}} / \varepsilon_{\mathrm{f}}\right)$ between a polymer and nanofiller causes the nanofiller to act as a hot spot which distorts the distribution of the electric field and unavoidably increases the local electric field of the polymer matrix, in particular in the interfacial area. Takada et al. ${ }^{73}$ created an "induced dipole moment model" to describe more traps for electrical charge carriers introduced by nanoparticles under a high electric field and found that the trapping density and depth largely depended on the dielectric permittivity of the nanoparticles. Compared with the region far from the nanofiller, the actual electric 
field of the polymer matrix in the interfacial region is higher and easily causes the breakdown of the entire material.

Regarding mechanical performances, the mechanical incompatibility between hard nanofillers and a soft polymer matrix often results in porosity. Kim et al. ${ }^{74}$ investigated the maximum volume fraction of spherical fillers that might be achievable without porosity. They found that the theoretical threshold of the maximum particle volume fraction was around 39\%, for which there were no air voids created inside the composite. The maximum volume fraction without pores in real cases is usually much lower than the theoretical value. Moreover, a large amount of filler will increase the processing viscosity and greatly reduce the flexibility of a polymer matrix and negatively affect the quality of the film. Therefore, to maintain the dielectric breakdown strength and flexibility of a polymer, the volume fraction of nanofillers should be well controlled to reduce the defects/porosity in the nanocomposites, and vol \% over 15 is usually not recommended.

When the content of nanofillers is low (i.e., less than $10 \mathrm{vol} \%$ ), the difference in surface properties between nanofillers and a polymer matrix can affect the breakdown strength. Grabowski et al. ${ }^{\mathbf{7 5}, 76}$ studied four kinds of high-purity amorphous polymer films - poly(methyl methacrylate) (PMMA), polystyrene, polyimide, and poly-4-vinylpyridine — and their nanocomposites with silica colloid. The results shown in Figure 9 indicated that adding colloidal silica to amorphous polymers with higher breakdown strengths (PMMA and polyimide) caused a reduction in the dielectric strength of the nanocomposites. Alternatively, amorphous polymers (poly-4-vinylpyridine and in particular polystyrene) with low breakdown strengths showed similar or even improved breakdown strengths for the nanocomposites with 7.5-15 vol \%. However, for the case of $15 \mathrm{vol} \%$ or greater silica content, all the nanocomposite films exhibited breakdown at similar electric fields, implying the independence of 
the polymer matrix in the case of high volume-fraction loading. Their explanation was that at low volume fractions, the presence of polar groups in PMMA or polyimide might act as additional scattering centers or charge trapping sites. These polar groups formed defects on the polar surface of silica which decreased the breakdown strength. They believed that this was a synergistic effect between the filler and the matrix. At high volume fractions, the surface area of silica are sufficient to dominate breakdown characteristics, and the failure of the nanocomposites becomes independent of the matrix. Higher breakdown-strength amorphous polymers sometimes exhibit reduced breakdown strength in their nanocomposites, while alternatively, low breakdown-strength amorphous polymers show enhanced breakdown strength after adding nanofillers under low volume fraction. Hence, a match of surface properties between a nanofiller and a polymer matrix influences the dielectric breakdown strength.
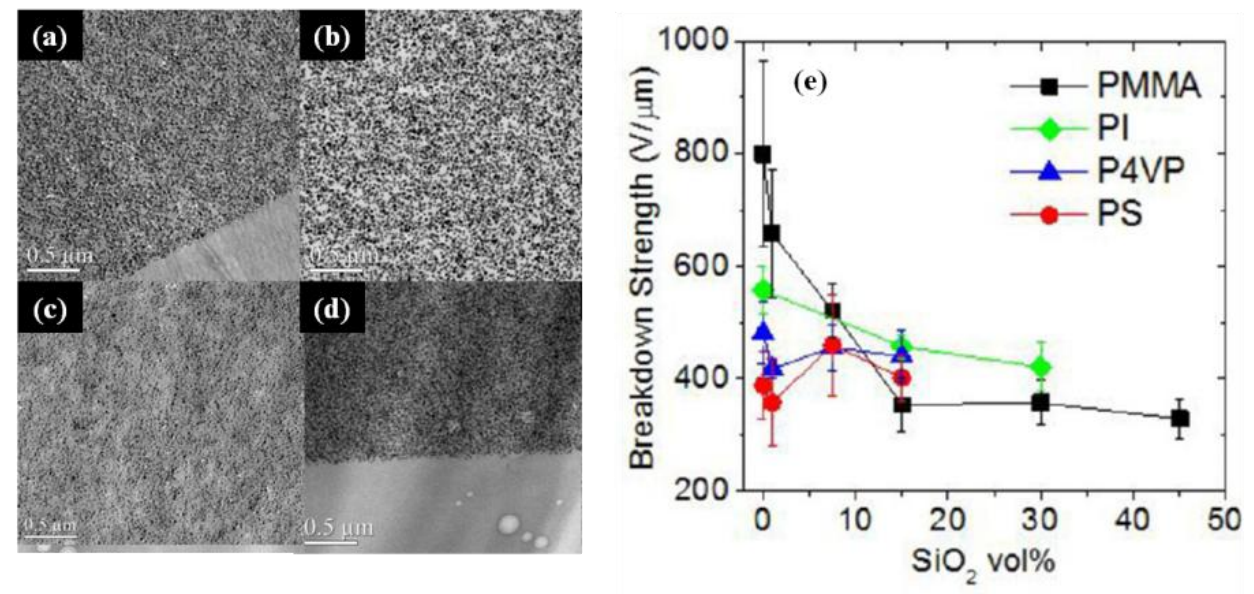

Figure $9^{75}$ TEM for the nanocomposites with 15\% Silica. (a) for PS, (b) for PMMA, (c) for P4VP and (d) for PI. (e) Characteristic breakdown strength of four films as a function of silica volume fraction, which was determined at $63.2 \%$ failure probability from a two-parameter linear Weibull failure analysis. Error bars represented one standard deviation of the breakdown values measured across $>15$ 
breakdown tests. Copyright (C) 2013, American Chemical Society

\section{(2) Dielectric anisotropy}

Dielectric anisotropy is caused by various morphologies, spatial arrangements, and directional alignments of nanofillers in a matrix. It influences the dielectric breakdown strength of a nanocomposite. ${ }^{77}$ For example, when spherical fillers align into chains in a matrix, the breakdown strength of the composite along the chain direction significantly improves. Shen et al. ${ }^{78}$ used a phase-field model to demonstrate the effects of dielectric anisotropy on the dielectric properties and energy storage density of nanocomposites. They found that changes in the microstructure can change the local electric field distribution. They compared polymer nanocomposites reinforced by spherical nanoparticles and one-dimension (1D) nanofibers. Under the same electric field and volume fraction loading, the increase in the electric field with spherical nanoparticles was higher than that with nanofibers. This difference in breakdown strength is the result of electric field distribution. For a spherical-nanoparticle reinforced nanocomposite, the electric field is concentrated at the two shoulders along the electric field direction. For a nanofiber-reinforced nanocomposite, the electric field is concentrated at the vertices of the nanofibers. When the front of the breakdown phase encounters the nanofillers, it is easier to get around the nanoparticles because of their spherical shape and the electrical tree keeps growing. But in the nanofiber case, the fiber shape blocks the growth of the electrical tree and the composite exhibits higher breakdown strength than that with spherical nanoparticles. Furthermore, they defined 400 microstructures for nanocomposites with 10 vol \% loading by assigning different length ratios to the nanofillers. As presented at the top of Figure 10, typically, the vertical nanofiber (S1) was defined with $a_{x} / a_{z}$ and $a_{y} / a_{z}$ both equal to 0.067 . The parallel nanosheet (S5) was 
defined with $a_{x} / a_{z}$ and $a_{y} / a_{z}$ both equal to 6 . The spherical nanoparticle (S3) was defined with $a_{x}: a_{y}: a_{z}$ $=1: 1: 1$. The ellipsoidal nanofiller (S6) was defined with $a_{x}: a_{y}: a_{z}=1: 1: 2$. When the morphology of the nanofiller changed from a vertical nanofiber (S1) to a parallel nanosheet (S5), the breakdown strength of the nanocomposite monotonically increased by 0.56 to 1.35 times that of the polymer matrix. Although the effective dielectric permittivity decreased by 2.24 to 1.08 times that of the polymer matrix, the energy density in Figure 10 (c) increased with the length ratio of the nanofiller. As a result, the nanocomposite with parallel nanosheet nanofillers exhibited the highest energy density, which was about 1.97 times that of the polymer matrix value.
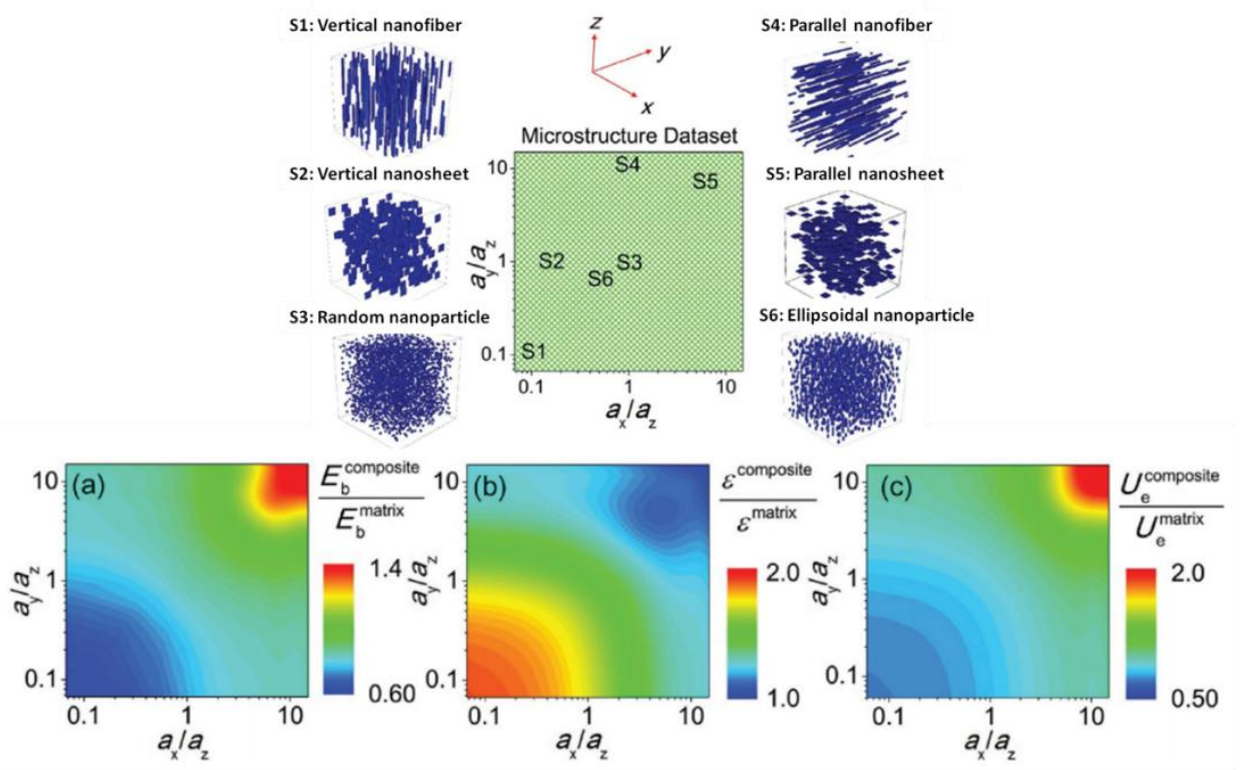

Figure $10^{78}$ On the top: definition of the microstructure dataset for the high throughput computation by assigning different length ratios of the nanofillers. The electric field is applied along the $z$ direction for performing the high throughput computation. The datasets of a) the breakdown strength, b) the effective dielectric permittivity, and c) the energy density outputted from the high throughput calculation. Copyright $\odot 2017$ WILEY-VCH Verlag GmbH \& Co. KGaA, Weinheim 
Scott et al. ${ }^{79}$ reported on a system composed of highly oriented organically modified montmorillonite and poly(vinyl butyral). As presented in Figure 11, they found that the nanolaminate system retarded the breakdown cascade perpendicular to the electrodes at intermediate volume fractions and resembled a discotic nematic phase where highly aligned high-aspect-ratio nanoplatelets were uniformly surrounded by nanoscopic regions of polymer. Compared to the nanocomposite of uniformly dispersed spherical fillers, the idealized arrangement of organically modified montmorillonite increased the tortuosity of the electrical treeing process during breakdown and enhanced the breakdown strength. Their numerical and experimental results showed that the optimized dispersion state and morphology of nanofillers in a matrix with nanofillers aligned in chains perpendicular to the applied field direction or using 1D nanofibers or 2D nanosheets can reduce the field concentration in the polymer matrix and improve the breakdown strength of a nanocomposite.
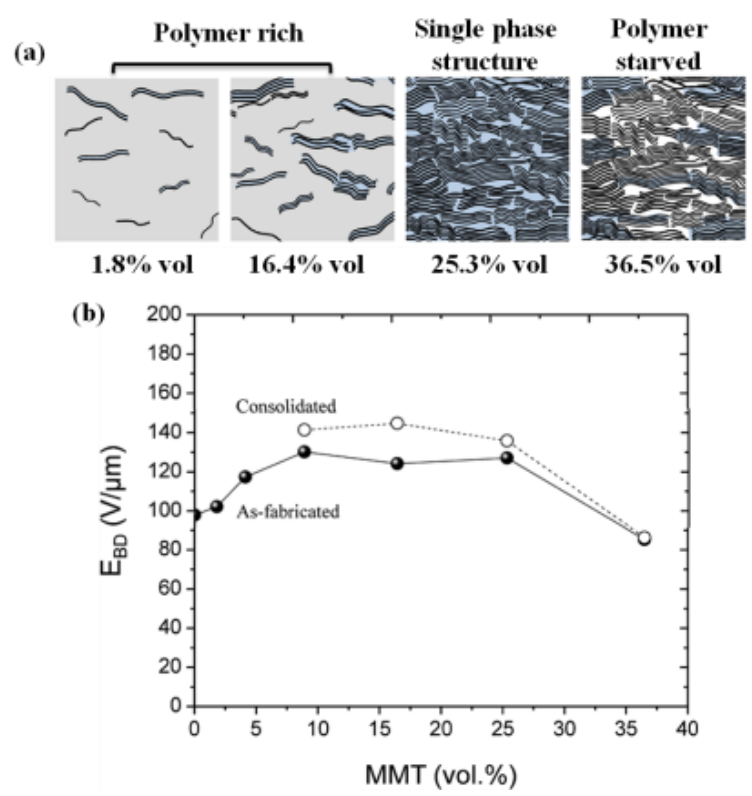

Figure $11^{79}$ (a) Schematic illustration of the oMMT/PVB nanolaminates. The oMMT layers are 
denoted by black lines, while matrix PVB is gray and PVB intercalated between the MMT layers is blue. At the highest fraction of inorganic, white signifies regions bereft of polymer. (b) Characteristic breakdown strength, as a function of oMMT volume percent, determined at $63.2 \%$ failure probability from a linear regressive fit of the two-parameter Weibull failure analysis. Copyright (C 2012, American Chemical Society

(3) Interface between nanofiller and matrix

The interface between an individual nanofiller and polymer matrix is defined as the range over which the permittivity changes from the value of the nanofiller to that of the polymer matrix. In nanocomposites, nanofillers usually create a large amount of interfacial area in the polymer matrix, which increases the possibility of trapping mobile electrons during collisions which may potentially reduce the breakdown strength. Therefore, it is essential to study the properties of nanocomposite interfaces to modify the interface for achieving an enhanced dielectric strength. In an ideal case, the spherical nanoparticles are assumed to be homogeneously dispersed in a matrix and some polymer chains will be attached to the surface of nanoparticles as a core-shell structure because of the high specific surface area of the nanoparticles. According to the multilayered core model of Tanaka as presented in Figure 12 (a), ${ }^{\mathbf{8 0}}$ the interface between the nanoparticles and the polymer matrix can be divided into three parts. The first part is the bonded layer with a thickness of about $1 \mathrm{~nm}$ corresponding to a transition region where both the nanofiller and the polymer are tightly bonded by ionic, covalent, or hydrogen bonds or van der Waals forces. The second part is the bound layer with a thickness of 2-9 $\mathrm{nm}$, where polymer chains are strongly bounded to or interact with the bonded layer as well as the surface of the nanoparticles. The third part is loosely coupled with the second part which has a greater 
thickness of several tens of nanometers, where the chain conformation, chain mobility, and even the free volume or crystallinity are different from that of the polymer far away from the nanoparticles. Consequently, for nanocomposites, it may be these core-shell nanoparticles with multilayered structures and not the naked nanoparticles that disperse in the polymer matrix. ${ }^{5}$ Considering the system as presented in Figure 12 (b) where the naked nanoparticle has a diameter $(d)$ and an interface thickness $(t)$, the interfacial volume fraction $(f)$ can be calculated as ${ }^{48}$

$$
\mathrm{f}=3 \frac{2 \mathrm{t}}{\mathrm{d}}\left[1-\left(\frac{2 \mathrm{t}}{\mathrm{d}}\right)+\frac{1}{3}\left(\frac{2 \mathrm{t}}{\mathrm{d}}\right)^{2}\right]
$$

If the diameter of a nanofiller is $10 \mathrm{~nm}$ and the thickness of the interface is $1.0 \mathrm{~nm}$, then the calculated interfacial volume exceeds $50 \%$ as illustrated in Figure 13 (c). Therefore, it is worth noting that the interfacial volume is comparable to the diameter of a nanoparticle, which implies that the dominant influence on dielectric breakdown strength is the interface in a composite with nanofillers. A well-functioned interface can effectively suppress the leakage current by building a barrier layer for electron tunneling, which improves the dielectric breakdown strength of the nanocomposite. Therefore, an ideal interface comprises a nanofiller with a gradient dielectric permittivity from the center to the border by the bridge of interfaces so that the contrast of dielectric properties between the nanofiller and the polymer matrix can be reduced and consequently realize high dielectric strength while maintaining reasonable dielectric permittivity. 


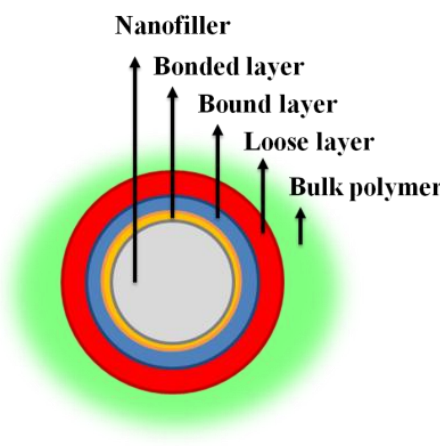

(a)

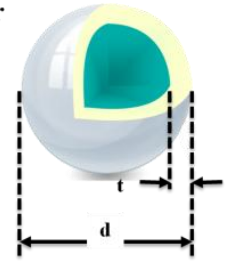

(b)

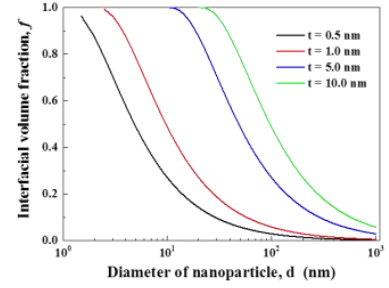

(c)

Figure 12 (a) Multi-core model for interfaces between nanofillers and polymer matrix. ${ }^{9}$ (b) Core-shell nanofiller with a diameter $(d)$ and an interfacial polymer layer with the thickness $(t)$. (c) Interfacial volume percentage as a function of $d$ when $t$ as $0.5,1.0,5.0$ and $10.0 \mathrm{~nm}$, respectively

In addition, the technology of film processing is also extremely important for enhancing high breakdown strength. The biaxial orientation process is a typical example which can achieve a highly ordered alignment of polymer chains. Two directions are used during the stretching: one is the machine direction (MD), which means the direction of movement of the flat sheets along the machine (length direction); the other is the transverse direction (TD), which is perpendicular to the MD (width direction). The conventional equipment for biaxial orientation are double bubble-blown film equipment and tenter frame. The thickness of a film by double bubble-blown equipment is usually about $15-250$ microns, which is too thick for a capacitor; while the tenter frame can produce a film with a thickness less than 15 microns, which is popular for large-scale production. ${ }^{\mathbf{8 1}} \mathrm{A}$ typical tenter process production line for biaxially oriented polymer films includes an extrusion section, an orientation section, usually rollers and clamps, and a film winding section. MD and TD stretching can be performed sequentially or simultaneously as shown in the Figure 13. In sequential biaxial stretching, the polymer sheets are first stretched in the MD to modify the crystallization features and then stretched in the TD. The typical 
stretch ratios in MD are around 1-5 with the annealing treatment to potentially decrease the MD film shrinkage. The MD annealing temperature is typically set above the glass transition temperature of the polymer. The TD annealing temperature is typically near or slightly higher than the melting point of the polymers. The stretch ratio in the TD is polymer dependent. For example, PP film is usually stretched up to 10-12 folds in this process, while PET can only be stretched to 3-4 folds. ${ }^{\mathbf{} 1}$

A polymer film after biaxial orientation usually has a uniform thickness, is as thin as possible, and has less defects and higher dielectric strength. Taking BOPP as an example, ${ }^{3}$ the variation in the thickness of a BOPP film of $3-\mu \mathrm{m}$ thickness is controlled with a $5 \%$ over a large area $\left(150 \mathrm{~m}^{2}\right)$. The number of defects (e.g., pinholes, gels, or particulates) is usually less than $1.0 / \mathrm{m}^{2}$ which results in extremely high dielectric strength. The biaxial stretching process produces films with improved breakdown strength, but the requirements of biaxial stretching are relatively critical. The candidate films should possess proper chain flexibility and deformability and a moderate crystallization degree and dynamics. Achieving a high and homogeneous quality similar to that of a commercial polymer film is usually hard for nanocomposite films. The mismatch in viscosity and mechanical properties between the matrix and nanofiller significantly increases the difficulty of the filming process. Therefore, to improve the breakdown strength of nanocomposite films, the interface modification between a nanofiller and the polymer matrix is more important. 


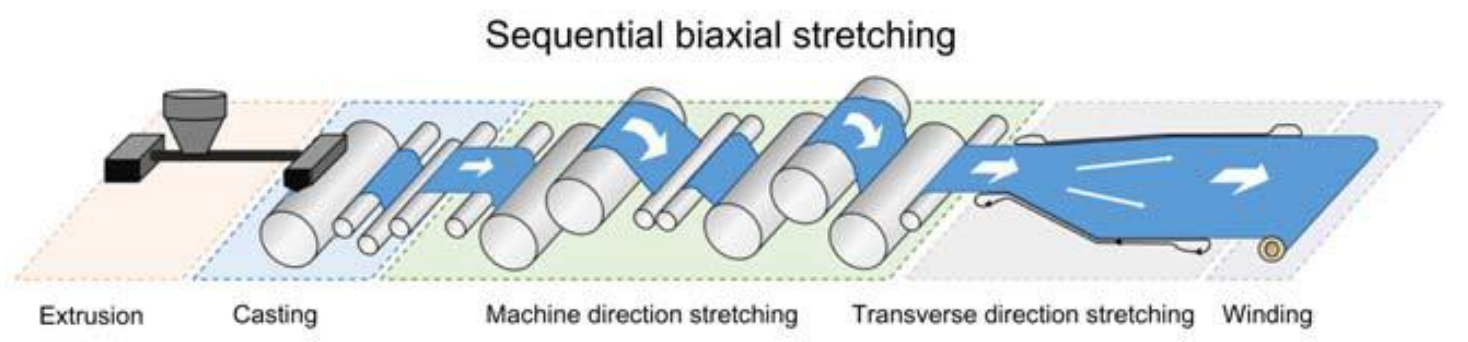

\section{Simultaneous biaxial stretching}

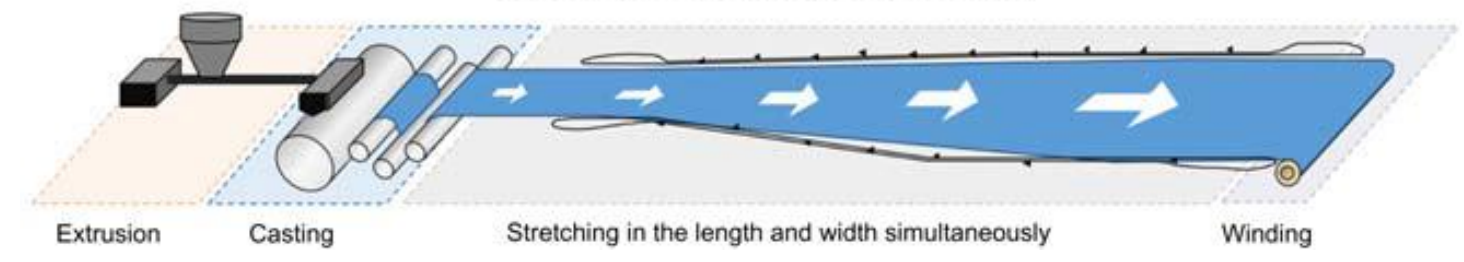

Figure 13 Typical tenter-frame biaxial stretching processes for the fabrication of polymer films

\subsection{Applications of core-shell structures}

Significant efforts have been devoted to the design and synthesis of core-shell nanofillers to modify the interface in order to increase the energy density of nanocomposites. ${ }^{82}$ Wang et al. ${ }^{83}$ employed phase-field modeling to study the influence of the morphology parameters of the core-shell structure on a composite's dielectric properties. By investigating several parameters such as the size, shape, and orientation of core particles, they found that an optimal design of a core-shell particle was required. Their shell had dielectric properties similar to those of a matrix polymer but much lower than those of fillers; in addition, a thick coating was preferable for the shell, i.e., the thickness of the shell was similar to that of the core radius. Their findings proved to be useful in the selection of appropriate materials and design structure parameters. General methods for the synthesis of core-shell nanofillers can be categorized into three strategies: (1) "grafting from," (2) "grafting to," and (3) deposition of inorganic precursors. The first two are usually achieved via surface ligand engineering for the synthesis of an organic shell. The third is often used for introducing inorganic shells by various methods such as hydrothermal, electric-spinning, and chemical vapor deposition which depend on the chemical 
properties of the inorganic shells and the morphologies of the cores.

Surface ligand engineering is a powerful technique for incorporating short molecules and additional functionalities on the surface of nanofillers to improve the compatibility with a polymer matrix. ${ }^{84} \mathrm{~A}$ significant feature for surface ligand engineering is to reduce the mobility of polymer chains in the interfacial region by grafting polar groups to increase entanglements and decrease free volumes in the interfacial region. Furthermore, for semi-crystalline polymers such as PE or PVDF, the covalent bonding between nanofillers and the matrix through cross-linkable functional groups is expected to influence the dipole polarization by altering the structure and morphology of the polymer crystalline region in the interfacial region. In addition, well-selected surface ligand modules can enhance electron trapping and/or scattering at the surface of nanofillers which benefits dielectric strength.

Generally, surface ligand engineering includes two types, namely, "grafting from" and "grafting to." The grafting-from method relies on the formation of nanocomposites by in-situ polymerization of monomers on initiator-functionalized nanofiller surfaces. This method generates a relatively high graft density because of the absence of steric hindrance. A variety of controlled radical polymerizations such as atom transfer radical polymerization (ATRP), nitroxide-mediated polymerization, and reversible addition-fragmentation chain transfer have been used to graft various polymers with a broad range of grafting densities. ${ }^{85-89}$ The Marks research group ${ }^{85,86}$ reported an effective method for preparing PP nanocomposites with high dielectric permittivity and low dielectric loss. As shown in Figures 14 (a) and (b), isostatic PP nanocomposites can be prepared by in-situ propylene polymerization mediated by anchoring/alkylating/activating $\quad \mathrm{C}_{2}$-symmetric dichloro-[rac-ethylenebisindenyl]zirconium(IV) $\left(\mathrm{EBIZrCl}_{2}\right)$ on methylaluminoxane-treated oxide nanofillers $\left(\mathrm{TiO}_{2}, \mathrm{BT}\right.$, and $\left.\mathrm{ZrO}_{2}\right)$. The methylaluminoxane co-catalyst layer on the surface of the metal oxide nanofiller served as a precursor 
for a thin $\mathrm{Al}_{2} \mathrm{O}_{3}$ layer to moderate the largely anticipated contract of dielectric permittivity between polyolefin-ferroelectric nanofiller and to improve the dispersibility of the nanofiller. The incorporation of hybrids with oxide nanofillers as the core and $\mathrm{Al}_{2} \mathrm{O}_{3}$ as the shell allowed the prepared PP nanocomposites to achieve not only greater dielectric properties but also higher dielectric strengths and consequently significantly enhanced energy density compared with pure PP as listed in Table 3 . Huang et al. reported a method based on ATRP and reversible addition-fragmentation chain transfer to prepare core-shell PMMA@BT ${ }^{87}$ and PS@BT ${ }^{88}$ nanocomposites, respectively. The chemical reactions and TEM images of core-shell nanoparticles are presented in Figure 15. Reinforced by core-shell nanofillers with a $10 \mathrm{~nm}$-thick polymer shell, the dielectric permittivity of two nanocomposites significantly increased, while the value of the dielectric loss was maintained at a level as low as that of the polymer matrix (see Table 4). Furthermore, the dielectric properties of the two nanocomposites were stable in a wide range of frequencies. Another example for modifying nanofillers was reported by Ejaz et al. ${ }^{89}$ They successfully prepared core-shell-structured BT-poly(glycidyl methacrylate) (BT-PGMA) nanocomposites by surface-initiated ATRP of GMA from the surface of a BT nanofiller. In the BT-PGMA core-shell structure, the BT nanofiller was covered by thin brushes $(20 \mathrm{~nm})$ of PGMA with $13.7 \%$ weight fraction. An improved dielectric permittivity $\left(54\right.$ at $\left.10^{3} \mathrm{~Hz}\right)$ and breakdown strength of $300 \mathrm{MV} / \mathrm{m}$ were obtained to assure a film with high energy density $\left(21.51 \mathrm{~J} / \mathrm{cm}^{3}\right)$. 


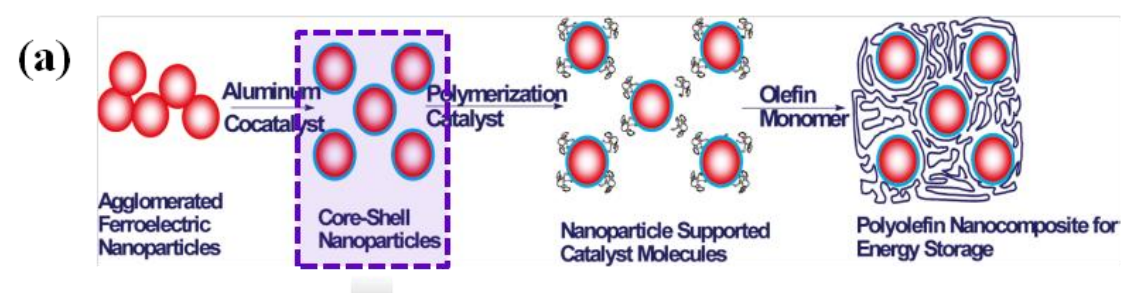

(b)

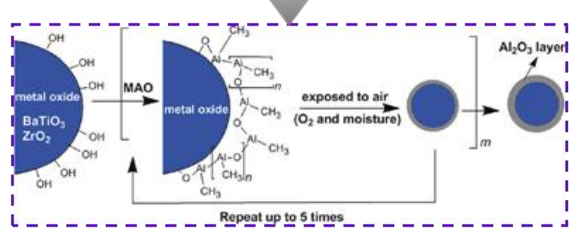

(c)

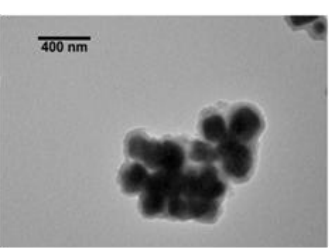

Figure $14(a)^{85}$ Scheme of synthesis of polyolefin-metal oxide nanocomposites. Copyright $\odot 2010$, American Chemical Society (b) ${ }^{86}$ Synthesis of $\mathrm{Al}_{2} \mathrm{O}_{3}$ shell around metal oxide nanofillers via a layer-by-layer MAO coating process. (c) ${ }^{86}$ TEM image of the nanofillers with core-shell structures Copyright @ 2010, American Chemical Society

Table $3^{85}$ Dielectric properties of metal oxide $/{ }^{\text {iso }} \mathrm{PP}$ nanocomposites.

\begin{tabular}{ccccc}
\hline Metal oxide & Volume fraction $(\%)$ & $\boldsymbol{\varepsilon}_{\mathbf{r}} @ \mathbf{1 0}^{\mathbf{3}} \mathbf{H z}$ & $\mathbf{E}_{\mathbf{b}}(\mathbf{M V} / \mathbf{m})$ & $\mathbf{U}_{\mathbf{e}}\left(\mathbf{J} / \mathbf{c m}^{\mathbf{3}}\right)$ \\
\hline $\mathrm{BaTiO}_{3}$ & 13.6 & $6.1 \pm 0.9$ & $>590$ & $9.4 \pm 1.3$ \\
$\mathrm{TiO}_{2}$ & 6.3 & $3.0 \pm 0.2$ & 470 & $2.8 \pm 0.2$ \\
$\mathrm{ZrO}_{2}$ & 9.4 & $6.9 \pm 2.6$ & 200 & $1.02 \pm 0.73$ \\
\hline
\end{tabular}




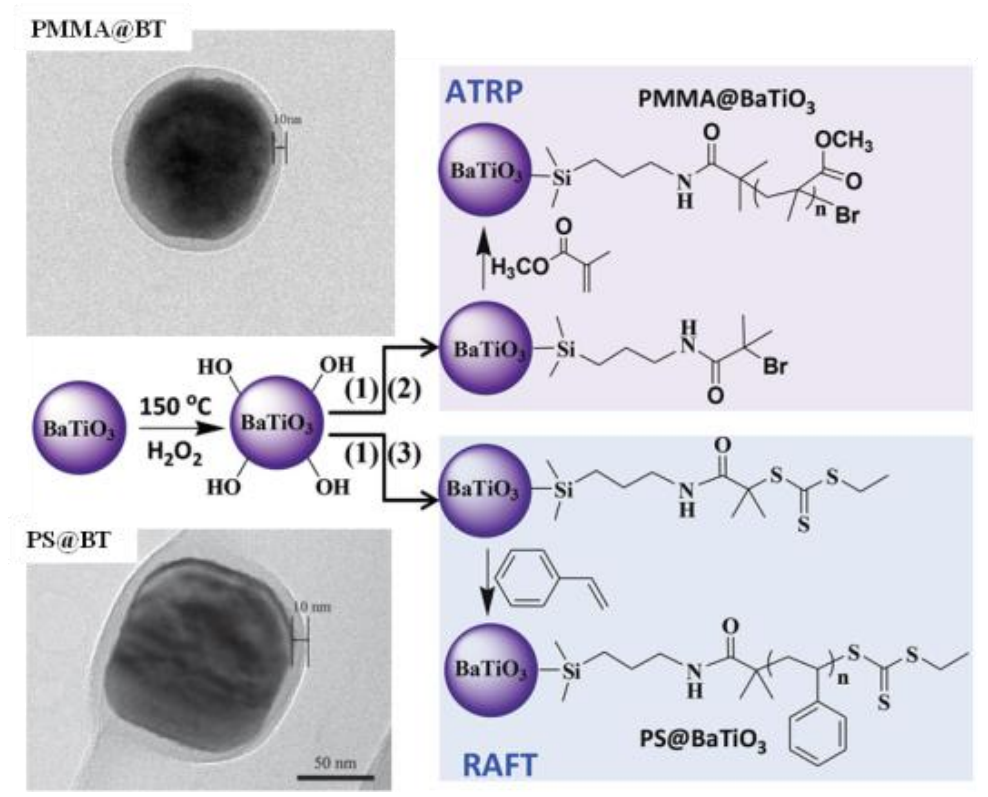

Figure 15 ${ }^{\mathbf{8 2}, 87,88}$ The synthesis of PMMA@BT and PS@BT nanofillers with core-shell structures and the TEM images of shell thickness. (The synthesis scheme: Copyright (C) 2014 WILEY-VCH Verlag GmbH \& Co. KGaA, Weinheim, TEM for PMMA@BT: Copyright (C) 2011, Royal Society of Chemistry, TEM for PS@BT: Copyright (C) 2012 WILEY-VCH Verlag GmbH \& Co. KGaA, Weinheim)

Table 4 Dielectric properties of PMMA@BT and PS@BT nanocomposites

\begin{tabular}{cccc}
\hline Sample & Content $(\mathbf{v o l} \%)$ & $\boldsymbol{\varepsilon}_{\mathbf{r}} @ \mathbf{1 0}^{\mathbf{3}} \mathbf{H z}$ & $\tan \boldsymbol{0} \mathbf{1 0}^{\mathbf{3}} \mathbf{H z}$ \\
\hline${ }^{87}$ Pure PMMA & 0 & 3.49 & 0.0412 \\
${ }^{87}$ PMMA@BT & 32 & 14.6 & 0.0372 \\
${ }^{88}$ Pure PS & 0 & 2.76 & 0.008 \\
${ }^{88}$ PS@BT & 42 & 18.47 & 0.012 \\
\hline
\end{tabular}


In the grafting-to method, the end-groups and functional groups of polymers react with the surface of a nanofiller by covalent bonding. The grafting density usually depends on the weight and flexibility of the molecules because of steric hindrance. The applications of coupling agents, surfactants, and "click chemistry" can be categorized as grafting- to methods for obtaining a robust interface layer. Gao et al. ${ }^{90}$ reported dielectric properties of treated BT/PVDF nanocomposites. BT nanofillers were first hydroxylated by $\mathrm{H}_{2} \mathrm{O}_{2}$ and then modified with a titanate coupling agent DN-101. Results showed that the polarization response of D-h-BT/PVDF was $18 \%$ greater than that of a nanocomposite with BT modified only by DN-101 (D-BT) without $\mathrm{H}_{2} \mathrm{O}_{2}$. Moreover, the energy density of D-h-BT/PVDF was as high as $9.01 \mathrm{~J} / \mathrm{cm}^{3}$, but for D-BT/PVDF without $\mathrm{H}_{2} \mathrm{O}_{2}$ was only $6.5 \mathrm{~J} / \mathrm{cm}^{3}$. Chen et al. ${ }^{32}$ investigated a rigid liquid-crystalline fluoropolymer (PTFMPCS)-modified BT nanofiller and studied its influence on the dielectric properties of P(VDT-TrFE-CTFE) nanocomposites. The experimental results demonstrated that PTFMPCS improved the compatibility between BT and a matrix and by using 5 vol $\%$ modified BT with an 11-nm thick shell of PTFMPCS; the energy density reached $16.18 \mathrm{~J} / \mathrm{cm}^{3}$ and the dielectric breakdown was $514 \mathrm{MV} / \mathrm{m}$. Recently Cho et al. ${ }^{39}$ fabricated (3-aminopropyl)trimethoxysilane-modified BT hollow nanospheres with an average diameter of $20 \mathrm{~nm}$. They found that the modification of the surface by (3-aminopropyl)trimethoxysilane increased the content of a high dielectric permittivity crystalline polymorph $\beta$ phase in the PVDF crystalline regions. Consequently, the obtained nanocomposite had extremely high dielectric permittivity $(\approx 109.6)$ and a very low dielectric loss (0.0002) and achieved an energy density as high as $21.7 \mathrm{~J} / \mathrm{cm}^{3}$ under a maintained breakdown strength of $381 \mathrm{MV} / \mathrm{m}$. Apart from the use of various coupling agents, biological dopamine (DOPA) with aromatic and amido groups has been recently explored as a compatibilizer to modify the interface between a nanofiller and a matrix in some nanocomposites. The 
introduction of DOPA on the surface of nanofillers not only improves the homogeneity of dispersion but also reduces dielectric loss and leakage current density in a nanocomposite. Wang et al. ${ }^{29}$ reported dielectric properties of poly(vinylidene fluoride-hexafluoropropylene) (P(VDF-HFP)) nanocomposites incorporated with $\mathrm{TiO}_{2}$ nanowires treated by a brush-like long-chain dopamine derivative (h-DOPA). With the incorporation of $2.5 \mathrm{vol} \% \mathrm{~h}$-DOPA, the dielectric permittivity and loss at $1 \mathrm{kHz}$ were 16.5 and 0.06 , respectively, and the breakdown strength was $520 \mathrm{MV} / \mathrm{m}$, which led to an increased energy density of $11.13 \mathrm{~J} / \mathrm{cm}^{3}$ for the nanocomposite.

Copper-catalyzed azide-alkyne cycloaddition (click chemistry) is a controllable method with high efficiency and specificity in a reaction. This method controls the grafting density of the macromolecular chains on the surface of a nanofiller and provides a deeper understanding of the influence of shell morphology on the dielectric properties of nanocomposites. ${ }^{91,}{ }^{92}$ Huang et al. $^{\mathbf{9 3}}$ investigated a thiolene reaction for preparing PS@BT and PMMA@BT by click reaction. They found that the dielectric loss of a nanocomposite at a low frequency largely depended on the molecular weight of the polymer chains and the grafting density. Polymer chains with high molecular weight tend to cause low grafting density which increases dielectric loss. They thought that the ideal shell in a core-shell nanofiller preferred a brush-shaped polymer chain graft with low molecular weight but high grafting density. Lin et al. $^{94}$ designed amphiphilic multiarmed star-like poly(acrylic acid)-block-poly(vinylidene fluoride) (PAA-b-PVDF) diblock copolymers consisting of hydrophilic PAA and hydrophobic PVDF blocks by combining ATRP and click reaction as presented in Figure 16. The diblock copolymers were covalently linked to a small core as nanoreactors to craft in-situ monodispersed BT nanofillers with tunable sizes. This method achieved a direct and stable connection between the BT nanofiller and PVDF chains and consequently excellent dielectric properties (dielectric 
permittivity $\approx 78$ and dielectric loss $\approx 0.02$ at $10^{3} \mathrm{~Hz}$ ) were obtained because of the well-defined interface of PVDF/BT without direct particle/particle contact.

(a)

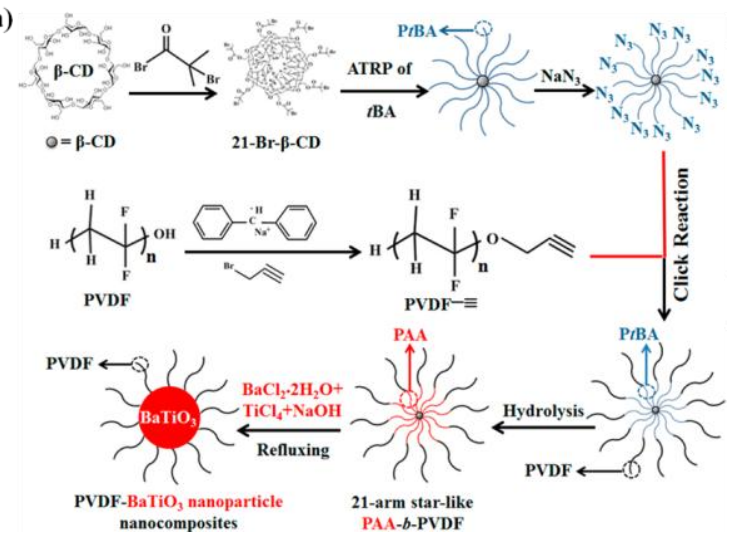

(b)

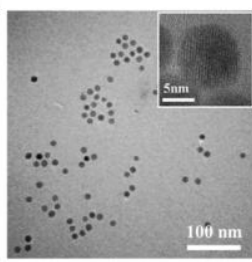

(c)

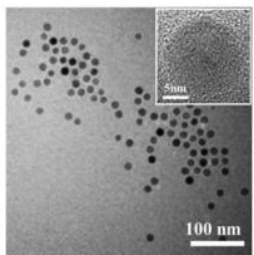

(d)

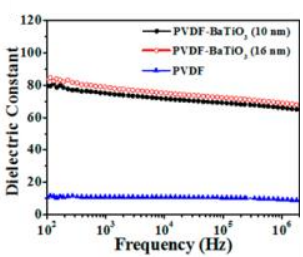

(e)

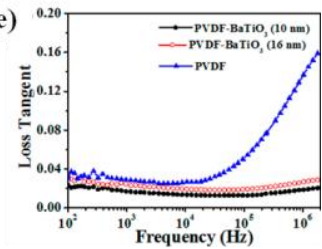

Figure $\mathbf{1 6}^{\mathbf{9 4}}$ (a) Synthetic route to amphiphilic 21-arm, star-like PAA-b-PVDF diblock copolymer and subsequent conversion into PVDF functionalized BT nanofillers. TEM images of PVDF-BT nanocomposites synthesized by capitalizing on star-like PAA-b-PVDF diblock copolymers with different molecular weights of PAA blocks as nanoreactors. (b) Diameter, D = $10.2 \pm 0.6 \mathrm{~nm}$, and (c) D $=16.1 \pm 0.8 \mathrm{~nm}$. Insets: The crystalline lattices of each nanofiller are clearly evident in HRTEM images. Dielectric constants (d) and loss tangents (e) of PVDF and PVDF-BT nanocomposites with different diameters of BT nanofillers. Copyright (C) 2015, American Chemical Society

Apart from core-shell-structured nanofillers with organic shell layers prepared by grafting routes, core-shell nanofillers with inorganic shells have also been studied, including metal-carbon $\left(\mathrm{C} @ \mathrm{Ag}^{95}\right.$, $\left.{ }^{96}\right)$, metal oxide-metal $\left(\mathrm{Al}_{2} \mathrm{O}_{3} @ \mathrm{Al}^{97}\right.$ and $\left.\mathrm{TiO}_{2} @ \mathrm{Ag}^{98}\right)$, and metal oxide-metal oxide $\left(\mathrm{BT} @ \mathrm{Al}_{2} \mathrm{O}_{3},{ }^{31,99}\right.$ BT@ $\mathrm{SiO}_{2},{ }^{100} \mathrm{BT} @ \mathrm{TiO}_{2}{ }^{36,40,101}$ and $\left.\mathrm{TiO}_{2} @ \mathrm{BT}^{102}\right)$. Zhang et al. investigated the application of $\mathrm{TiO}_{2}$ nanofibers coated with $\mathrm{BT}\left(\mathrm{BT} @ \mathrm{TiO}_{2}\right)$ as presented in Figure 17 and compared the dielectric properties of nanocomposites with 3 vol \% of $\mathrm{BT} @ \mathrm{TiO}_{2}$ nanofiber, $\mathrm{TiO}_{2}$ nanofiber, and $\mathrm{BT}$ nanofiller 
in $\mathrm{PVDF}^{36}$ and $\mathrm{P}(\mathrm{VDF}-\mathrm{HFP})^{40}$ polymer matrices. Using the annular bright field atomic-scale imaging technique, they found the existence of Ba-Ti mutual occupation and a large strain in the interfacial region between $\mathrm{BT}$ and $\mathrm{TiO}_{2}$ owing to the large difference in lattice parameters between $\mathrm{BT}$ and $\mathrm{TiO}_{2}$ along the [001] direction. These two features enhanced the polarization and electric displacement of BT@ $\mathrm{TiO}_{2}$ nanofibers. Therefore, compared with the $\mathrm{TiO}_{2}$ nanofibers and $\mathrm{BT}$ nanofillers shown in Figures 17 (c) and (d), the nanocomposites with $\mathrm{BT} @ \mathrm{TiO}_{2}$ nanofibers had a remarkable breakdown strength and energy density at the same volume fraction inclusion. In the case of $\mathrm{BT} @ \mathrm{TiO}_{2}$ nanofiber/PVDF, the dielectric permittivity and loss were about 17 and 0.025 at $1 \mathrm{kHz}$, respectively, and the dielectric breakdown strength and energy density were $646 \mathrm{MV} / \mathrm{m}$ and $20 \mathrm{~J} / \mathrm{cm}^{3}$, respectively. In the case of $\mathrm{BT} @ \mathrm{TiO}_{2}$ nanofiber/P(VDF-HFP), the dielectric permittivity and loss were about 18 and 0.05 at $10^{3} \mathrm{~Hz}$, respectively, and the dielectric breakdown strength and energy density were $797 \mathrm{MV} / \mathrm{m}$ and $31.2 \mathrm{~J} / \mathrm{cm}^{3}$, respectively. This is the highest energy density achieved by nanocomposites and shows a promising avenue for the application of core-shell structure to achieve films with high energy density.
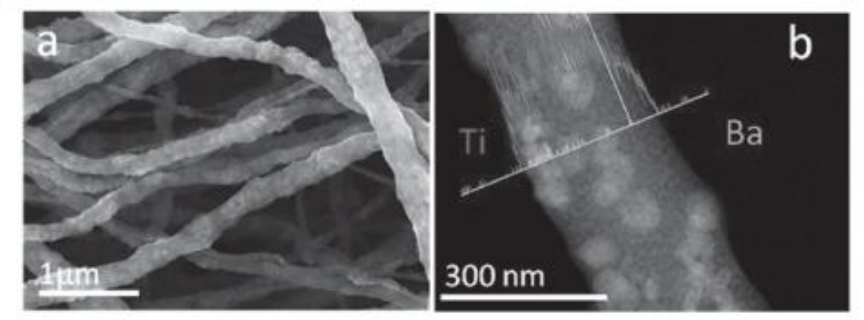

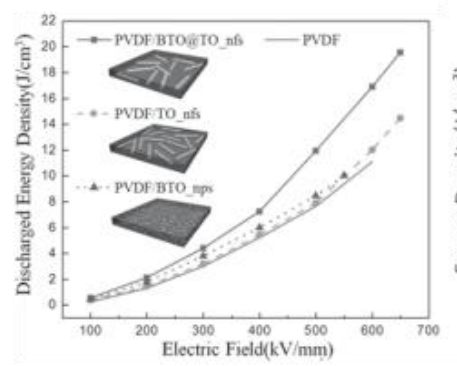

(c)

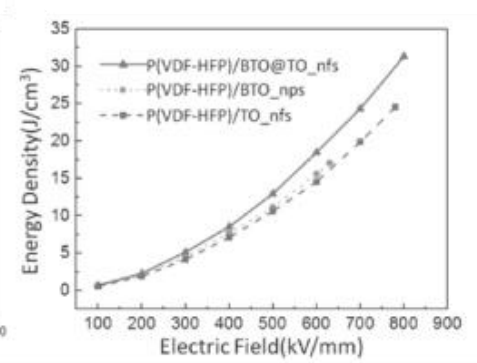

(d) 


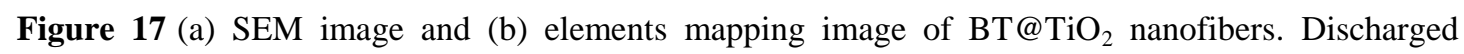
energy density of PVDF (c) and P(VDF-HFP) ${ }^{101}$, Copyright @ 2014 WILEY-VCH Verlag GmbH \& Co. KGaA, Weinheim, (d) nanocomposites embedded with BT@ $\mathrm{TiO}_{2}$ nanofibers, $\mathrm{TiO}_{2}$ nanofibers, BT nanofillers and pure PVDF films as a function of electric field. The volume fraction of three nano-inclusions were fixed at $3 \%$ in all composites ${ }^{102}$ Copyright $@ 2016$ WILEY-VCH Verlag GmbH \& Co. KGaA, Weinheim

\subsection{Applications of multilayer structures}

Recent theoretical and experimental investigations have indicated that a tailored architecture of oriented and spatially distributed constituents in the form of high-aspect ratio plates or strings can improve the field response of a nanocomposite. ${ }^{78}$ Therefore, the design of a dielectric film with a multilayer structure is another way to solve the paradox of achieving a simultaneous increase in breakdown strength and dielectric permittivity for nanocomposites. Compared to conventional single-layered thin film, in a multilayered thin film, layers with high dielectric permittivity and layers with high breakdown strength are stacked layer-by-layer to provide synergistic advantages for enhancing energy density.

$\mathrm{Hu}$ et al. ${ }^{103}$ investigated a sandwich-structured PVDF matrix nanocomposite film by combining spherical BT nanoparticles and BT nanofibers. In the nanocomposite film, two out-layers had 10 vol \% BT nanofillers as a "soft layer" and the middle-layer had 2 vol \% BT nanofibers as a "hard layer" according to their different dielectric strengths. As a result, the optimally tailored topological structure exhibited energy density of $9.72 \mathrm{~J} / \mathrm{cm}^{3}$ with a dielectric breakdown strength of $453 \mathrm{MV} / \mathrm{m}$. Wang et al. ${ }^{104}$ investigated opposite sandwich-structured BT/PVDF nanocomposites. They combined the middle 
"hard layer" with 1 vol \% BT to provide a higher breakdown strength and two "soft" out-layers with 20 vol \% BT to provide a higher dielectric permittivity. The nanocomposite exhibited a dielectric permittivity of 17 , a dielectric loss of 0.03 , a breakdown strength of $470 \mathrm{MV} / \mathrm{m}$, and an energy density of $18.8 \mathrm{~J} / \mathrm{cm}^{3}$. They used finite element simulation to analyze the breakdown process in the nanocomposite. It was found that the enhanced dielectric strength resulted from the heterogeneous distribution of the electric field in the nanocomposite film. The growth of electrical trees was blocked in the low electric field region around interfaces between the "hard layer" and "soft layer" as shown in Figure 18. The "hard layer" tolerated a higher electric field when it was introduced into a sandwich structured film. On the contrary, the electric field of the "soft layers" was smaller than that of the samples with a single layer of $20 \mathrm{vol} \% \mathrm{BT}$ and protected the nanocomposite from electric breakdown.
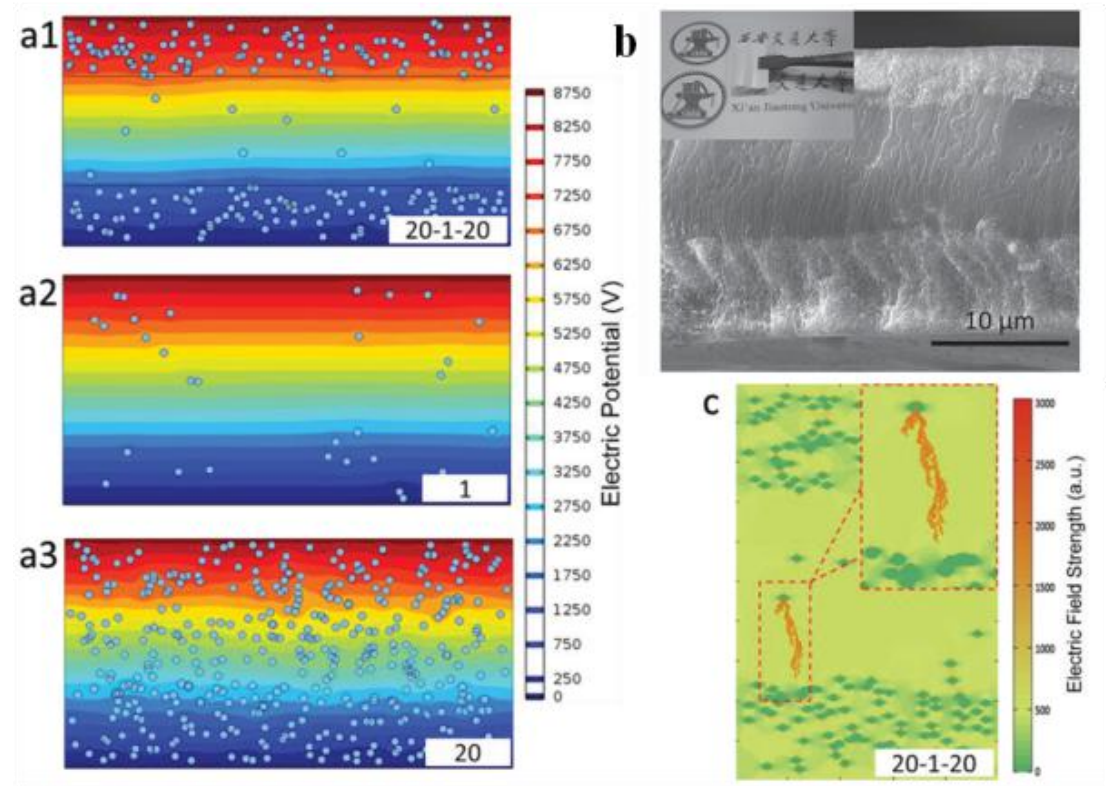

Figure $\mathbf{1 8}^{\mathbf{1 0 4}}$ The distribution of electric field in: (a1) sandwiched BT/PVDF nanocomposites with 20 vol\% BT in "soft layers" and 1 vol\% BT in "hard layer," (a2) single layer BT/PVDF nanocomposites with 1 vol\% BT, and (a3) single layer BT/PVDF nanocomposites with 20 vol\% BT, simulated by finite 
element methods. (b) SEM image for the sandwiched nanocomposite (c) The incomplete breakdown in sandwiched BT/PVDF with 20 vol\% BT in the "soft layer" at the applied voltage of $9 \mathrm{kV}$ simulated by finite element method. Copyright @ 2015 WILEY-VCH Verlag GmbH \& Co. KGaA, Weinheim

Boron nitride nanosheet (BNNS), a type of 2D insolated nanomaterial with a wide band gap (6 eV) insulator and ultrahigh thermal conductivities (300-2000 W/mK) has been recently investigated for energy storage applications in nanocomposites. ${ }^{37,58,59,} 105$ Liu et al. ${ }^{105}$ investigated a PVDF matrix nanocomposite with a multilayered structure loaded by BNNS and barium strontium titanate nanowires. In this structure, the out-layer was functionalized with 10 vol \% BNNS to provide high breakdown strength, whereas the middle-layer contained a high dielectric permittivity 8 vol $\%$ barium strontium titanate nanowire to improve the electrical polarization of the composite. The prepared sandwiched nanocomposites displayed impressive capacitive energy storage properties including breakdown strength of $588 \mathrm{MV} / \mathrm{m}$ and energy density of $20.5 \mathrm{~J} / \mathrm{cm}^{3}$. The dielectric properties for currently reported nanocomposites with multilayered structures are summarized in Table 5. These nanocomposites with multilayer structures and ameliorated dielectric performances offer another simple but effective method to exploit perspective dielectric candidates by various hierarchical structures and combinations.

Table 5 Dielectric properties of polymer matrix nanocomposites of multilayer structure

\begin{tabular}{|c|c|c|c|c|}
\hline Components & $\varepsilon_{\mathrm{r}}{ }^{\prime}$ & $\tan \delta$ & $\mathbf{E}_{\mathbf{b}}$ & $\mathbf{U}_{\mathbf{e}}$ \\
\hline & $@ 10^{3} \mathrm{~Hz}$ & @ $10^{3} \mathrm{~Hz}$ & $(\mathbf{M V} / \mathbf{m})$ & $\left(\mathrm{J} / \mathrm{cm}^{3}\right)$ \\
\hline${ }^{106} \mathrm{PVDF}-\mathrm{BT}_{(\mathrm{np}) *}(1 \%$ vol $)$ & 10.1 & $<0.025$ & 390 & 7.02 \\
\hline
\end{tabular}


$\operatorname{PVDF}_{-\mathrm{BT}_{(\mathrm{np})}}(1 \% \mathrm{vol})$

\begin{tabular}{|c|c|c|c|}
\hline${ }^{107} \mathrm{PVDF}_{-\mathrm{TiO}_{2(\mathrm{np})}}(30 \% \mathrm{vol})$ & $\approx 14$ & $<0.03$ & 300 \\
\hline PVDF-BSBT $_{(\mathrm{nf}) *}^{*}(3 \% \mathrm{vol})$ & & & \\
\hline
\end{tabular}

P(VDF-HFP)-NBBT@PVP (1\% vol)-three layers

P(VDF-HFP)-NBBT@PVP (30\% vol)-one layer 


\begin{tabular}{|c|c|c|c|c|}
\hline${ }^{111}$ PVDF-BT (3\% vol) & $\approx 11.5$ & $\approx 0.03$ & 411 & 16.2 \\
\hline \multicolumn{5}{|l|}{ PVDF } \\
\hline \multicolumn{5}{|l|}{ PVDF-BT (3\% vol) } \\
\hline${ }^{104} \mathrm{PVDF}^{-B T_{(\mathrm{np})}}(20 \%$ vol $)$ & 17 & 0.03 & 472 & 18.8 \\
\hline \multicolumn{5}{|l|}{$\mathrm{PVDF} \mathrm{BT}_{\text {(np) }}(1 \%$ vol $)$} \\
\hline \multicolumn{5}{|l|}{ PVDF-BT $_{(\mathrm{np})}(20 \%$ vol $)$} \\
\hline${ }^{112} \mathrm{PVDF}$ & 18 & $\approx 0.055$ & 495 & 19.37 \\
\hline \multicolumn{5}{|l|}{ BT (np) } \\
\hline \multicolumn{5}{|l|}{ PVDF } \\
\hline${ }^{104}$ PVDF-BNNS* (10\% vol) & - & - & 588 & 20.5 \\
\hline \multicolumn{5}{|l|}{$\operatorname{PVDF~BST}_{(\mathrm{nw}) *}(8 \%$ vol $)$} \\
\hline PVDF-BNNS (10\% vol) & & & & \\
\hline
\end{tabular}

*np: nanofiller

BZTBCT: $0.5 \mathrm{Ba}\left(\mathrm{Zr}_{0.2} \mathrm{TiO}_{0.8}\right) \mathrm{O}_{3}-0.5\left(\mathrm{Ba}_{0.7} \mathrm{Ca}_{0.3}\right) \mathrm{TiO}_{3}$

BSBT: $\mathrm{Bi}_{2} \mathrm{O}_{3}$-doped $\mathrm{Ba}_{0.3} \mathrm{Sr}_{0.7} \mathrm{TiO}_{3}$

nf: nanofiber

NBBT: $\left(\mathrm{Na}_{0.5} \mathrm{Bi}_{0.5}\right)_{0.93} \mathrm{Ba}_{0.07} \mathrm{TiO}_{3}$

BST: $\mathrm{Ba}_{0.5} \mathrm{Sr}_{0.5} \mathrm{TiO}_{3}$

nw: nanowire 
BNNS: Haxagonal BN nanosheet

\section{All-polymer dielectric films}

The development of all-polymer dielectrics is another direction for achieving film materials with high energy density. In this section, the current state-of-art all-polymer dielectric films are presented based on the relation of dielectric properties with band gaps and polar segments, crystalline and amorphous regions, rheological properties, and multilayer structures.

\subsection{Molecular structures}

For homogeneously structured dielectrics, to select promising polymer repeat units, Sharma et al. ${ }^{113}$ studied the function of the corresponding computed band gaps with molecular structures based on 267 hydrocarbon-based polymers and provided the dielectric permittivity from electronic and atomic (or ionic) parts using density functional theory calculations. As shown in Figure 19, a near inverse dependence was presented which imposed a theoretical limit on the achievable electronic part of dielectric permittivity. Furthermore, even after achieving high electronic polarization in polymers, this dependence led to poor insulators and reduced dielectric strength. In the case of the ionic part, the central phonon modes displayed a time-varying dipole moment that determined the ionic part of dielectric permittivity and not the band gap. Therefore, strengthening the ionic part can be further exploited for the high dielectric permittivity of polymers. They summarized the appropriate polymer repeat units that enhanced the ionic part of the dielectric permittivity as listed in Table 6 , and these units were composed of at least one of the polar units $\mathrm{NH}, \mathrm{CO}$, or $\mathrm{O}$ and at least one of the aromatic rings $\mathrm{C}_{6} \mathrm{H}_{4}$ or $\mathrm{C}_{4} \mathrm{H}_{2} \mathrm{~S}$. 

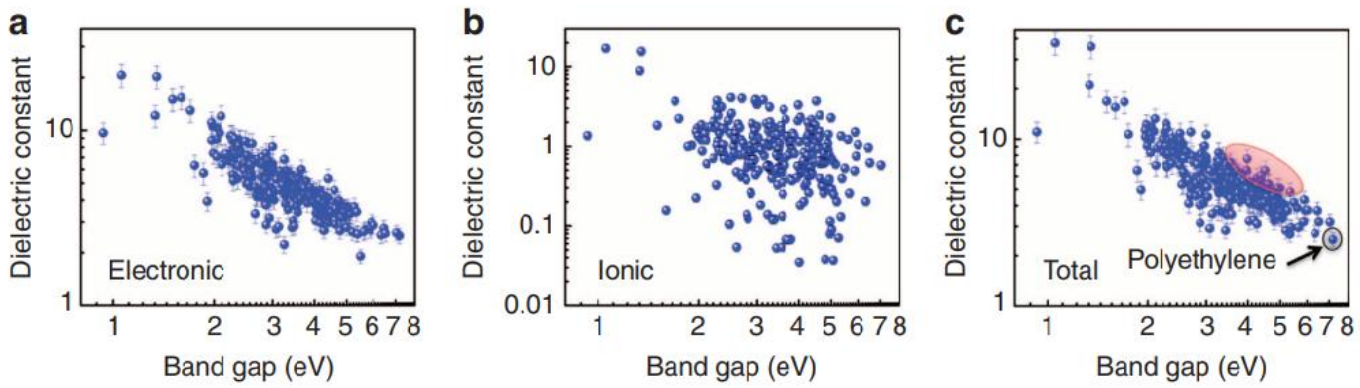

Figure $19^{113}$ The dielectric permittivity versus band gap relationship of polymers: (a) for electronic part, (b) for ionic part and (c) for the sum of two parts (along the polymer chain axis). Copyright $($ ) 2014, Springer Nature

Table $6^{113}$ Promising polymer repeat units identified from the investigation by Sharma et al. Copyright (C) 2014, Springer Nature

System repeat unit

NH-CO-NH- $\mathrm{C}_{6} \mathrm{H}_{4}$

$\mathrm{CO}-\mathrm{NH}-\mathrm{CO}-\mathrm{C}_{6} \mathrm{H}_{4}$

$\mathrm{NH}-\mathrm{CS}-\mathrm{NH}-\mathrm{C}_{6} \mathrm{H}_{4}$

NH- $\mathrm{C}_{6} \mathrm{H}_{4}-\mathrm{C}_{6} \mathrm{H}_{4}-\mathrm{C}_{6} \mathrm{H}_{4}$

$\mathrm{CO}-\mathrm{C}_{6} \mathrm{H}_{4}-\mathrm{CO}-\mathrm{O}$

$\mathrm{C}_{6} \mathrm{H}_{4}-\mathrm{C}_{6} \mathrm{H}_{4}-\mathrm{C}_{6} \mathrm{H}_{4}-\mathrm{O}$

$\mathrm{CH}_{2}-\mathrm{C}_{6} \mathrm{H}_{4}-\mathrm{C}_{6} \mathrm{H}_{4}-\mathrm{O}$

$\mathrm{CH}_{2}-\mathrm{CO}-\mathrm{C}_{6} \mathrm{H}_{4}-\mathrm{O}$

$\mathrm{CH}_{2}-\mathrm{C}_{6} \mathrm{H}_{6}-\mathrm{CO}-\mathrm{O}$

$\mathrm{CH}_{2}-\mathrm{NH}-\mathrm{CO}-\mathrm{NH}$

\section{Polymer class}

Polyurea

Polyimide

Polythiourea

Polyamine

Polyester, polyanhydride

Polyether

Polyether

Polyether, polyketone

Polyester

Polyurea 
CH2-NH-CS-NH

$\mathrm{CH} 2-\mathrm{C} 6 \mathrm{H} 4-\mathrm{CH} 2-\mathrm{O}$
Polythiourea

Polyether

Based on theoretical simulations for polarization and molecular structure, synthesizing polymers by the rational selection of chemical functionalities has become popular. For instance, Sotzing et al. ${ }^{43,114}$ investigated different types of polyimides with variations of structures as presented in Figure 20. They found that the incorporation of different functional groups such as carbonyl and ether could work as additional permanent dipole moments or change the cross-conjugation length in polyimide chains to alter the delocalization of $\pi$ electrons. As a result, the longest cross-conjugated system obtained polyimide polymerized by BTDA and HK511 exhibited a high dielectric permittivity of 7.8, a loss less than $1 \%$, a breakdown strength of $676 \mathrm{MV} / \mathrm{m}$, and a potential energy density around $15 \mathrm{~J} / \mathrm{cm}^{3}$.

(a)

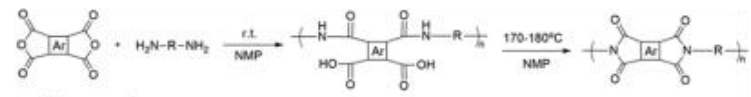

a

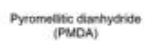

$1 \mathrm{H}_{2} \mathrm{~N} \sim \mathrm{NH}^{\mathrm{N}}$

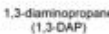

o inis

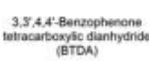

$2 \mathrm{H}_{2} \mathrm{~N} \sim \mathrm{NH}_{2}$ 1.0.0.amnothate

$c$ ond?

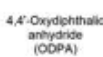

$3 \mathrm{CH}_{3} \mathrm{~N}_{\mathrm{CH}} \mathrm{NH}_{2}$ Jerfamine 0230
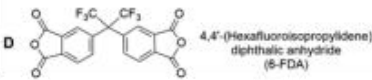

$4 \mathrm{CH}_{\substack{x \\ x+2=12 . y-2 \\ \text { JEFFAMINE HKS11 }}}^{\mathrm{CH}_{2} \mathrm{~N}-\mathrm{CH}_{2}}$

(b)

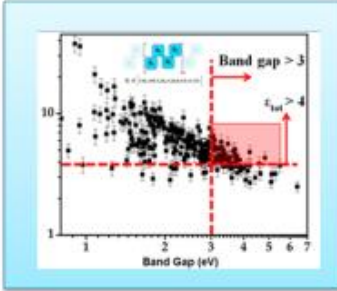

(c)

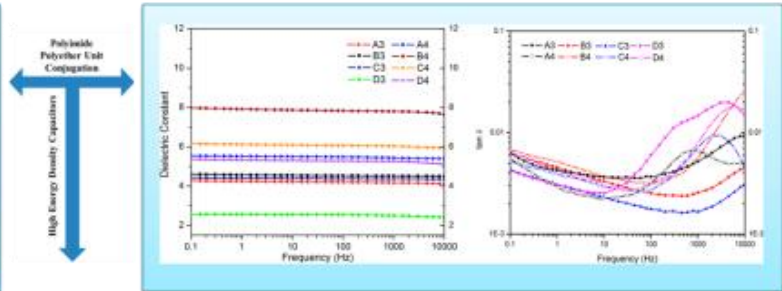

Figure $20^{114}$ (a) Scheme of monomers and syntheses of polyimides A1-D4. (b) DFT-based initial screening results. (c) Dielectric permittivity (left) and loss (right) vs frequency at room temperature for 
various types of PI. Copyright @ 2014 , American Chemical Society

Wang et al. ${ }^{115}$ reported on a poly(diaminodiphenyl methanediphenyl methane diisocyanate) thin film fabricated via a vacuum thermal vapor deposition with two monomers, 4-4'-MDA and 4-4'-MDI, as presented in Figure 21. ${ }^{116}$ The polyurea film could be used at high temperatures $\left(200{ }^{\circ} \mathrm{C}\right)$ because of the polymerized aromatic structures. Moreover, a dielectric permittivity of $\approx 4.2$ and a loss of 0.005 at $10^{3}$ $\mathrm{Hz}$ were stable in the entire investigated frequency range. In particular, the dielectric strength of the film could reach near $800 \mathrm{MV} / \mathrm{m}$ which made the energy density higher than $12 \mathrm{~J} / \mathrm{cm}^{3}$.
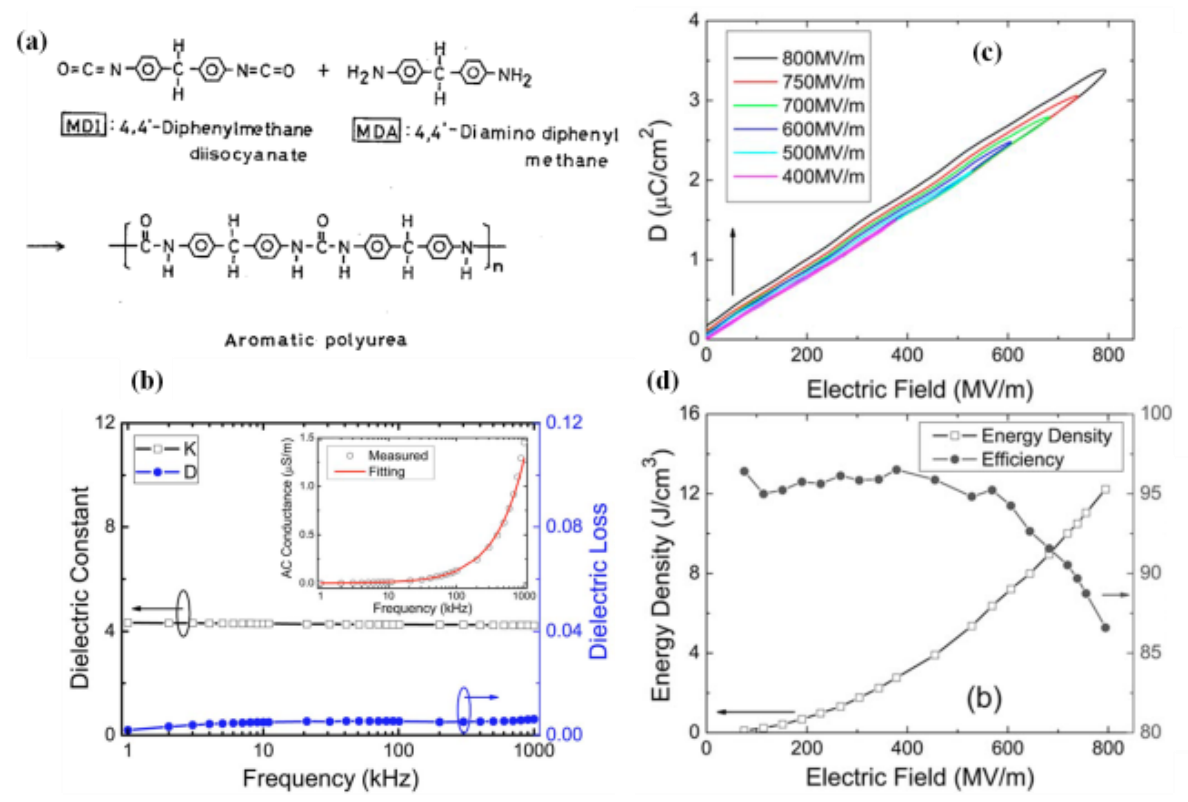

Figure 21 (a) ${ }^{116}$ Scheme of vapor deposition polymerization of aromatic polyurea from MDA and MD1 monomers. Rights managed by AIP Publishing LLC (b) ${ }^{\mathbf{1 1 5}}$ : Frequency-dependence of dielectric permittivity and dielectric loss of aromatic polyurea at room temperature, inset graph is the measured and fitting data of aromatic polyurea's AC conductance. (c) ${ }^{\mathbf{1 1 5}}$ : The electric displacement-electric field measured at $1 \mathrm{kHz}$ for different applied field levels. (d) ${ }^{\mathbf{1 1 5}}$ : Discharged energy density open squares and 
charge-discharge efficiency solid circles vs electric field. Rights managed by AIP Publishing LLC

$\mathrm{Wu}$ et al. $^{117}$ reported on the synthesis of a new aromatic polythiourea (ArPTU) film by the microwave-assisted polycondensation of 4,4'-diphenylmethanediamine (MDA) with thiourea in N-methyl-2-pyrrolidone and p-toluenesulfonic acid as a catalyst. As shown in Figure 22, the ArPTU film had a dielectric permittivity of $\approx 4.5$, a loss less than 0.01 , and an ultrahigh dielectric strength greater than $1000 \mathrm{MV} / \mathrm{m}$ which exhibited an energy density as large as $22 \mathrm{~J} / \mathrm{cm}^{3}$. The results of XRD indicated that the film was almost amorphous and did not possess long-range crystalline ordering. The authors suggested that the presence of random dipoles and the amorphous glass-phase structure of ArPTU provided substantially strong scattering to charge carriers and resulted in low conduction loss.

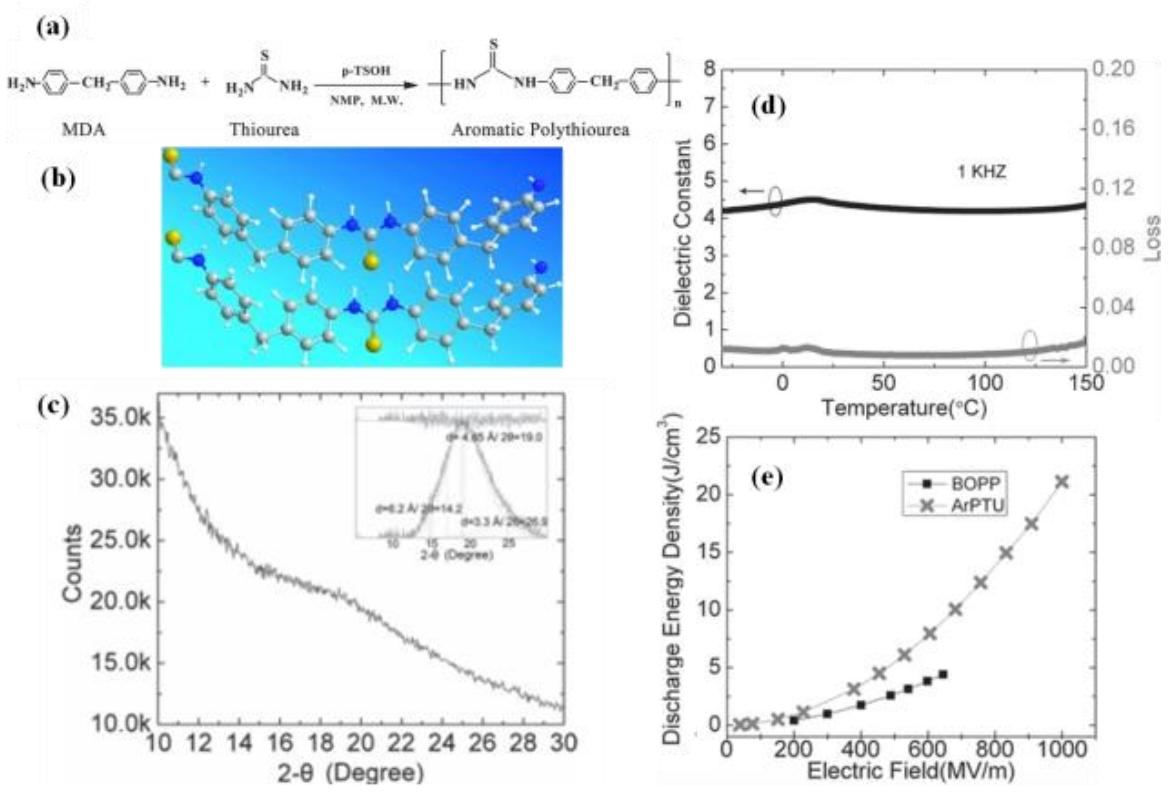

Figure $22^{117}$ (a) Scheme of synthesis of polythiourea via microwave-assisted polycondensation of MDA and thiourea. (b) Molecular structure of the ArPTU. (c) Wide-angle X-ray diffraction of ArPTU film. (d) Delectric properties at $1 \mathrm{kHz}$ vs temperature of ArPTU films. (e) Energy density of ArPTU 
film compared with BOPP. Copyright @ 2013 WILEY-VCH Verlag GmbH \& Co. KGaA, Weinheim

\subsection{Polar dipoles and polar segments}

The introduction of dipolar groups to polymer chains to increase dielectric permittivity is based on the dipolar polarization in the relaxation regime. Small molecules such as pure water can exhibit high dielectric permittivity $(\approx 80)$ but low dielectric loss $(<0.005)$ since the dipole relaxation peak for pure water at $25{ }^{\circ} \mathrm{C}$ occurs at $20 \mathrm{GHz}$ as proven by Fukasawa et al. ${ }^{118}$ Zhu et al. ${ }^{7}$ proposed that polymers with high dielectric permittivity and low loss could be achieved if the dipolar relaxation peak could be pushed to the gigahertz range by substantially simulating dipole mobility. Functionalizing polymers by directly attaching polar dipoles with large dipole moments such as $\mathrm{CN}(\approx 4.0 \mathrm{D}), \mathrm{NO}_{2}(\approx 3.6 \mathrm{D})$, and $\mathrm{SO}_{2}(\approx 4.3 \mathrm{D})$ to either main chains or side chains has enhanced dielectric permittivity in recent

reports. ${ }^{119-123}$ In general, these polar groups attached on side-chains are more effective than those on main chains because the main chains of polymers are usually more sterically hindered than side chains. For example, Chung et al. ${ }^{119,}{ }^{120}$ introduced $\mathrm{OH}$ groups in side chains of $\mathrm{PP}$, and the dielectric permittivity of hydroxylated PP increased from 2.2 to 4.6 at $10^{3} \mathrm{~Hz}$, while the loss was still less than 0.005. Hydroxylated PP had the highest breakdown strength of $600 \mathrm{MV} / \mathrm{m}$. Moreover, introducing polar pendant groups $\mathrm{CN}$ in polyurethane ${ }^{121}$ and polydimethylsiloxane $\mathrm{e}^{122}$ also further increased dielectric permittivity.

Copolymerization with different monomers can be an efficient method for introducing polar polymer segments to polymeric chains to improve dipolar polarization. For example, Zhang et al. ${ }^{124}$ reported poly(methyl methacrylate-methallyl alcohol) copolymers by an indirect polymerization process involving the partial hydrogenation of PMMA. The energy density and dielectric strength were 13 
$\mathrm{J} / \mathrm{cm}^{3}$ and $550 \mathrm{MV} / \mathrm{m}$, respectively. Therefore, by adding polar pendant groups or performing copolymerization, a polyolefin structure is obtained with enhanced dipole-dipole and dipole-matrix interactions, and consequently higher dielectric permittivity can be obtained in the linear region before dipole saturation.

\subsection{Crystalline structures}

Crystalline properties exhibit a significant influence on the energy-storage performance of semi-crystalline polymers as their aggregation structures (e.g., crystalline polymorph, average size of crystal grain, and crystallinity) affect the dielectric permittivity and breakdown strength of a polymer film. ${ }^{4,5}{ }^{83} \mathrm{PVDF}$ is a typical example to illustrate the influence of crystalline structures on dielectric properties. PVDF presents a degree of crystallinity of $35-70 \%$ and has five distinct crystalline polymorphs- $\alpha, \beta, \gamma, \delta$, and $\varepsilon$-which can be characterized by XRD and Fourier transform infrared spectrometer. ${ }^{127} \alpha$ and $\delta$ phases both have conformations of trans-gauche-trans-gauche' (TGTG'); the $\beta$ phase has a conformation of trans-trans-trans (TTT); and the $\gamma$ and $\varepsilon$ phases both have conformations of trans-trans-trans-gauche-trans-trans-trans-gauche' (TTTGTTTG'). The crystalline structures and behaviors of PVDF film depend on preparation conditions, ${ }^{3,44,125,126}$ such as mechanical stretching and thermal treatment.

Li et al. ${ }^{128}$ prepared neat PVDF films with three crystalline polymorphs $(\alpha-\mathrm{PVDF}, \beta-\mathrm{PVDF}$, and $\gamma$-PVDF) and investigated the effect of each crystalline polymorph on energy storage by controlling the parameters of thermal treatments and uniaxial stretching. The results of D-E loops for three types of PVDF in Figure 23 indicated that $\alpha$-PVDF and $\gamma$-PVDF with lower polarity had higher energy storage efficiency than that of $\beta$-PVDF. Moreover, among them, only $\gamma$-PVDF could be applied under a high 
electric field $(500 \mathrm{MV} / \mathrm{m})$ because, unlike $\alpha$-PVDF and $\beta$-PVDF, $\gamma$-PVDF had neither the phase transition nor the early polarization saturation. As a result, the discharged energy density in $\gamma$-PVDF was as high as $14 \mathrm{~J} / \mathrm{cm}^{3}$, while that of $\beta$-PVDF was $1.5 \mathrm{~J} / \mathrm{cm}^{3}$ at $150 \mathrm{MV} / \mathrm{m}$ despite having the highest dielectric permittivity.
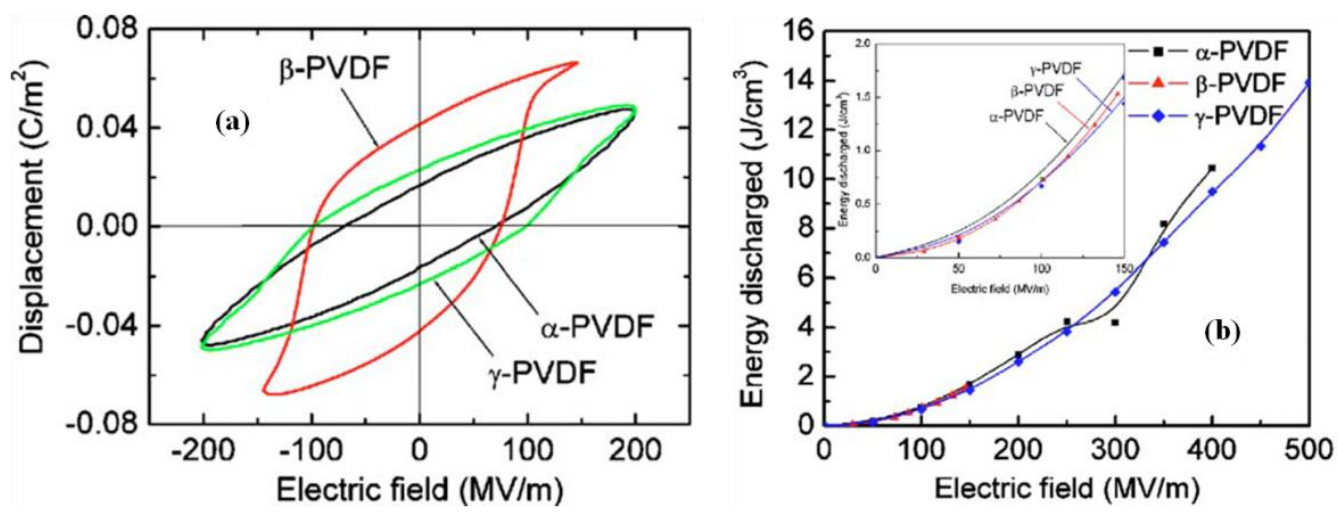

Figure $\mathbf{2 3}^{128}$ (a) D-E hysteresis loops of PVDF of different crystalline polymorphs measured under AC field. (b) Energy density for three PVDF as a function of electric field. Rights managed by AIP Publishing LLC

Tuning crystalline structures by certain defect modifications by high-energy irradiation light is an effective method to improve the dielectric performances of semi-crystalline polymers. This technique has been widely used in PVDF copolymers for reducing dielectric loss and achieving high energy storage. ${ }^{129}$ The PVDF copolymers as reported in scientific papers include poly(vinylidene fluoride-trifluoroethylene) $\quad(\mathrm{P}(\mathrm{VDF}-\mathrm{TrFE})), \quad$ poly(vinylidene $\quad$ fluoride-co-hexafluoropropene) (P(VDF-HFP)), poly(vinylidene fluoride-co-chlorotrifluoroethylene) (P(VDF-CTFE)), poly(vinylidene fluoride-co- $\quad$ bromotrifluoroethylene $) \quad(\mathrm{P}(\mathrm{VDF}-\mathrm{BTFE}), \quad$ and $\quad$ poly(vinylidene 
fluoride-trifluoroethylene-chlorotrifluoroethylene) (P(VDF-TrFE-CTFE)). The chemical structures and reported dielectric properties are presented in Figure 24 and Table 7, respectively. ${ }^{\mathbf{4 4}, 130}$

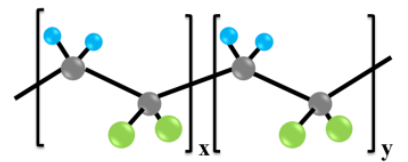

(a) P(VDF-TrFE)

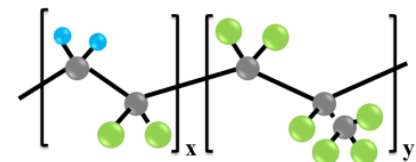

(b) P(VDF-HFP)

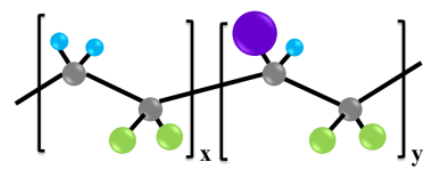

(c) P(VDF-BTFE)

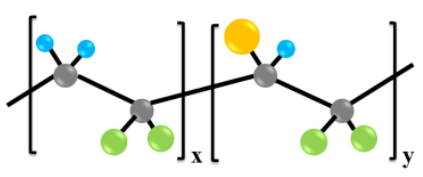

(d) P(VDF-CTFE)

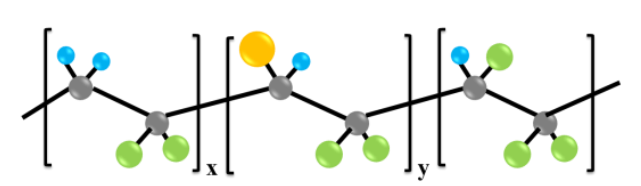

(e) P(VDF-TrFE-CTFE)

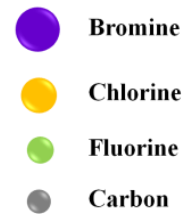

Hydrogen

Figure 24 Schematic representation of the (a) P(VDF-TrFE), (b) P(VDF-HFP), (c) P(VDF-BTFE), (d) P(VDF-CTFE), and (e) P(VDF-TrFE-CTFE) repeat units.

Table 7 Dielectric properties of the copolymers of PVDF

\begin{tabular}{|c|c|c|c|c|}
\hline Copolymer & $\varepsilon_{\mathrm{r}} @ 10^{3} \mathrm{~Hz}$ & $\tan \delta @ 10^{3} \mathrm{~Hz}$ & Eb (MV/m) & $\mathrm{U}_{\mathrm{e}}\left(\mathrm{J} / \mathrm{cm}^{\mathbf{3}}\right)$ \\
\hline${ }^{129} \mathrm{P}(\mathrm{VDF}-\mathrm{TrFE})$ & $18-28$ & $0.06-0.1$ & - & - \\
\hline${ }^{44} \mathrm{P}(\mathrm{VDF}-\mathrm{HPT})$ & 5.6 & 0.4 & 600 & 12.5 \\
\hline${ }^{131},{ }^{132} \mathrm{P}(\mathrm{VDF}-\mathrm{BTFE})$ & 11 & 0.03 & 750 & 20.8 \\
\hline${ }^{133} \mathrm{P}(\mathrm{VDF}-\mathrm{CTFE})$ & 13 & 0.03 & 600 & 25 \\
\hline${ }^{44} \mathrm{P}$ (VDF-TrFE-CTFE) & $47-55$ & $0.05-0.21$ & $300-400$ & $4.2-9$ \\
\hline
\end{tabular}

$\mathrm{P}(\mathrm{VDF}-\mathrm{TrFE})$ has a certain content of trifluoroethylene (TrFE) in the VDF unit shown in Figure 24 (a).

The addition of bulky TrFE groups into the PVDF chains can weaken the intermolecular interaction and the thermodynamic destabilization and lead to all trans-confirmation in crystallinity. ${ }^{129}$ Thus, the 
dielectric permittivity of $\mathrm{P}(\mathrm{VDF}-\mathrm{TrFE})$ had a higher value $(\sim 18)$ than that of PVDF (6-12), but the dielectric loss was also large $\left(<0.1\right.$ at $\left.10^{3} \mathrm{~Hz}\right)$, which led to a moderate improvement in energy storage. The high dielectric loss of $\mathrm{P}(\mathrm{VDF}-\mathrm{TrFE})$ originated from ferroelectric hysteresis, ${ }^{3}$ which is caused by the multidomain state with a non-homogeneous distribution of the spontaneous polarization in the polycrystalline structure.

$\mathrm{P}(\mathrm{VDF}-\mathrm{HFP})$ is prepared by the introduction of hexafluoropropylene (HFP) in a PVDF matrix as presented in Figure 24 (b). ${ }^{44}$ Compared to PVDF, P(VDF-HFP) has a comparatively lower crystallinity because of the presence of bulky $\mathrm{CF}_{3}$ groups. Moreover, the remnant polarization reduces as the content of HFP in the copolymer increases. Therefore, P(VDF-HFP) has a higher energy density $\left(11-13.5 \mathrm{~J} / \mathrm{cm}^{3}\right.$ at $\left.\approx 600 \mathrm{MV} / \mathrm{m}\right)$ than PVDF and $\mathrm{P}(\mathrm{VDF}-\mathrm{TrFE})$.

Wang et al. ${ }^{131},{ }^{132}$ reported on the synthesis of copolymers consisting of VDF and bromotrifluoroethylene (BTFE) as presented in Figure 24 (c). They found that P(VDF-BTFE) copolymers with small BTFE contents $(<2$ mol \%) under uniaxial stretching stabilized the $\gamma$ phase more than PVDF copolymers such as $\mathrm{P}(\mathrm{VDF}-\mathrm{CTFE})$ and $\mathrm{P}(\mathrm{VDF}-\mathrm{HFP})$ which are largely composed of the $\alpha$ phase. The obtained $\mathrm{P}(\mathrm{VDF}-\mathrm{BTFE})$ exhibited an excellent high-field performance with a discharge energy density of $20.8 \mathrm{~J} / \mathrm{cm}^{3}$ at $750 \mathrm{MV} / \mathrm{m}$ and a Weibull breakdown strength of $716 \mathrm{MV} / \mathrm{m}$. Their results demonstrated that the manipulation of the $\gamma$ phase by tuning the content of monomers can develop PVDF copolymers with high energy density.

The addition of chlorotrifluoroethylene (CTFE) into a PVDF chain as presented in Figure 24 (d) can cause the formation of $\mathrm{P}(\mathrm{VDF}-\mathrm{CTFE})$. The dielectric permittivity of $\mathrm{P}(\mathrm{VDF}-\mathrm{CTFE})$ is nearly independent of temperature $(\approx 13)$ because of the absence of phase transition, which makes it stand out from other PVDF copolymers. However, the energy density of P(VDF-CTFE) largely depends on the 
preparation conditions. The solution-processed P(VDF-CTFE) has a discharged energy density of 7-10 $\mathrm{J} / \mathrm{cm}^{3}$ at the poling field around $400 \mathrm{MV} / \mathrm{m}$. After uniaxially stretching, the energy density can increase to $\approx 20 \mathrm{~J} / \mathrm{cm}^{3}$ because of the drastic increase in the breakdown strength $(600-700 \mathrm{MV} / \mathrm{m})$. With an extrusion-blowing process following the uniaxially stretching, the discharged energy density can be further improved up to $25-27 \mathrm{~J} / \mathrm{cm}^{3} .{ }^{133}$

The $\mathrm{P}(\mathrm{VDF}-\mathrm{TrFE})$ polymer can be further modified by the addition of CTFE to form $\mathrm{P}($ VDF-TrFE-CTFE) as shown in Figure 24 (e). CTFE breaks the coherent polarization domains and randomizes the coupling of interchain and intrachain polar groups by a T-G confirmation which further reduces the remnant polarization and thereby decreases the hysteresis loss. The dielectric permittivity and loss of P(VDF-TrFE-CTFE) (62.2/30.2/7.6 mol \%) were 47 and 0.1 (at $\left.10^{3} \mathrm{~Hz}\right)$, respectively. Moreover, Smith et al. ${ }^{134}$ suggested that the dielectric properties of P(VDF-TrFE-CTFE) can be further improved by altering the processing conditions to obtain more $\alpha$-phase crystalline polymorph. By spin-coating and thermal treatments, a highly crystalline $\alpha$-phase film was obtained with a large dielectric permittivity of $77 \pm 10$ but a low loss $(<0.04)$ at $1 \mathrm{kHz}$. The highly crystalline $\alpha$-phase terpolymer films obtained through the improved processing method showed a sizable energy density of $9.7 \mathrm{~J} / \mathrm{cm}^{3}$ at a field of $470 \mathrm{MV} / \mathrm{m}$. Under millisecond pulsed charge-discharge measurements, a three-fold increase in energy density $\left(27 \mathrm{~J} / \mathrm{cm}^{3}\right)$ was obtained at a field of $\approx 600 \mathrm{MV} / \mathrm{m}$.

\subsection{Polymer blends}

The blending of two or more polymers to combine the various dielectric characteristics of single polymers has been widely studied. The dielectric properties of reported systems are summarized in Table 8. By blending various polymers with different molecular structures, surface properties, and 
mechanical and dielectric properties, some are able to enhance dielectric permittivity and dielectric strength simultaneously. For instance, $\mathrm{Li}$ et al. ${ }^{145}$ reported using solution casting to prepare a film blended by PVDF and aromatic ArPTU (90/10 vol). The blend film had a higher dielectric permittivity of 9.2 and a lower dielectric loss of 0.02 at $10^{3} \mathrm{~Hz}$ than that of a pure PVDF film (dielectric permittivity of 8.4 and dielectric loss of 0.05 at $10^{3} \mathrm{~Hz}$ ). More importantly, the blend film inhibited the early polarization saturation at low fields which resulted in a significant enhancement in breakdown strength (700 MV/m) and energy density $\left(10.8 \mathrm{~J} / \mathrm{cm}^{3}\right)$.

Zhang et al. ${ }^{147}$ recently reported a film blended by P(VDF-TrFE-CFE) and PVDF (40/60 vol) with a dielectric permittivity of 36 and dielectric loss of 0.05 at $10^{3} \mathrm{~Hz}$, and consequently the film achieved a high energy density of $19.6 \mathrm{~J} / \mathrm{cm}^{3}$ at $\approx 640 \mathrm{MV} / \mathrm{m}$. They found that the improved dielectric strength of the blend film was the result of the existence of P(VDF-TrFE-CFE) which increased the elastic modulus and reduced the mobility of the polymer chains. The phase-field simulations revealed that the interfaces between PVDF and P(VDF-TrFE-CFE) could suppresses early polarization saturation in $\mathrm{P}(\mathrm{VDF}-\mathrm{TrFE}-\mathrm{CFE})$ and induce additional interfacial polarization which improved the dielectric strength and permittivity simultaneously.

In all reported polymer blends, the highest energy density was achieved by PVDF/VDF oligomer blends reported by Rahimabady et al. ${ }^{148}$ These blends were prepared by dense $\alpha$-phase blend films of vinylidene fluoride (VDF) oligomer and PVDF (80/20 vol) of various compositions by chemical solution deposition. Although the dielectric permittivity of the film was around 13 at $10^{3} \mathrm{~Hz}$, the mechanical strength was higher than either of the two components and led to an ultrahigh dielectric breakdown strength (> $850 \mathrm{MV} / \mathrm{m}$ ). As a result, a large electric energy density up to $27.3 \mathrm{~J} / \mathrm{cm}^{3}$ was obtained. The excellent dielectric properties were attributed to the blend structure with high 
crystallinity and a densely packed rigid amorphous phase incorporating long and short PVDF chains and VDF oligomer.

Table 8 Dielectric properties of polymer blends

\begin{tabular}{|c|c|c|c|c|c|}
\hline Polymer blends & Contents & $\varepsilon_{\mathbf{r}}^{\prime}$ & $\tan \delta$ & $\mathbf{E}_{\mathbf{b}}$ & $\mathbf{U}_{\mathbf{e}}$ \\
\hline & & $@ 10^{3} \mathrm{~Hz}$ & @ $10^{3} \mathrm{~Hz}$ & (MV/m) & $\left(\mathrm{J} / \mathrm{cm}^{3}\right)$ \\
\hline${ }^{135} \mathrm{PP} / \mathrm{MA}-\mathrm{g}-\mathrm{PP}{ }^{*}$ & 90/10 (vol) & 2.1 & 0.007 & 437.2 & 1.96 \\
\hline${ }^{136} \mathrm{PP} / \mathrm{LDPE}$ & $80 / 20$ (vol) & $\approx 2.4$ & $<0.0018$ & - & - \\
\hline${ }^{137} \mathrm{PC} / \mathrm{MA}-\mathrm{g}-\mathrm{PP}{ }^{*}$ & $90 / 10(w t)$ & $\approx 2.8$ & 0.018 & - & - \\
\hline \multirow[t]{2}{*}{${ }^{138} \mathrm{PP} / \mathrm{PA}$} & 60/40 (wt) & $\approx 3.05$ & $\approx 0.0075$ & - & - \\
\hline & & $(\mathrm{D} 150)^{*}$ & $(\mathrm{D} 257)^{*}$ & & \\
\hline${ }^{139} \mathrm{PP} / \mathrm{MA}-\mathrm{g}-\mathrm{PP} * \mathrm{PVDF}$ & $70 / 10 / 20(\mathrm{vol})$ & $\approx 3.7$ & $<0.002$ & - & - \\
\hline${ }^{140} \mathrm{PP} / \mathrm{PVDF}$ & $40 / 60$ (vol) & $\approx 7$ & $\approx 0.05$ & 170 & - \\
\hline \multirow[t]{2}{*}{${ }^{141} \mathrm{PP} / \mathrm{PVDF} / \mathrm{SAM}^{*}$} & $80 / 20(\mathrm{vol}) / 3 \%$ & $\approx 13$ & $\approx 0.02$ & - & - \\
\hline & (wt) & & & & \\
\hline${ }^{142} \mathrm{PVDF} /(\mathrm{PA} 66-\mathrm{g}-\mathrm{VM}){ }^{*}$ & $80 / 20$ (vol) & $\approx 12$ & $\approx 0.075$ & - & - \\
\hline${ }^{143} \mathrm{PVDF} / \mathrm{PA} 11 / \mathrm{VA}-\mathrm{MA}{ }^{*}$ & $80 / 20(\mathrm{vol})$ & 15.1 & $\approx 0.057$ & - & - \\
\hline${ }^{144} \mathrm{P}(\mathrm{VDF}-\mathrm{TrFE}-\mathrm{CTFE}) / \mathrm{PMMA}$ & $50 / 50(w t)$ & $\approx 5$ & $\approx 0.05$ & 733 & 10.67 \\
\hline${ }^{145}$ ArPTU/PVDF & 90/10 (vol) & 9.2 & 0.02 & 700 & 10.8 \\
\hline${ }^{146} \mathrm{ArPTU}^{*} / \mathrm{P}(\mathrm{VDF}-\mathrm{TrFE}-\mathrm{CTFE})$ & $15 / 85(w t)$ & $\approx 12$ & $\approx 0.01$ & 700 & 19.2 \\
\hline${ }^{147} \mathrm{PVDF} / \mathrm{P}(\mathrm{VDF}-\mathrm{TrFE}-\mathrm{CTFE})$ & $60 / 40$ (vol) & $\approx 36$ & $\approx 0.05$ & 650 & 19.6 \\
\hline${ }^{148} \mathrm{PVDF} / \mathrm{VDF}$ oligomer & $20 / 80$ (vol) & $\approx 13$ & - & 820 & 27.3 \\
\hline
\end{tabular}


*MA-g-PP: maleic anhydride grafted polypropylene

D150 and D257: tested by ASTM standards D150 and D257

SAM: styrene maleic anhydride copolymer

PA66-g-VM: vinyl acetic-maleic anhydride modified polyamide

ArPTU: aromatic polythiourea

VA-MA: a compatilizer vinyl acetate-maleic anhydride

\subsection{Multilayer structured polymer films}

Multilayer coextrusion is a process in which polymers are extruded and joined together in a feedblock or die to form a single structure with multiple layers. The multiple layers in a multilayer structured film normally have a uniform thickness. ${ }^{149,}{ }^{150}$ The number of layers in a multilayer structured film can be increased by placing two-channel interfacial surface generators in series as shown in Figure 25. Each new two-channel interfacial surface generator doubles the number of layers of the previous structure. This means that placing $n$ number of two-channel interfacial surface generators in series will produce $2^{\mathrm{n}}$ layers when starting with a two-layer structure. The individual layer thickness in the multilayer film can be as low as $10 \mathrm{~nm}$, and thus the nanoconfinement effect plays an important role on the properties of a dielectric material. 


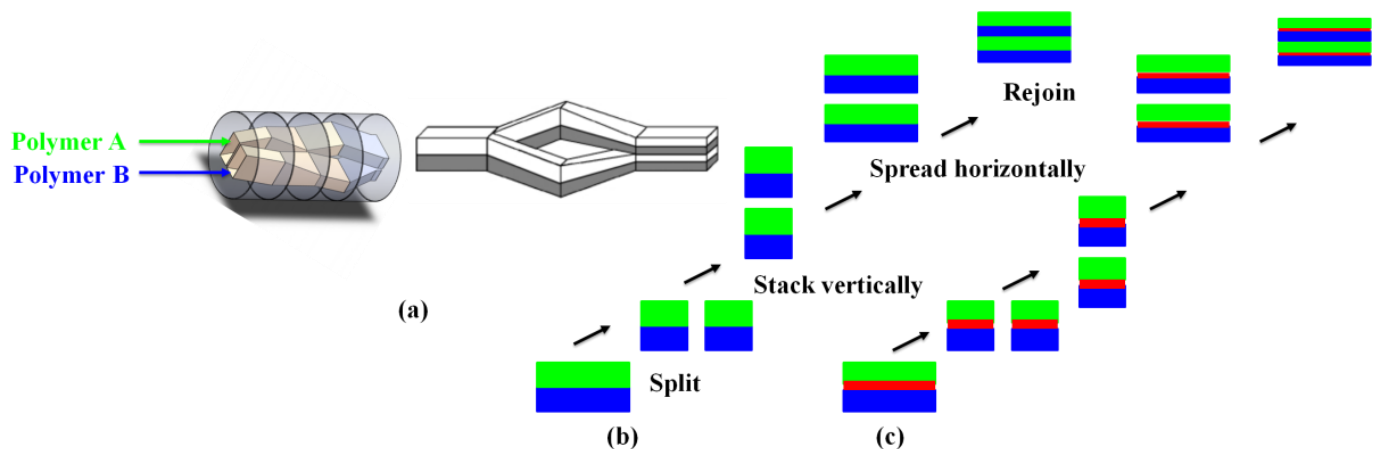

Figure 25 (a) Layer pattern produced in an interfacial surface generator (b) Layer multiplication starting with two layers of equal thickness, (c) Layer multiplication starting with three layers of unequal thickness

Examples of the applications of multilayer films in high energy storage are listed in Table 9. These multilayer dielectric films often consist of alternating layers of a polymer with high dielectric permittivity and a dielectric polymer with high dielectric strength ${ }^{3}$ similar to the previously mentioned multilayered nanocomposites with "soft" and "hard" layers. Polymers with high dielectric permittivity can be PVDF and its copolymers. Polymers with high breakdown strength can be PC and PET. The dielectric permittivity of these linear dielectric polymers is usually low, ranging from 2.9 to 3.6 , but they can adhere reasonably well to a polymer with high dielectric permittivity. Experimental results show that a multilayer film with a greater number of individual layers usually tends to exhibit higher dielectric breakdown strength since the interface of each layer can block "tree-like" breakdown patterns. For example, Mackey et al. ${ }^{153}$ studied low-field dielectric properties and high-field hysteresis losses of multilayered PC and PVDF with different layer morphologies. The layer thickness and standard deviation were determined from AFM images as shown in Figure 26 to be $6200 \pm 780 \mathrm{~nm}$, $1600 \pm 160 \mathrm{~nm}$, and $50 \pm 10 \mathrm{~nm}$ for 50PC/50PVDF 2-, 8-, and 256-layer films, respectively. Comparing the D-E loops of four films with different layers, they found that the hysteresis decreased as 
the PVDF layer thickness decreased in PC/PVDF multilayer films. The dielectric spectra exhibited a charge migration attenuated by decreasing the layer thickness. This indicated that the layered structure and interface (or PC blocking layers) prevented the charge species from passing from one layer to the next (bottom panel in Figure 26). In films with thinner PVDF layers, the amount of ion motion and charge buildup at the interface was minimized, which caused a reduction in the charge-migration-induced dielectric loss peak and hysteresis. Thus, the multilayer film of PC/PVDF (50/50 vol) with 256 layers had an output energy density of $14 \mathrm{~J} / \mathrm{cm}^{3}$.
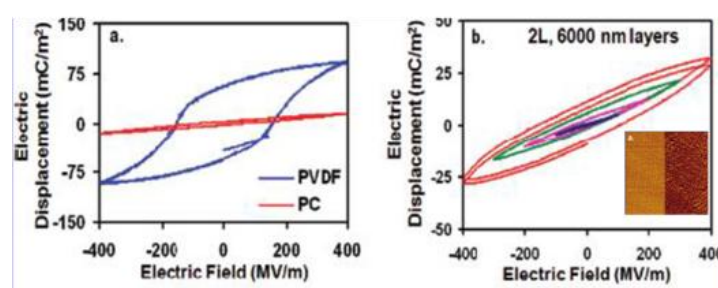

(e)

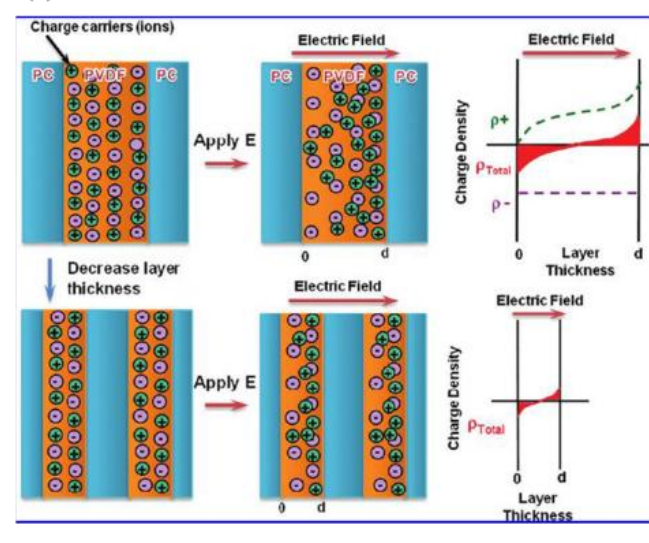

Figure $26^{153}$ D-E hysteresis loops of monolithic controls and 50PC/50PVDF layered films with different layer thicknesses. (a) monolithic PC and PVDF controls, $12 \mu \mathrm{m}$ thick; (b) 2 layers (12 $\mu \mathrm{m} / 6000 \mathrm{~nm})$; (c) 8 layers $(12 \mu \mathrm{m} / 1500 \mathrm{~nm})$; (d) 256 layers $(12 \mu \mathrm{m} / 50 \mathrm{~nm})$. Inset graphs were AFM phase images for the sample: the light and dark colored layers were PC and PVDF, respectively. (e) Schematic of charge migration in layered films: (top panel) thick layers and (bottom panel) thin layers. Both positive and negative ions were needed to maintain a zero net charge. For simplicity, it was assumed that only one of the charge carriers moved. After an electric field was applied, there was a gradient in charge concentration. Compared with thick PVDF layers, thin PVDF layers had less charge 
motion and total charge buildup. Copyright (C) 2012, American Chemical Society

Not all polymer pairs can be fabricated into a multilayer film. The polymer materials for individual layers must "stick" to each other to avoid delamination but must be simultaneously immiscible." Moreover, as reported by Bironeau et al., ${ }^{151}$ for processing a film with high quality, the selected polymer pair needs to meet the requirement of rheological match; e.g., a ratio of viscosity in the range from 0.6 to 0.8 and a ratio of elasticity in the range from 0.2 to 0.5 . Thus, in some cases of multilayer films, a tie layer polymer will be introduced to modify the interfacial adhesion, and the tie layer polymer is usually miscible with one layer and compatible with another. For instance, Yin et al. ${ }^{\mathbf{1 5 6}}$ studied the processing properties of PET/PMMA/P(VDF-HFP) three-component multilayer films. Through introducing a tie layer PMMA, the interfacial adhesion between the PET and P(VDF-HFP) layers was effectively improved because of the miscibility of PMMA with P(VDF-HFP) and the compatibility with PET. Thus, the obtained multilayer film had good mechanical properties under biaxial orientation treatment. The PET/PMMA/P(VDF-HFP) 65-layer films with 8 vol \% PMMA exhibited optimal dielectric properties with an energy density of $17.4 \mathrm{~J} / \mathrm{cm}^{3}$ at breakdown because of the synergistic effects of improved interfacial adhesion and biaxial orientation. Zhou et al. ${ }^{152}$ studied three-component multilayer films to determine the effect of a tie-layer polymer on dielectric properties. Three different tie materials-PMMA, styrene-co-acrylonitrile copolymer with $30 \%$ acrylonitrile content, and poly(ethylene terephthalate-co-1,4-cycohexanedimethylene terephthalate)—were chosen because of their various degrees of interaction with either P(VDF-HFP) or PC. They found PMMA had the best interaction with the interfaces of P(VDF-HFP) and PC. Therefore, studying various polymer pairs and tie layers as well as the interfacial adhesion will assure the fabrication of high quality 
multilayer films and consequently benefit dielectric performance.

Table 9 The dielectric properties and microstructure of multilayer films

\begin{tabular}{|c|c|c|c|c|}
\hline \multirow[t]{3}{*}{ Components } & $\varepsilon_{\mathrm{r}}^{\prime}$ & $\tan \delta$ & $\mathbf{E}_{\mathbf{b}}$ & $\mathbf{U}_{\mathbf{e}}$ \\
\hline & $@ \mathbf{1 0}^{3}$ & @ $10^{3} \mathrm{~Hz}$ & $(\mathbf{M V} / \mathbf{m})$ & $\left(\mathrm{J} / \mathrm{cm}^{3}\right)$ \\
\hline & $\mathbf{H z}$ & & & \\
\hline${ }^{152} \mathrm{PC} / \mathrm{PMMA} / \mathrm{P}(\mathrm{VDF}-\mathrm{HFP})-(46 / 8 / 46$ vol) 65 layers & 4.98 & $\approx 0.018$ & 850 & 8.36 \\
\hline${ }^{153} \mathrm{PC} / \mathrm{PVDF}-(50 / 50$ vol) 32 layers & - & - & $>650$ & 11 \\
\hline${ }^{154} \mathrm{PC} / \mathrm{co}-\mathrm{PVDF}^{*}-(50 / 50$ vol) 256 layers & 3.5 & - & 750 & $\approx 14$ \\
\hline${ }^{155} \mathrm{PET} / \mathrm{P}(\mathrm{VDF}-\mathrm{TFE})-(70 / 30$ vol) 32 layers & $\approx 5.8$ & $\approx 0.05$ & 1000 & 16 \\
\hline${ }^{156} \mathrm{PET} / \mathrm{PMMA} / \mathrm{P}(\mathrm{VDF}-\mathrm{HFP})-(46 / 8 / 46$ vol) 65 layers & 5.3 & 0.013 & 1000 & 17.4 \\
\hline
\end{tabular}

\section{$5 \quad$ Summary and perspectives}

Polymer-based materials with high energy density have been receiving tremendous attention and research because of their flexibility and multifunctionality. In the last decade, many remarkable advances have been achieved, and many reported polymer-based films have had energy densities at least five times as high as that of a neat polymer, and some films have achieved energy densities over $30 \mathrm{~J} / \mathrm{cm}^{3}$. These achievements can be summarized into two main domains: nanocomposite films and all-polymer dielectric films.

In the case of nanocomposite films, core-shell and multilayer structures are two major methods for achieving improved dielectric performances, and both are associated with interface optimization. For core-shell-structured nanofillers, the dielectric properties and morphologies of a shell material should 
be matched with the core filler and polymer matrix. Nanofillers with $1 \mathrm{D}$ or $2 \mathrm{D}$ morphologies or spherical shapes with a certain alignment have proven to be more effective for enhancing dielectric strength. The ideal core-shell structure reduces the contrast of dielectric properties between the nanofiller and the matrix and achieves gradient dielectric permittivity from the center of the nanofiller to the border of the matrix. For multilayer structured films, the combination of layers with high dielectric strength and high dielectric permittivity has made it possible to exploit various materials and laminated structures.

In the case of all-polymer dielectrics, based on instinct dielectric properties (dielectric permittivity, dielectric loss, and dielectric breakdown strength), electronic properties (band gaps and defect/trap states), structural properties (crystalline/amorphous structure and morphology), and biaxial orientation process technology, attaching polar units for further stimulating the mobility of dipoles in polymer chains, blending multiphase polymers, and applying multilayer coextrusion can be viewed as promising methods. These methods require research on the synthesis of novel macromolecular chains, compatibilizers, and copolymerization by chemical engineering.

Facing the present development and issues of polymer-based materials, besides achieving improved dielectric performances and high energy storage, the following key research directions and engineering technologies should be focused on for the next generation of dielectric films.

First, most polymers become soft at elevated temperature conditions, and thus the availability of high-temperature polymer-based dielectric materials is desirable for advanced electronic and electrical power systems operating under extreme environment conditions.

Second, the charge-discharge efficiency under a targeted operation scenario is a parameter related to the dielectric loss of a polymer. Research on the further reduction of dielectric loss and improvement of 
charge-discharge efficiency is essential to achieve a more complete release of stored energy during the discharge process.

Third, the enhancement of thermal conductivity of polymer-based dielectric materials is attractive for achieving multifunctionalities ranging from pulsed power generation and field-activated actuators to energy storage and mechanical energy harvesting.

Fourth, developing advanced filming techniques to obtain films with homogeneous thickness is important and challenges the design of manufacturing equipment. A thin-as-possible film with uniform thickness, less defects, and higher mechanical strength can usually assure not low dielectric strength. However, the mismatch in viscosity and mechanical properties between a matrix and a nanofiller will greatly hinder the success of filming technology. Therefore, the study of film processing technologies based on nanocomposites and post-treatments requires more attention in academia and industry.

\section{Acknowledge}

This work is supported by the State Grid Corporation of China: The key technology research in dielectric films with large storage capacity for HVDC transmission (SGRDGKJ[2017]634).

\section{References}

1 Ho J., Jow T. and Boggs S. Historical Introduction to Capacitor Technology. IEEE Electr. Insul.

Mag. 2010; 26: 20-25

2 Shen Y., Lin Y., and Zhang Q. Polymer nanocomposites with high energy storage densities.

MRS Bull. 2015; 40: 753-759

3 Chen Q., Shen Y., Zhang S. and Zhang Q. Polymer-based dielectrics with high energy storage density. Annu. Rev. Mater. Res. 2015; 45: 433-458 

polymeric dielectrics for high energy density applications. Prog. Mater. Sci. 2016; 83: 236-269 power energy storage. Adv. Mater. 2013; 25: 6334-6365 Yao Z., Song Z., Hao H., Yu Z., Cao M., Zhang S., Lanagan M., and Liu H. Homogeneous/Inhomogeneous-Structured Dielectrics and their Energy-Storage Performances. Adv. Sci. News. 2017; 1601727: 1-15

Baer E. and Zhu L. 50th Anniversary Perspective: Dielectric Phenomena in Polymers and Multilayered Dielectric Films. Macromolecules 2017; 50: 2239-2256

Qi L., Petersson L. and Liu T. Review of Recent Activities on Dielectric Films for Capacitor Applications. J. Inter. Counc. Electr. Eng. 2014; 4: 1-6

Pourrahimi A., Olsson R., and Hedenqvist M. The Role of Interfaces in Polyethylene/Metal-Oxide Nanocomposites for Ultrahigh-Voltage Insulating Materials. Adv. Mater. 2017; 1703624: 1-25.

10 Ji W., Deng H. and Fu Q. Fabrication of Graphene Oxide/Nickelous Hydroxide Nanosheets Hybrid Filler to Improve the Energy Density of Poly(vinylidene fluoride) Based Dielectric Composites. IEEE Trans. Dielectr. Electr. Insul. 2017; 24: 749-756

11 Guo D., Cai K., Wang Y. Distinct mutual phase transition in new PVDF based lead-free composite film with enhanced dielectric and energy storage performance and low loss. J. Mater.

Chem. C. 2017; 5: 2531-2541

12 Chinya I., Pal A. and Sen Shrabanee. Polyglycolated zinc ferrite incorporated poly(vinylidene fluoride)(PVDF) composites with enhanced piezoelectric response. J. Alloy Compos., 2017; 
722: $829-838$

13 Wang Y., Li J. and Deng Y. Enhanced ferroelectricity and energy storage in poly(vinylidene fluoride)-clay nanocomposite films via nanofiller surface charge modulation. RSC Adv. 2015;

\section{5: $85884-85888$}

14 Yuan J., Dang Z., Yao S., Zha J., Zhou T., Li S. and Bai J. Fabrication and dielectric properties of advanced high permittivity polyaniline/poly(vinylidene fluoride) nanohybrid films with high energy storage density. J. Mate. Chem. 2010; 20: 2441-2447

15 Liu S., Xue S., Xiu S., Shen B. and Zhai J. Surface-modified $\mathrm{Ba}\left(\mathrm{Zr}_{0.3} \mathrm{Ti}_{0.7}\right) \mathrm{O}_{3}$ nanofibers by polyvinylpyrrolidone filler for poly(vinylidene fluoride) composites with enhanced dielectric constant and energy storage density. Sci. Rep. 2016; 6: 26198 (1-11)

16 Hou Y., Deng Y., Wang Y., Gao H. Uniform Distribution of Low Content $\mathrm{BaTiO}_{3} \mathrm{Nanoparticles}$ in Poly(vinylidene fluoride) Nanocomposite: Toward High Dielectric Breakdown Strength and Energy Storage Density. RSC Adv. 2015; 5: 72090-72098

17 Yang L., Qiu J., Ji H., Zhu K., Wang J. and Liu J. MWCNTs-TiO 2 core-shell nanoassemblies for fabrication of poly(vinylidene fluoride) based composites with high breakdown strength and discharged energy density. J. Polym. Res. 2016; 23:65 (2-9)

18 Liu S., Wang J., Wang J., Shen B., Zhai J., Guo C., Zhou J. Core-shell structured BaTiO $@ S i O 2$ nanofibers forpoly(vinylidene fluoride) nanocomposites with high discharged energy. Mater. Lett., 2017; 189: 176-179

19 Liu S., Zhai J. Improving the dielectric constant and energy density of poly(vinylidene fluoride) composites induced by surface-modified $\mathrm{SrTiO}_{3}$ nanofibers by polyvinylprrolidone. J. Mater. Chem. A. 2015; 3: 1511-1517 
20 Pan Z., Yao L., Zhai J., Liu S., Yang K., Wang H., Liu J. Fast discharge and high energy density of nanocomposite capacitors using $\mathrm{Ba}_{0.6} \mathrm{Sr}_{0.4} \mathrm{TiO}_{3}$ nanofibers, Ceram. Inter. 2016; 42: $14667-14674$

21 Pan Z., Yao L., Zhai J., Shen B., Wang H. Significantly improved dielectric properties and energy density of polymer nanocomposites via small loaded of $\mathrm{BaTiO}_{3}$ nanotubes. Compos. Sci. Technol. 2017; 147: 30-38

22 Liu S., Xiao S., Xiu S., Shen B., Zhai J. and An Z. Poly(vinylidene fluoride) nanocomposite capacitors with a significantly enhanced dielectric constant and energy density by filling with surfacefluorinated $\mathrm{Ba}_{0.6} \mathrm{Sr}_{0.4} \mathrm{TiO}_{3}$ nanofibers. RSC Adv. 2015; 5: $40692-40699$

23 Chi Q., Ma T., Zhang Y., Cui Y., Zhang C., Lin J., Wang X. and Lei Q. Significantly enhanced energy storage density for poly(vinylidene fluoride) composites by induced PDA-coated 0.5Ba $\left(\mathrm{Zr}_{0.2} \mathrm{Ti}_{0.8}\right) \mathrm{O}_{3}-0.5\left(\mathrm{Ba}_{0.7} \mathrm{Ca}_{0.3}\right) \mathrm{TiO}_{3}$ nanofibers. J. Mater. Chem. A. 2017; 5: 16757-16766

24 Zhang H., Zhu Y., Li Z., Fan P., Ma W., Xie B. High discharged energy density of polymer nanocomposites containing paraelectric $\mathrm{SrTiO}_{3}$ nanowires for flexible energy storage device. J. Alloys Compos. 2018; 744: 116-123

Niu Y., Yu K., Bai Y., Xiang F. and Wang H. Fluorocarboxylic acid-modified barium titanate/poly(vinylidene fluoride) composite with significantly enhanced breakdown strength and high energy density. RSC Adv. 2015; 5: 64596-64603

26 Hao Y., Wang X., Bai K., Zhang J., Huang Y., Wu L., Zhao P., Xu K., Lei M., Li L. Significantly enhanced energy storage performance promoted by ultimate sized ferroelectric $\mathrm{BaTiO}_{3}$ fillers in nanocomposite films. Nano Energy. 2017; 31: 49-56

27 Yao L., Pan Z., Liu S., Zhai J., and Chen H. Significantly Enhanced Energy Density in 
Nanocomposite Capacitors Combining the $\mathrm{TiO}_{2}$ Nanorod Array with Poly(vinylidene fluoride).

ACS Appl. Mater. Interfaces. 2016; 8: 26343-26351

Sarkar S., Garain S., Mandal D. and Chattopadhyay K. Electro-active phase formation in

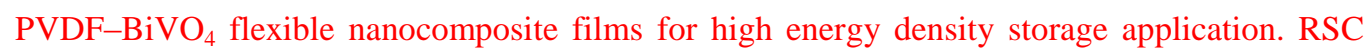
Adv. 2014; 4: 48220-48227

29 Wang G., Huang X. and Jiang P. Bio-inspired polydopamine coating as a facile approach to constructing polymer nanocomposites for energy storage. J. Mate. Chem. C. 2017; 5: $3112-3120$

30 Li J., Khanchaitit P., Han K., and Wang Q. New Route Toward High-Energy-Density Nanocomposites Based on Chain-End Functionalized Ferroelectric Polymers. Chem. Mater. 2010; 22: 5350-5357

31 Pan Z., Yao L., Zhai J., Yang K., Shen B., and Wang H. Ultrafast Discharge and High-Energy-Density of Polymer Nanocomposites Achieved via Optimizing the Structure Design of Barium Titanates. ACS Sustainable Chem. Eng. 2017; 5: 4707-4717

32 Chen S., Lv X., Han X., Luo H., Bowenc C., Zhang D. Significantly improved energy density of $\mathrm{BaTiO}_{3}$ nanocomposites by accurate interfacial tailoring using a novel rigid-fluoro-polymer. Polym. Chem. 2018; 9: 548-557

Yang C., Hao S., Dai S., Zhang X. Nanocomposites of poly(vinylidene fluoride)-Controllable hydroxylated/carboxylated graphene with enhanced dielectric performance for large energy density capacitor. Carbon. 2017; 117: 301-312

34 Tomer V., Manias E. and Randall C. A. High field properties and energy storage in nanocomposite dielectrics of poly(vinylidene fluoride-hexafluoropropylene). J. Appl. Phys. 
2011; 110: $044107(1-10)$

Jin Y., Xia N., Gerhardt R. Enhanced dielectric properties of polymer matrix composites with $\mathrm{BaTiO}_{3}$ and MWCNT hybrid fillers using simple phase separation. Nano Energy. 2016; 30: 407-416

Zhang X., Shen Y., Zhang Q., Gu L., Hu Y., Du J., Lin Y., Nan C. Ultrahigh Energy Density of Polymer Nanocomposites Containing $\mathrm{BaTiO}_{3} @ \mathrm{TiO}_{2}$ Nanofibers by Atomic-Scale Interface Engineering. Adv. Mater. 2015; 27: 819-824

Li Q., Zhang G., Liu F., Han K., Gadinski M., Xiong C. and Wang Q. Solution-processed ferroelectric terpolymer nanocomposites with high breakdown strength and energy density utilizing boron nitride nanosheets. Energy Environ. Sci. 2015; 8: 922-931

Li Q., Han K., Gadinski M., Zhang G., and Wang Q. High Energy and Power Density Capacitors from Solution Processed Ternary Ferroelectric Polymer Nanocomposites. Adv. Mater. 2014; 26 : 6244-6249

Cho S., Lee J. and Jang J. Enhanced Crystallinity, Dielectric, and Energy Harvesting Performances of Surface-Treated Barium Titanate Hollow Nanospheres/PVDF Nanocomposites. Adv. Mater. Interfaces. 2015; 2:1500098 (1-13)

Density and Improved Discharge Efficiency of Solution-Processed Polymer Nanocomposites for Dielectric Energy Storage. Adv. Mater. 2016; 28: 2055-2061

41 Kasap S.O. Principles of Electronic Materials And Devices. New York: Mc Graw Hill Education. 2007. p. 583-609 
96-111

Arun M., Treich G., Huan T., Ma R., Tefferi M., Cao Y., Sotzing G. and Ramprasad R. Rational

Co-Design of Polymer Dielectrics for Energy Storage. Adv. Mate. 2016; 28: 6277-6291

Prateek V. and Raju K. Recent Progress on Ferroelectric Polymer-Based Nanocomposites for High Energy Density Capacitors: Synthesis, Dielectric Properties, and Future Aspects. Chem. Rev. 2016; 116: 4260-4317

45 Nan C., Shen Y., Ma J. Physical properties of composites near percolation. Annu. Rev. Mater. Res. 2010; 40:131-151

46 Ramesh S., Shutzberg B., Huang C., Gao J. and Giannelis E. Dielectric Nanocomposites for Integral Thin Film Capacitors: Materials Design, Fabrication and Integration Issues. IEEE Trans. Adv. Pack. 2003; 26:17-24

Lee DW, Li LL, Wang SX, Lu JX, Wong CP, Bhattacharya SW, et al. Embedded Passives. In: Lu D, Wong C, editors. Materials for Advanced Packaging. Berlin: Springer Science Business Media. 2009: p. 459-502

Lewis T. Nanometric Dielectrics. IEEE Trans. Dielectr. Electri. Insul. 1994; 1: 812-825

49 Hanemann T. and Szabo D. Polymer-nanoparticle composites: from synthesis to modern application. Mate. 2010; 3: 3468-3517

Zhang L. and Cheng Z. Development of polymer-based 0-3 composites with high dielectric constant. J. Adv. Dielectr. 2011; 1: 389-406

51 Balasubramanian B., Kraemer K., Reding N., Skomski R., Ducharme S. and Sellmyer D. Synthesis of Monodisperse $\mathrm{TiO}_{2}-$ Paraffin Core-Shell Nanoparticles for Improved Dielectric Properties. ACS Nano. 2010; 4: 1893-1900 
52 Zou C., Kushner D., Zhang S. Wide temperature polyimide/ $/ \mathrm{ZrO}_{2}$ nanodielectric capacitor film with excellent electrical performance. Appl. Phys. Lett. 2011; 98: 082905 (1-3)

53 Fan B., Zha J., Wang D., Zhao J., Zhang Z., Dang Z. Preparation and dielectric behaviors of thermoplastic and thermosetting polymer nanocomposite films containing $\mathrm{BaTiO}_{3}$ nanoparticles with different diameters. Compos. Sci. Technol. 2013; 80: 66-72

54 Fan B., Zha J., Wang D., Zhao J., Dang Z. Size-dependent low-frequency dielectric properties in the $\mathrm{BaTiO}_{3}$ /poly(vinylidene fluoride) nanocomposite films. Appl. Phys. Lett. 2012; 100: 012903 $(1-4)$

55 Fan B., Zha J., Wang D., Zhao J., Dang Z. Experimental study and theory prediction of dielectric permittivity in BaTiO3/Polyimide nanocomposite films. Appl. Phys. Lett. 2012; 100: 092903 $(1-4)$

56 Dang Z., Zhou T., Yao S., Yuan J., Zha J., Song H., Li J., Chen Q., Yang W., Bai J. Advanced calcium copper titanate/polyimide functional hybrid films with high dielectric permittivity. Adv. Mater. 2009; 21: 2077-2082

57 Tang H., Lin Y., Sodano H. Enhanced energy storage in nanocomposite capacitors through aligned PZT nanowires by uniaxial strain assembly. Adv. Energy Mater. 2012; 2: 469-476

58 Li Q., Chen L., Gadinski M., Zhang S., Zhang G., Li H., Haque A., Chen L., Jackson T. and Wang Q. Flexible high-temperature dielectric materials from polymer nanocomposites. Nature. 2015; 523: 576-580

59 Lu C., Yuan L., Guan Q., Liang G., Gu A. Optimizing Ply Pattern and Composition of Layered Composites based on Cyanate Ester, Carbon Nanotube, and Boron Nitride: Toward Ultralow Dielectric Loss and High Energy Storage. J. Phys. Chem. C. 2018; 122: 5238-5247 
60 Yang K., Huang X., He J. and Jiang P. Strawberry-like core-shell Ag@polydopamine@BaTiO hybrid nanoparticles for high- $\mathrm{k}$ polymer nanocomposites with high energy density and low dielectric loss. Adv. Mater. Interfaces. 2015; 1500361: 1-10

61 Li G., Yu S., Sun R., Lu D. Clean and in-situ synthesis of copper-epoxy nanocomposite as a matrix for dielectric composites with improved dielectric performance. Compos. Sci. Technol. 2015; 110: 95-102

62 Parveen S., Manju A., Govind G., Bipin G., Singh K., Nand V., Veena C. High permittivity polyaniline-barium titanate nanocomposites with excellent electromagnetic interference shielding response. Nanoscale. 2013; 5: 4330-4336

63 Yang R., Reddy P., Chang C., Chen P., Chen J., Chang C. Synthesis and characterization of $\mathrm{Fe}_{3} \mathrm{O}_{4} /$ polypyrrole/carbon nanotube composites with tunable microwave absorption properties: Role of carbon nanotube and polypyrrole content. Chem. Eng. J. 2016; 285: 497-507

64 Huang Y. and Schadler L. Understanding the strain-dependent dielectric behavior of carbon black reinforced natural rubber-An interfacial or bulk phenomenon? Compos. Sci. Technol. 2017; 142: 91-97

65 Huang M., Tunnicliffe L., Zhuang J., Ren W., Yan H. and Busfield J. Strain-dependent dielectric behavior of carbon black reinforced natural rubber. Macromolecules. 2016; 49: 2339-2347

66 Fan B., Bedoui F. Weigand S. and Bai J. Conductive network and $\beta$ polymorph content evolution caused by thermal treatment in carbon nanotubes- $\mathrm{BaTiO}_{3}$ hybrids reinforced polyvinylidene fluoride composites. J. Phys. Chem. C. 2016; 120: 9511-9519

67 B. Fan, D. He, Y. Liu and J. Bai, Influence of thermal treatments on the evolution of conductive paths in carbon nanotube- $\mathrm{Al}_{2} \mathrm{O}_{3}$ hybrid reinforced epoxy composites, Langmuir, 2017, 33: 
$9680-9686$

68 Wu C., Huang X., Wang G., Wu X., Yang K., Li S. and Jiang P. Hyperbranched-polymer functionalization of graphene sheets for enhanced mechanical and dielectric properties of polyurethane composites. J. Mater. Chem. 2012; 22: 7010-7019

Opris D., Molberg M., Walder C., Ko Y., Fischer B. and Nüesch F. New silicone composites for dielectric elastomer actuator applications in competition with acrylic foil. Adv. Funct. Mate. $2011 ; 21: 3531-3539$

70 Wang M. and Pan N. Predictions of effective physical properties of complex multiphase materials. Mater. Sci. Eng. R. 2008; 63: 1-30

Nan C. Physics of inhomogeneous inorganic materials. Prog. Mate. Sci. 1993; 37: 1-116

72 Ducharme S. An inside-out approach to storing electrostatic energy. ACS Nano. 2009; 3: $2447-2450$

Takada T., Hayase Y., Tanaka Y. Space Charge Trapping in Electrical Potential Well Caused by Permanent And Induced Dipoles for LDPE/MgO Nanocomposites. IEEE Trans. Dielectr. Electr. Insul. 2008; 15: 152-160

74 Kim P., Doss N., Tillotson J., Hotchkiss P., Pan M., Marder S., Li J., Calame J. and Perry J. High Energy Density Nanocomposites Based on Surface-Modified $\mathrm{BaTiO}_{3}$ and a Ferroelectric Polymer. ACS Nano. 2009; 3: 2581-2592

75 Grabowski C., Fillery S., Westing N., Chi C., Meth J., Durstock M. and Vaia R. Dielectric Breakdown in Silica-Amorphous Polymer Nanocomposite Films: The Role of the Polymer Matrix. ACS Appl. Mater. Interfaces. 2013; 5: 5486-5492

76 Grabowski C., Koerner H., Meth J., Dang A., Hui C., Matyjaszewski K., Bockstaller M., 
Durstock M. and Vaia R. Performance of Dielectric Nanocomposites: Matrix-Free, Hairy Nanoparticle Assemblies and Amorphous Polymer-Nanoparticle Blends, The Role of the Polymer Matrix. ACS Appl. Mater. Interfaces., 2014; 6: 21500-21509

Wang Y. and Tan D. Computational study of filler microstructure and effective property relations in dielectric composites. J. Appl. Phys. 2011; 109: 104102 (1-8)

Shen Z., Wang J., Lin Y., Nan C., Chen L. and Shen Y. High-Throughput Phase-Field Design of High-Energy-Density Polymer Nanocomposites. Adv. Mater. 2018; 1704380:1-6

Fillery S., Koerner H., Drummy L., Dunkerley E., Durstock M., Schmidt D. and Vaia R. Nanolaminates: Increasing Dielectric Breakdown Strength of Composites. ACS Appl. Mater. Interfaces. 2012; 4: 1388-1396

80 Tanaka T. Dielectric Nanocomposites with Insulating Properties. IEEE Trans. Dielectr. Electr. Insul. 2005; 12: 914-928

81 Dang Z. Dielectric polymer materials for high-density energy storage, Chapter 12 Processing of polymeric dielectrics for high energy density capacitors. Elsevier Inc. 2018. p. 431-437

82 Huang X. and Jiang P. Core-Shell Structured High- $k$ Polymer Nanocomposites for Energy Storage and Dielectric Applications. Adv. Mater. 2014; 27: 1-9

83 Wang Y., Tan D. and Krahn J. Computational study of dielectric composites with core-shell filler particles. J. Appl. Phys. 2011; 110: 044103 (1-6)

84 Li Y., Krentz T., Wang L., Benicewicz B. and Schadler L. Ligand Engineering of Polymer Nanocomposites: From the Simple to the Complex. ACS Appl. Mater. Interfaces. 2014; 6: $6005-6021$

85 Guo N., DiBenedetto S., Tewari P., Lanagan M., Ratner M. and Marks T. Nanoparticle, Size, 
Shape, and Interfacial Effects on Leakage Current Density, Permittivity and Breakdown Strength of Metal Oxide-Polyolefin Nanocomposites: Experiment and Theory. Chem. Mater. 2010; 22: $1567-1578$

Li Z., Fredin L., Tewari P., DiBenedetto S., Lanagan M., Ratner M. and Marks T. In Situ Catalytic Encapsulation of Core-Shell Nanoparticles Having Variable Shell Thickness: Dielectric and Energy Storage Properties of High-Permittivity Metal Oxide Nanocomposites. Chem. Mater. 2010; 22: 5154-5164

Xie L., Huang X., Wu C. and Jiang P. Core-shell structured poly(methyl methacrylate)/BaTiO nanocomposites prepared by in situ atom transfer radical polymerization: a route to high dielectric constant materials with the inherent low loss of the base polymer. J. Mater. Chem. 2011; 21: 5897-5906 Polystyrene/BaTiO $\mathrm{H}_{3}$ Hybrid Nanodielectrics Prepared by In Situ RAFT Polymerization: A Route to High Dielectric Constant and Low Loss Materials with Weak Frequency Dependence. Macromolecular Rap. Commun. 2012; 33: 1921-1926

Ejaz M., Puli V., Elupula R., Adireddy S., Riggs B., Chrisey D., Grayson S. Core-Shell Structured Poly(glycidyl methacrylate)/BaTiO ${ }_{3}$ Nanocomposites Prepared by Surface-Initiated Atom Transfer Radical Polymerization: A Novel Material for High Energy Density Dielectric Storage. J. Polym. Sci. A Polym. Chem. 2015; 53: 719-728

90 Gao L., He J., Hu J., and Li Y. Large Enhancement in Polarization Response and Energy Storage Properties of Poly(vinylidene fluoride) by Improving the Interface Effect in Nanocomposites. J. Phys. Chem. C. 2014; 118: 831-838 
91 Chen J., Sun R., Liao X., Han H., Li Y., Xie M. Tandem Metathesis Polymerization-Induced Self-Assembly to Nanostructured Block Copolymer and the Controlled Triazolinedione Modification for Enhancing Dielectric Properties. Macromolecules. 2018; 51: 10202-10213

92 Li P., Wang X., Zhao Y. Click chemistry as a versatile reaction for construction and modification of metal-organic frameworks. Coord. Chem. Rev. 2018; 380: 484-518

93 Yang K., Huang X., Zhu M., Xie L., Tanaka T. and Jiang P. Combining RAFT Polymerization and Thiol-Ene Click Reaction for Core-Shell Structured Polymer@BaTiO Nanodielectrics $_{3}$ with High Dielectric Constant, Low Dielectric Loss, and High Energy Storage Capability. ACS Appl. Mater. Interfaces. 2014; 6: 1812-1822

94 Jiang B., Pang X., Li B., and Lin Z. Organic-Inorganic Nanocomposites via Placing Monodisperse Ferroelectric Nanocrystals in Direct and Permanent Contact with Ferroelectric Polymers. J. Am. Chem. Soc. 2015; 137: 11760-11767

95 Shen Y., Lin Y., Li M., and Nan C. High Dielectric Performance of Polymer Composite Films Induced by a Percolating Interparticle Barrier Layer. Adv. Mater. 2007; 19: 1418-1422

96 Shen Y., Lin Y. and Nan C. Interfacial Effect on Dielectric Properties of Polymer Nanocomposites Filled with Core/Shell-Structured Particles. Adv. Funct. Mater. 2007; 17: $2405-2410$

97 Xu J. and Wong C. Low-loss percolative dielectric composite. Appl. Phys. Lett. 2005; 87 : $082907(1-3)$

98 Xiao X., Yang H., Xu N., Hu L. and Zhang Q. High performance of P(VDF-HFP)/Ag@ $\mathrm{TiO}_{2}$ hybrid films with enhanced dielectric permittivity and low dielectric loss. RSC Adv. 2015; 5 : 79342-79347 
99 Liu S., Wang J., Hao H., Zhao L., Zhai J. Discharged energy density and efficiency of nanocomposites based on poly(vinylidene fluoride) and core-shell structured $\mathrm{BaTiO}_{3} @ \mathrm{Al}_{2} \mathrm{O}_{3}$ nanoparticles. Ceram. Int. 2018; 44: 22850-22855

100 Yu K., Niu Y., Bai Y., Zhou Y. and Wang H. Poly(vinylidene fluoride) polymer based nanocomposites with significantly reduced energy loss by filling with core-shell structured $\mathrm{BaTiO}_{3} / \mathrm{SiO}_{2}$ nanoparticles. Appl. Phys. Lett. 2013; 102: 102903 (1-5)

101 Hu P., Jia Z., Shen Z., Wang P., Liu X. High dielectric constant and energy density induced by the tunable $\mathrm{TiO}_{2}$ interfacial buffer layer in PVDF nanocomposite contained with core-shell structured $\mathrm{TiO}_{2} @ \mathrm{BaTiO}_{3}$ nanoparticles. Appl. Surf. Sci. 2018; 44: 824-831

102 Kang D., Wang G., Huang Y., Jiang P. and Huang X. Decorating $\mathrm{TiO}_{2}$ Nanowires with

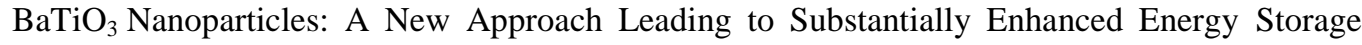
Capability of High- $k$ Polymer Nanocomposites. ACS Appl. Mater. Interfaces. 2018; 10: 4077-4085

103 Hu P., Shen Y., Guan Y., Zhang X., Lin Y., Zhang Q. and Nan C. Topological-Structure Modulated Polymer Nanocomposites Exhibiting Highly Enhanced Dielectric Strength and Energy Density. Adv. Funct. Mater. 2014; 24: 3172-3178

104 Wang Y., Cui J., Yuan Q., Niu Y., Bai Y. and Wang H. Significantly Enhanced Breakdown Strength and Energy Density in Sandwich-Structured Barium Titanate/Poly(vinylidene fluoride) Nanocomposites. Adv. Mater. 2015; 27: 6658-6663

105 Liu F., Li Q., Cui J., Li Z., Yang G., Liu Y., Dong L., Xiong C., Wang H. and Wang Q. High-Energy-Density Dielectric Polymer Nanocomposites with Trilayered Architecture. Adv. Funct. Mater. 2017; 1606292:1-7 
106 Wang Y., Hou Y., Deng Y. Effects of interfaces between adjacent layers on breakdown strength and energy density in sandwich-structured polymer composites. Compos. Sci. Technol. 2017; 145: $71-77$

107 Hu P., Wang J., Shen Y., Guan Y., Lin Y. and Nan C. Highly enhanced energy density induced by hetero-interface in sandwich-structured polymer nanocomposites. J. Mater. Chem. A. 2013; 1: $12321-12326$

108 Zhang Y., Zhang T., Liu L., Chi Q., Zhang C., Chen Q., Cui Y., Wang X. and Lei Q. Sandwich-Structured PVDF-Based Composite Incorporated with Hybrid $\mathrm{Fe}_{3} \mathrm{O}_{4} @ \mathrm{BN}$ Nanosheets for Excellent Dielectric Properties and Energy Storage Performance. J. Phys. Chem. C. $2018 ; 122: 1500-1512$

109 Jiang C., Zhang D., Zhou K., Zhou X., Luo H. and Abrahams I. Significantly enhanced energy storage density of sandwich-structured $\left(\mathrm{Na}_{0.5} \mathrm{Bi}_{0.5}\right)_{0.93} \mathrm{Ba}_{0.07} \mathrm{TiO}_{3} / \mathrm{P}(\mathrm{VDF}-\mathrm{HFP})$ composites induced by PVP-modified two-dimensional platelets. J. Mater. Chem. A. 2016; 4: 18050-18059

110 Shi Z., Wang J., Mao F., Yang C., Zhang C. and Fan R. Significantly improved dielectric performances of sandwich-structured polymer composites induced by alternating positive-k and negative-k layers. J. Mater. Chem. 2017; 5: 14575-14582

111 Wang Y., Cui J., Wang L., Yuan Q., Niu Y., Chen J., Wang Q. and Wang H. Compositional Tailoring Effect on Electric Field Distribution for Significantly Enhanced Breakdown Strength and Restrained Conductive Loss in Sandwich-Structured Ceramic/Polymer Nanocomposites. J. Mater. Chem. A. 2017; 5: 4710-4718

112 Hao Y., Wang X., Brien S., Lombardi J. and Li L. Flexible BaTiO 3 /PVDF gradated multilayer nanocomposite film with enhanced dielectric strength and high energy density. J. Mater. Chem. 
C. $2015 ; 3: 9740-9747$

113 Sharma V., Wang C., Lorenzini R., Ma R., Zhu Q., Sinkovits D., Pilania G., Oganov A., Kumar S., Sotzing G., Boggs S. and Ramprasad R. Rational design of all organic polymer dielectrics. Nat. Commun. 2014; 5: 4845 (1-8)

114 Ma R., Baldwin A., Wang C., Offenbach I., Cakmak M., Ramprasad R. and Sotzing G. Rationally Designed Polyimides for High-Energy Density Capacitor Applications. ACS Appl. Mater. Interfaces. 2014; 6: 10445-10451

115 Wang Y., Zhou X., Lin M., and Zhang Q. High-energy density in aromatic polyurea thin films. Appl. Phys. Lett. 2009; 94: 202905 (1-3)

116 Takahashi Y., Ukishima S., Iijima M. and Fukada E. Piezoelectric properties of thin films of aromatic polyurea prepared by vapor deposition polymerization. Appl. Phys. Lett. 1991; 70: 6983-6987

117 Wu S., Li W., Lin M., Burlingame Q., Chen Q., Payzant A., Xiao K. and Zhang Q. Aromatic Polythiourea Dielectrics with Ultrahigh Breakdown Field Strength, Low Dielectric Loss, and High Electric Energy Density. Adv. Mater. 2013; 25: 1734-1738

118 Fukasawa T., Sato T., Watanabe J., Hama Y., Kunz W. and Buchner R. Relation between dielectric and low-frequency Raman spectra of hydrogen-bond liquids. Phys. Rev. Lett. 2005; 95: $197802(1-4)$

119 Yuan X., Matsuyama Y., and Chung T. Synthesis of Functionalized Isotactic Polypropylene Dielectrics for Electric Energy Storage Applications. Macromolecules. 2010; 43: 4011-4015

120 Chung T. Functional Polyolefins: Synthesis and Energy Storage Applications. Adv. Polym. Sci. $2013 ; 258: 233-278$ 
121 Chen G., Liang Y., Xiang D., Wen S. and Liu L. Relationship between microstructure and dielectric property of hydroxyl-terminated butadiene-acrylonitrile copolymer-based polyurethanes. J. Mater. Sci. 2017; 52: 10321-10330

122 Racles C., Alexandru M., Bele A., Musteata V., Cazacua M. and Opris D. Chemical modification of polysiloxanes with polar pendant groups by co-hydrosilylation. RSC Adv. 2014; 4: $37620-37628$

123 Boyles B., Edmondson D., Filipova C., Fontanella T., Westgate J., Wintersgill M. Dielectric properties of bisphenol A polycarbonate and its tethered nitrile analogue. Macromolecules. 2013; 46: 4024-4033

124 Wang Z., Liu J., Gong H., Zhang X., Lu J. and Zhang Z. Synthesis of Poly(methyl methacrylate-methallyl alcohol) via Controllable Partial Hydrogenation of Poly(methyl methacrylate) towards High Pulse Energy Storage Capacitors Application. RSC Adv. 2016; 6: 34855-34865 Zhou X. High Energy/Capacitance Density Poly(vinylidene fluoride) Based Polymers for Energy Storage Capacitor Applications. PhD thesis. The Pennsylvania State University. 2009. Chapter 1.p. 1-15

Li Q., Wang Q. Ferroelectric Polymers and Their Energy-Related Applications. Macromolecular Chem. Phys. 2016; 217: 1228-1244

Bohlen M. and Bolton K. Inducing the $\beta$-phase of Poly(vinylidene fluoride) - A Review. Annu. Rev. Nanosci. Nanotechnol. 2015; 150110: 1-5 
Electron-Irradiated Poly(vinylidene fluoride-trifluoroethylene) Copolymer. Science. 1998; 280:

2101-2104

130 Wang Y., Zhou X., Chen Q., Chu B. and Zhang Q. Recent Development of High Energy Density Polymers for Dielectric Capacitors. IEEE Trans. Dielectr. Electri. Insul. 2010; 17: 1036-1042

131 Gadinski M., Han K., Li Q., Zhang G., Reainthippayasakul W. and Wang Q. High Energy Density and Breakdown Strength from $\beta$ and $\gamma$ Phases in Poly(vinylidene fluoride-co-bromotrifluoroethylene) Copolymers. ACS Appl. Mater. Interfaces. 2014; 6: $18981-18988$

Gadinski M., Chanthad C., Han K., Dong L., Wang Q. Synthesis of Poly(vinylidene fluoride-cobromotrifluoroethylene) and Effects of Molecular Defects on Microstructure and Dielectric Properties. Polym. Chem. 2014; ;5:5957-5966

Zhou X., Chu B., Neese B., Lin M. and Zhang Q. Electrical Energy Density and Discharge Characteristics of a Poly(vinylidene fluoride-chlorotrifluoroethylene) Copolymer. IEEE Trans. Dielectr. Electri. Insul. 2007; 14: 1133-1138

134 Smith O., Kim Y., Kathaperumal M., Gadinski M., Pan M., Wang Q. and Perry J. Enhanced Permittivity and Energy Density in Neat Poly(vinylidene fluoride trifluoroethylene chlorotrifluoroethylene) Terpolymer Films through Control of Morphology. ACS Appl. Mater. Interfaces. 2014; 6: 9584-9589

135 Chen X., Wang Y., He D., Deng Y. Enhanced dielectric performances of polypropylene films via polarity adjustment by maleic anhydride grafted polypropylene. J. Appl. Polym. Sci. 2017; 134: 45029 
136 Chand N. and Khare N. Investigation on dielectric properties of polypropylene/waste low density polyethylene blends. Indian J. Pure Appl. Phys. 2000; 38: 526-529

137 Madbouly S., Otaigbe J. Broadband dielectric spectroscopy of nanostructured maleated polypropylene/polycarbonate blends prepared by in situ polymerization and compatibilization. Polymer. 2007; 48: 4097-4107

138 Yu D., Wu J., Zhou L., Xie D., Wu S. The dielectric and mechanical properties of a potassium-titanate-whisker-reinforced PP/PA blend. Compos. Sci. Technol. 2000; 60: 499-508

139 Dang Z., Yan W., Xu H. Novel High Dielectric Permittivity Poly(vinylidene fluoride)/Polypropylene Blend Composites: The Influence of the Poly(vinylidene fluoride) Concentration and Compatibilizer. J. Appl. Polym. Sci. 2007; 105: 3649-3655

140 Zhao J., Yin X., Shi J., Zhao X., Wang X., Chen M., Dang Z. and Hu G. Effect of the Mixing on the Dielectric Constant of Poly(vinylidene fluoride)/Isotactic Polypropylene Blends. Sci. Adv. Mater. 2013; 5: 505-511

141 Chen Z., Pei J. and Li R. Study of the Preparation and Dielectric Property of PP/SMA/PVDF Blend Material. Appl. Sci. 2017; 7: 1-8

142 Li R., Chen Z. and Pei J. High Dielectric Performance of Polyamide 66/Poly(Vinylidene Fluoride) Flexible Blends Induced by Interfacial Copolymer for Capacitors. Polymers. 2016; $8: 1-8$

143 Kuang D., Li R. and Pei J. Polyamide 11/Poly(vinylidene fluoride)/Vinyl Acetate-Maleic Anhydride Copolymer as Novel Blends Flexible Materials for Capacitors. Polymers. 2014; 6: $2146-2156$

144 Liu F., Li Z., Wang Q., Xiong C. High breakdown strength and low loss binary polymer blends 
of poly(vinylidene fluoride-trifluoroethylenechlorofluoroethylene) and poly(methyl methacrylate). Polym. Adv. Technol. 2018; 29: 1-7

145 Li W., Jiang L., Zhang X., Shen Y. and Nan C. High-energy-density dielectric films based on polyvinylidene fluoride and aromatic polythiourea for capacitors. J. Mater. Chem. A. 2014; 2 : 15803-15807

146 Zhu H., Liu Z. and Wang F. Improved dielectric properties and energy storage density of poly(vinylidene fluoride-co-trifluoroethyleneco-chlorotrifluoroethylene) composite films with aromatic polythiourea. J. Mater. Sci. 2017; 52: 5048-5059

147 Zhang X., Shen Y., Shen Z., Jiang J., Chen L., and Nan C. Achieving high energy density in PVDF-based polymer blends: suppression of early polarization saturation and enhancement of breakdown strength. ACS Appl. Mater. Interfaces. 2016; 8:27236-27242

148 Rahimabady M., Chen S., Yao K., Tay F. and Lu L. High electric breakdown strength and energy density in vinylidene fluoride oligomer/poly(vinylidene fluoride) blend thin films. Appl. Phys. Lett. 2011; 99142901 (1-3)

149 Dooley J. Viscoelastic Flow Effects in Multilayer Polymer Coextrusion. PhD thesis. Technische Universiteit Eindhoven. 2002. Chapter 1.p. 1-22

150 Huang R. Multilayer Co-extrusion and Twin-Screw Compounding of Polymeric Elastomer Systems. PhD thesis. Case Western Reserve University. 2014. Part 1.p. 21-28

151 Bironeau A., Salez T., Miquelard-Garnier G., Sollogoub C. Existence of a critical layer thickness in PS/PMMA nanolayered films. Macromolecules. 2017; 50: 4064-4073

152 Zhou Z., Carr J., Mackey M., Yin K., Schuele D., Zhu L., Baer E. Interphase/Interface Modification on the Dielectric Properties of Polycarbonate/Poly(vinylidene 
fluoride-co-hexafluoropropylene) Multilayer Films for High-Energy Density Capacitors. J. Polym. Sci. B: Polym. Phys. 2013; 51: 978-991

153 Mackey M., Schuele D., Zhu L., Flandin L., Wolak M., Shirk J., Hiltner A. and Baer E. Reduction of Dielectric Hysteresis in Multilayered Films via Nanoconfinement. Macromolecules. 2012; 45: 1954-1962

154 Wolak M., Pan M., Wan A., Shirk J., Mackey M., Hiltner A., Baer E. and Flandin L. Dielectric response of structured multilayered polymer films fabricated by forced assembly. Appl. Phys. Lett. 2008; 92: $113301(1-3)$

155 Carr J., Mackey M., Flandin L., Schuele D., Zhu L., Baer E. Effect of Biaxial Orientation on Dielectric and Breakdown Properties of Poly(ethylene terephthalate)/Poly(vinylidene fluoride-cotetrafluoroethylene) Multilayer Films. J. Polym. Sci. B Polym. Phys. 2013; 51: 882-896

156 Yin K., Zhou Z., Schuele D., Wolak M., Zhu L. and Baer E. Effects of Interphase Modification and Biaxial Orientation on Dielectric Properties of Poly(ethylene terephthalate)/Poly(vinylidene fluoride-co-hexafluoropropylene) Multilayer Films. ACS Appl. Mater. Interfaces. 2016; 8: 13555-13566 